University of Louisville

ThinkIR: The University of Louisville's Institutional Repository

$12-2017$

\title{
A risky business : examining the prevalence and correlates of post traumatic stress disorder symptomology and social support in Kentucky's adult correctional staff.
}

Ashley Terrell French

University of Louisville

Follow this and additional works at: https://ir.library.louisville.edu/etd

Part of the Criminology Commons

\section{Recommended Citation}

French, Ashley Terrell, "A risky business : examining the prevalence and correlates of post traumatic stress disorder symptomology and social support in Kentucky's adult correctional staff." (2017). Electronic Theses and Dissertations. Paper 2860.

https://doi.org/10.18297/etd/2860

This Doctoral Dissertation is brought to you for free and open access by ThinkIR: The University of Louisville's Institutional Repository. It has been accepted for inclusion in Electronic Theses and Dissertations by an authorized administrator of ThinkIR: The University of Louisville's Institutional Repository. This title appears here courtesy of the author, who has retained all other copyrights. For more information, please contact thinkir@louisville.edu. 


\title{
A RISKY BUSINESS: EXAMINING THE PREVALENCE AND CORRELATES OF POST TRAUMATIC STRESS DISORDER SYMPTOMOLOGY AND SOCIAL SUPPORT IN KENTUCKY'S ADULT CORRECTIONAL STAFF
}

\author{
By \\ Ashley Terrell French \\ B.A. Utah State University, 2000 \\ M.S., University of Louisville, 2010 \\ A Dissertation \\ Submitted to the Faculty of the \\ College of Arts and Sciences of the University of Louisville \\ In Partial Fulfillment of the Requirements \\ for the Degree of \\ Doctor of Philosophy \\ in Criminal Justice \\ Department of Criminal Justice \\ University of Louisville \\ Louisville, Kentucky
}

December 2017 


\section{Copyright 2017 by Ashley Terrell French}

All rights reserved. 



\title{
A RISKY BUSINESS: EXAMINING THE PREVALENCE AND CORRELATES OF POST TRAUMATIC STRESS DISORDER SYMPTOMOLOGY AND SOCIAL SUPPORT IN KENTUCKY'S ADULT CORRECTIONAL STAFF
}

\author{
By \\ Ashley Terrell French \\ B.A., Utah State University, 2000 \\ M.S., University of Louisville, 2010
}

A Dissertation Approved on

November 27, 2017

By the following Dissertation Committee:

Dissertation Director, Kristin Swartz, Ph.D.

Committee Members: Deborah Keeling, Ph.D.

Bradley Campbell, Ph.D.

Gaylene Armstrong, Ph.D. 


\section{DEDICATION}

This dissertation is dedicated to my husband (Joseph), my children (Lincoln and Isabella), and my parents (Stephen and Patricia Terrell). 


\section{ACKNOWLEDGMENTS}

Many thanks to my dissertation committee (Dr. Gaylene Armstrong, Dr. Deborah Keeling, and Dr. Bradley Campbell) for their guidance and patience. I hesitated in asking each one of you to be on my committee considering your impressive CVs with published works and grants. However, I am glad I asked and am honored that you accepted. Every suggestion from the removal of a comma to an addition of a section has been carefully considered. I hope this final dissertation makes you proud to be a part of something that is life changing for me.

While my dissertation committee has been wonderful, my dissertation chair, Dr. Kristin Swartz, has been fantastic. It is difficult to put into words how much I appreciate all that she has done for me. From the first day of theory class, to the prison tour, to the grant work, she has always taken the time to share her knowledge. Throughout my time in the UofL $\mathrm{PhD}$ program, she has consistently provided suggestions and guidance with patience and kindness. Interspersed with this has been constant praise and encouragement. I fear, without her, I would have quit long ago. I hope one day, I can be half the mentor she has been to me.

My parents-in-law (Gary \& Cheryl French) deserve a huge thank you for their support throughout this long journey. In addition to offering a helping hand to the routine day-to-day activities, they provided reassurance and faith that I could do it.

Many thanks to my parents (Stephen \& Patricia Terrell) for setting good examples. They always professed faith in my abilities to accomplish anything if I worked hard. They also stressed that education is important, however, little did they know that I would gravitate to criminal justice education. It's incredible to be a second generation college graduate as well as a second generation doctor. I can now say that I went "all the way."

Last, but not least, my husband (Joe) has been wonderful throughout this process. It has not been easy, but after the tears and the pizza nights (more than I care to admit) he always encouraged and reassured me that this was a worthwhile endeavor. He listened when I attempted to process the information. He constantly told me how proud he was of me. He let me sleep in after a late night of working on my dissertation. He was my rock and always believed in me, even when I lost the faith. I love you, so much. 


\section{ABSTRACT \\ A RISKY BUSINESS: EXAMINING THE PREVALENCE AND CORRELATES OF POST TRAUMATIC STRESS DISORDER SYMPTOMOLOGY AND SOCIALSUPPORT IN KENTUCKY'S ADULT CORRECTIONAL STAFF \\ Ashley Terrell French}

November 29, 2017

The purpose of this study was to determine the prevalence and correlates of post traumatic stress disorder (PTSD) symptomology among correctional staff, using a sample of staff who work in an adult facility for the Kentucky Department of Corrections (KY DOC). Participants $(\mathrm{N}=775)$ were asked to complete a written survey to indicate not only demographic variables (age, race, education, and gender) but also the amount of violent and traumatic events experienced, the duration of employment within the KY DOC, whether they were assigned to a custodial/security role, and whether they worked in a maximum security facility. Furthermore, their perceived level of social support was examined with participants providing information regarding their marital status/the presence of a significant other, family social support, supervisor social support, and coworker social support. Results indicated a 30.2\% PTSD symptomology rate of concern. Analysis indicated that female staff, those with an assignment of security, and those working in a maximum security custody facility had higher rates of symptomology. Of the social support variables, family and coworker social support mitigated symptomology. Implications and future areas of research are discussed. 


\section{TABLE OF CONTENTS}

ACKNOWLEDGMENTS .......................................................................... iv

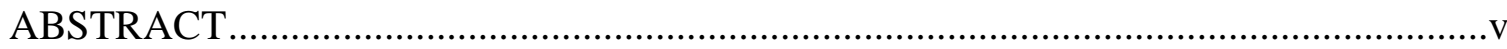

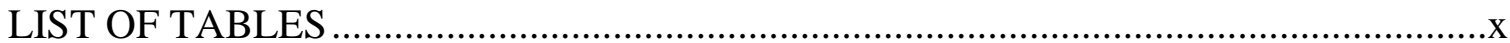

CHAPTER 1. INTRODUCTION TO THE PROBLEM: PTSD IN CORRECTIONAL

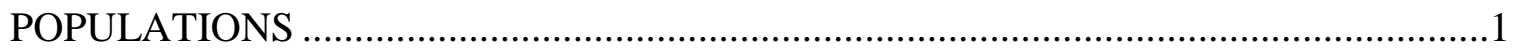

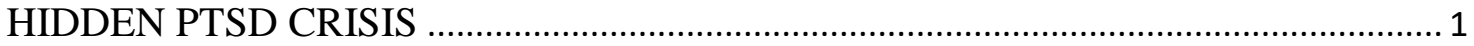

THE PRESENT STUDY …................................................................................... 4

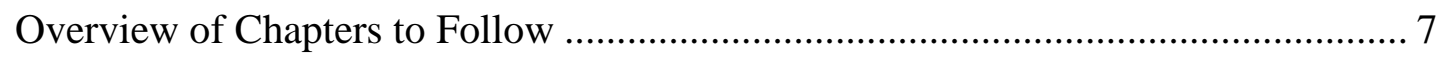

CHAPTER 2. THEORETICAL OVERVIEW: STRESS AND PTSD ............................

CORRECTIONAL OFFICER STRESS AND PTSD ….............................................. 8

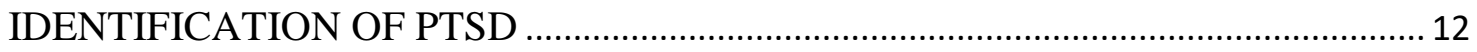

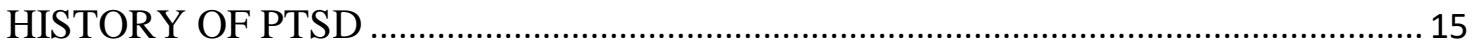

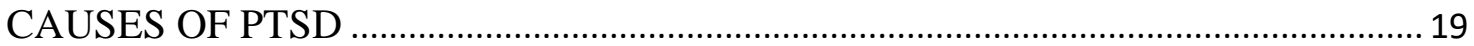

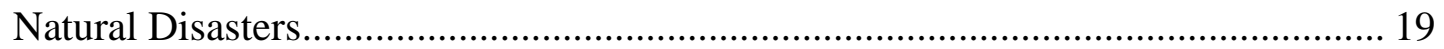

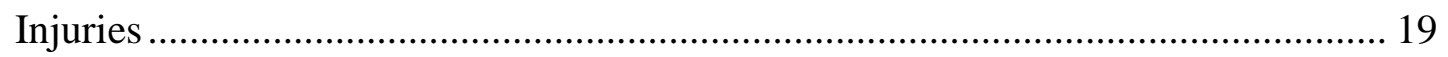

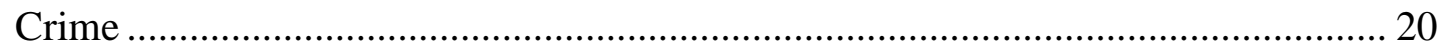


Mass Violence

Terror Attacks

Torture 22

EFFECTS OF PTSD

SUMMARY

CHAPTER 3. PTSD: GENERAL POPULATION AND FIRST RESPONDERS. .34

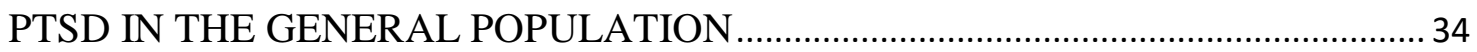

Gender 34

Age 35

Race 36

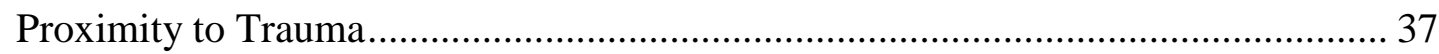

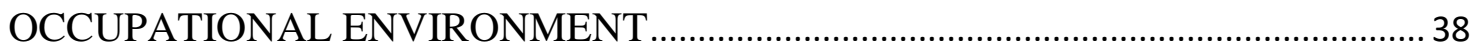

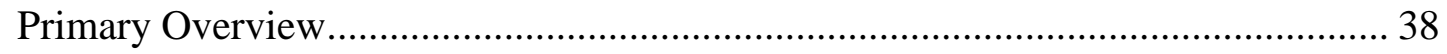

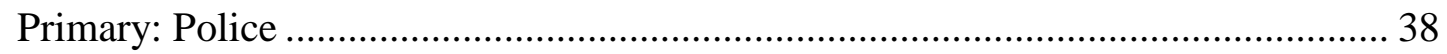

Primary: Ambulance Personnel ............................................................................... 49

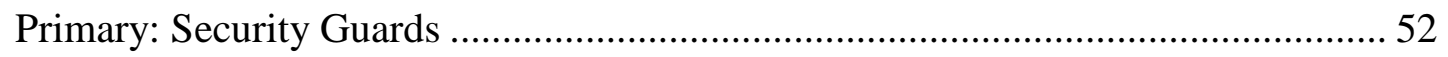

Primary: Compound Studies......................................................................... 52

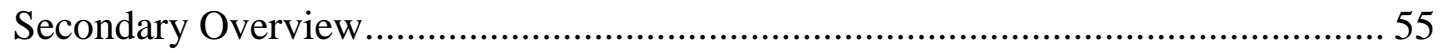

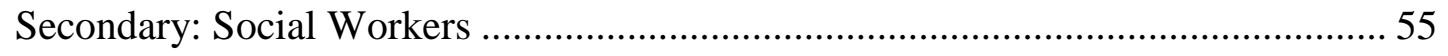


Secondary: Trauma Therapists

Secondary: Health Care Professionals...................................................................... 56

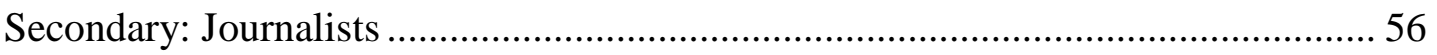

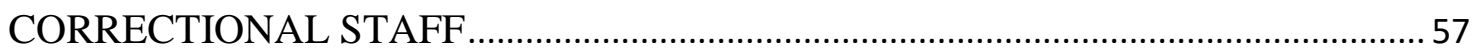

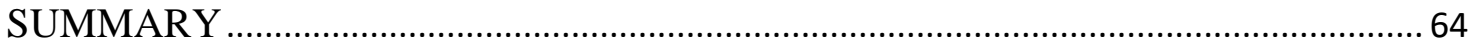

CHAPTER 4. METHODOLOGY ……………………….........................................68

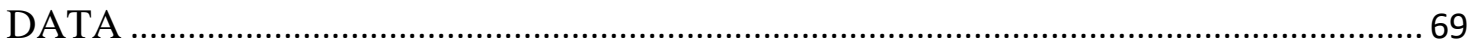

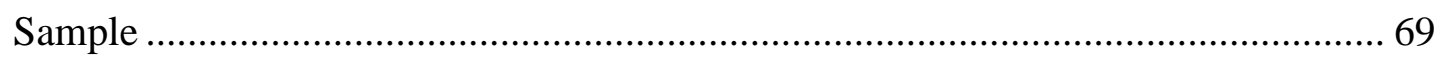

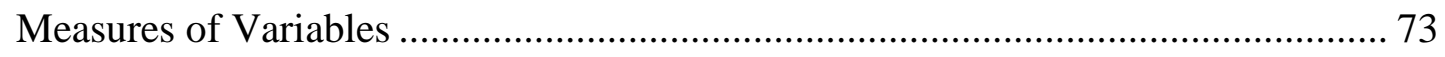

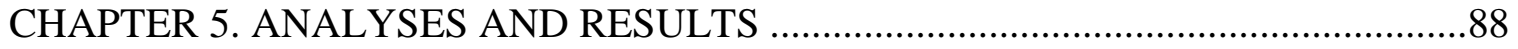

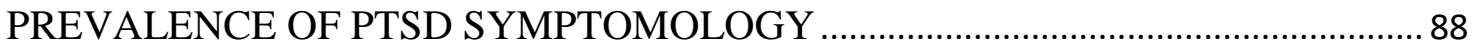

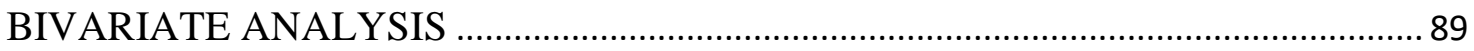

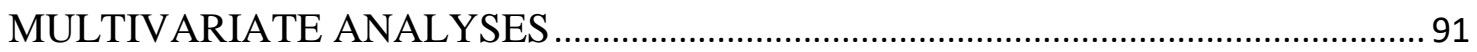

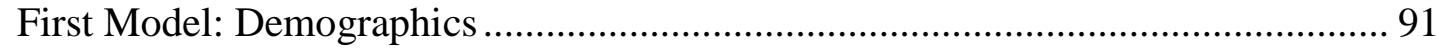

Second Model: Exposure to Violence and Trauma ………......................................... 91

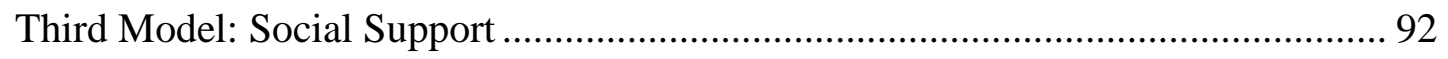

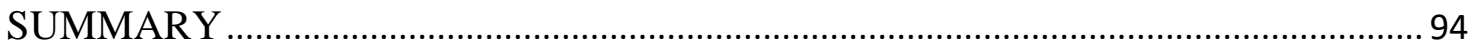

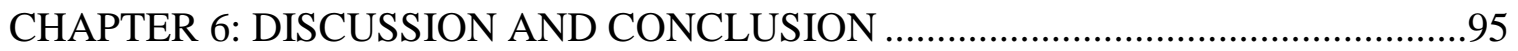

SUMMARY OF FINDINGS ………………………………………………… 95

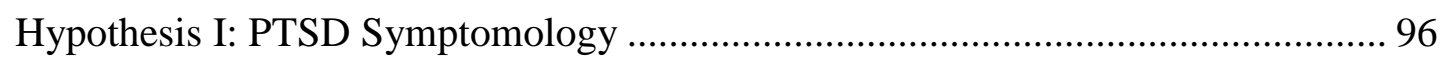


Hypothesis II: Model 1 (Demographic Variables)

Hypothesis III: Model 2 (Exposure to Violence and Trauma) ................................ 97

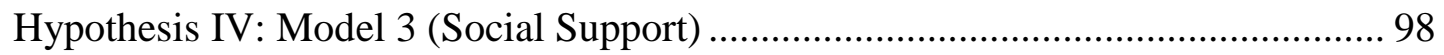

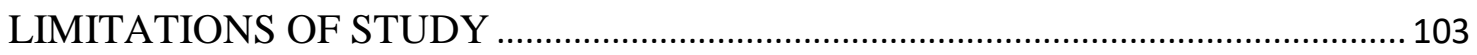

IMPLICATIONS FOR POLICY, PRACTICE, AND FURTHER RESEARCH ......... 104

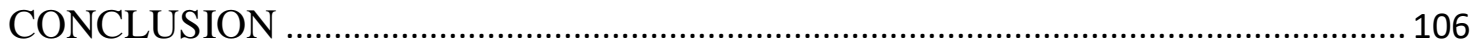

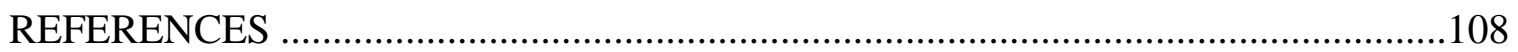

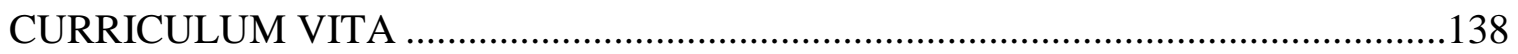




\section{LIST OF TABLES}

TABLE

PAGE

1. Police PTSD Studies to Date (Routine Duties)

42

2. Police PTSD Studies to Date (Event Specific Duties)

3. Firefighter PTSD Studies to Date 48

4. Ambulance Personnel PTSD Studies to Date 51

5. Compound PTSD Studies to Date 54

6. Correctional Staff PTSD Studies to Date 63

7. KY DOC Adult Facilities $\quad 71$

8. TRAUMA Symptomology Range 77

9. Descriptive Statistics, Variables, and Scales 78

10. Violent and Traumatic Occurrences in the Past 2 Years 82

11. Prevalence Rates Of PTSD Concern 89

12. Bivariate Correlations $\quad 90$

13. Regression Models $\quad 93$

14. Overview of the Findings 94

15. Support for Hypotheses 101 


\section{CHAPTER 1. INTRODUCTION TO THE PROBLEM: PTSD IN CORRECTIONAL POPULATIONS}

\section{HIDDEN PTSD CRISIS}

The roles of correctional staff, regardless of title, are many and varied. Oftentimes they are teachers, supervisors, counselors, rehabilitators, inspectors, evaluators, and security. These roles are performed in a confined environment that houses violent individuals held against their will who may have violent tendencies and try to arm themselves with homemade weapons. Furthermore, this environment is also considered a de facto asylum as the population of those incarcerated with mental health issues was ten times the number of those in state hospitals in 2012 (The Treatment Advocacy Center, 2014). Recent statistics report that $56 \%$ of state prisoners have a mental health problem (Kim, Becker-Cohen, \& Serakos, 2015) and considering that more state inmates who are mentally ill have been charged with physically or verbally assaulting correctional staff and have been injured in a fight (James \& Glaze, 2006), it can be concluded that correctional staff are exposed to violent situations. Unfortunately, an increase in the inmate population combined with reduced correctional budgets and staff turnover, has led to overcrowding and reduced staff to inmate ratios. Hence, the staff are outnumbered, unarmed, and often encounter unsafe working conditions which can result in trauma. This trauma is often examined in relationship to posttraumatic stress disorder (PTSD) which is classified as an anxiety disorder. Its core clinical features are intrusive memories 
of the trauma, avoidance of stimuli associated with the event, and persistent symptoms of increased arousal. Individuals with PTSD have been shown to have deficits in immediate and delayed verbal memory and in explicit short-term memory and have performed poorly on attentional tasks, which are those that require concentration by the mind on a single object or thought.

In the last few years, PTSD has been found in about $20 \%$ of the general population who experience trauma. However, certain factors such as race, gender, and proximity to trauma make some individuals more susceptible and, while extensive research has been conducted on PTSD and its effect on emergency personnel such as law enforcement officers and firefighters, the research on correctional staff is not nearly as extensive. PTSD among correctional staff may have both direct and indirect effects with the direct effects to include an impact on their health, functioning, and well-being. Furthermore, PTSD may have an indirect and substantial fiscal and organizational impact on correctional agencies and departments. Examples could include an increase in the amount of sick days used per year, an increase in the receipt of disciplinary infractions, and a decrease in retention. And, while the consequences of PTSD among correctional officers are extreme, research is limited.

The lack of research could be due to the fact that it has only been recently that correctional staff have been officially recognized as first responders by the National First Responders Organization (NFRO) (2014). According to the NFRO, both correctional officers and wardens are considered first responders under their definition of "any individual who runs toward an event rather than away" (National First Responders Organization, 2014, para. 1). 
While academic research may be lacking, mainstream media is beginning to explore the significance of this issue. For example, the Guardian published an article in 2015 describing a son coming home to find his father, Michael Van Patten a 30-year corrections veteran, with a gun in his hand (Lisitsina, 2015). The father had spent nearly three decades as a correctional officer at the Oregon State Penitentiary and decided the only way to cope was to commit suicide (Lisitsina, 2015). Previously, Michael had been assaulted while assisting a nurse. An inmate had dislocated his skull from his spinal vertebrae preventing him from walking for five months and even from holding his newborn child (Lisitsina, 2015). Consequently, this, as well as exposure to other events such as hangings, cut arteries, and stabbings, took its toll on Michael and he began exhibiting signs of PTSD to include insomnia, phantom violence while asleep, and cold sweats. Michael's treatment of choice was alcohol and exercise due to his lack of knowledge about PTSD.

Newsweek ran a similar article about how corrections officers need help for PTSD but are reluctant to request it, similar to other first-responders such as police officers. The story begins with a call from a spouse to the New York City Corrections Officers' Benevolent Association indicating a girlfriend is suicidal (Lopez, 2014). The girlfriend, after working 20 years as corrections officer, reached her limit and planned to cut her throat at lunch with a razor stashed in her car (Lopez, 2014). She was taken to the local hospital where she stated that she had nothing else to live for (Lopez, 2014).

Stories like this are not uncommon. Corrections officers often assume a battle mode when entering the gates of a correctional facility. One warden likened it to being non-human, robotic, and emotionless (Lisitsina, 2015). Furthermore, the culture is one of 
strength, toughness, and machismo. Similar to inmates, officers cannot be weak. As one officer stated, "We're doing time too, we're just getting paid for it" (Lisitsina, 2015, para. $31)$.

Other articles about PTSD among corrections staff have been published on salon.com, thecrimereport.org, correctionsone.com, and inpublicsafety.com. Many of them repeat themselves with the message that PTSD is found in correctional staff, correctional agencies and administrators should cease minimizing these issues, and correctional staff need assistance in managing this disorder.

\section{THE PRESENT STUDY}

The modern study of trauma is informed by psychiatrists' and psychologists' observations who treated veterans of WWI and WWII (Grinker \& Speigel, 1945; Kardiner \& Speigel, 1947). These clinicians observed that veterans who were exposed to war-related violence and degradation continued to experience intrusion of painful memories of the events they witnessed. They also observed that veterans had intense emotional and physiological reactions when reminded of their trauma. Although these early observations were made, it was not until 1980 that symptoms of PTSD were formally classified in the U.S. (Litz \& Roemer, 1996). Since that time, PTSD has been linked to many occupations, with first responders, such as police and firefighters, as the typical focus. However, police and firefighters are not the only occupational categories to experience PTSD symptoms. One emerging occupation of focus has been correctional staff. Although current research on this occupation is sparse, one recent seminal study sought to identify a relationship between correctional work and PTSD with results indicating an overall rate of $27 \%$ for symptoms experienced over the past 30 days 
(Spinaris, Denhof, \& Kellaway, 2012). This study suggests that the examination of symptoms in correctional staff is a significant issue and should continue to be investigated.

Consequently, this dissertation advances the literature in many ways. First, the current study uses comprehensive data from a representative sample of Kentucky Department of Corrections staff to determine the prevalence rate of PTSD symptomology, which to date does not have symptomology data about its adult correctional staff. Second, the data analyzed here uses a different PTSD assessment tool than the other studies on U.S. correctional staff allowing comparisons of prevalence rates across different assessments to be made. In other words, if the current study finds similar prevalence rates as previous studies, this provides more confidence that these findings are robust.

Third, while the body of literature on correctional officer stress is well established, the relationship between these stressors and PTSD is largely unexplored. This dissertation aims to close the gap between correctional stress and PTSD. Hence, this dissertation could produce results that indicate types of stressors produce a higher likelihood of symptomology. This may allow management to target those incidents with a greater focus on PTSD prevention and management techniques.

Fourth, this dissertation extends research findings by focusing on not only the violent and traumatic events experienced, but also on whether PTSD symptomology is associated with the duration of employment (in months) for the Kentucky Department of Corrections (KYDOC) and working in a maximum security facility. While it may be reasonable to assume that longer tenure in the KYDOC would affect PTSD 
symptomology, some research suggests otherwise reporting working longer in corrections does not affect symptomology (Robinson, Sigman, \& Wilson, 1997). Similarly, research exploring whether the facility's custody level (minimum, medium, maximum) affects symptomology is limited to one study (Denhof \& Spinaris, 2016).

Once the research has established the prevalence of PTSD and the relationship between PTSD and exposure to violence is determined, the question of prevention logically follows. Hence, this dissertation seeks to determine the factors which may insulate staff from experiencing symptoms of PTSD to include social support. Current research shows evidence that the presence of a significant other (Mgoqi-Mbalo, Zhang, \& Ntuli, 2017) and legal spouse reduces the likelihood of PTSD symptoms (Berger, Figueira, Maurat, Bucassio, Vieira, Jardim, Coutinho, Mari, \& Mendlowicz, 2007; Corneil, Beaton, Murphy, Johnson, \& Pike, 1999). Included in this dissertation is the variable of marital status/presence of a significant other to determine if this has an effect, and if so, what kind?

This dissertation will also extend the research on social support by separating family, supervisor, and coworker support to assess each individually. This will extend the research as the presence of social support has been proven to reduce the likelihood of symptoms (Corneil, Beaton, Murphy, Johnson, \& Pike, 1999; Declercq, Vanheule, Markey, \& Willemsen, 2007; Feinstein, Owen, \& Blair, 2002). Hence, this dissertation provides a solid base of information, to include symptomology, for which additional prevention and management measures may be implemented; see chapter 5 for a discussion of these. 
Finally, this dissertation will provide something unique to the literature, a focus on corrections staff. Recently, it seems as though the trend has been towards inmates and their propensity for PTSD. However, little is known about these other law enforcement professionals who are often unrecognized for their personal and professional sacrifices.

\section{Overview of Chapters to Follow}

Chapter 2 begins by discussing the differences between stress and PTSD symptomology and noting the significant distinctions. It continues with the historical origins of identifying PTSD and traces refinement of our understanding over time. Then, it turns to exposure to violence and trauma as a risk factor, as well as various measures of social support and the role they these could play in mitigating the symptoms or severity PTSD.

Chapter 3 focuses on PTSD symptomology prevalence in the general population and then moves to a discussion of prevalence in first responder populations. This chapter concludes with PTSD symptomology prevalence in correctional staff, which forms the basis of this dissertation's analysis.

Chapter 4 offers a discussion of the methods, research questions, and hypotheses examined in the analysis. The chapter concludes with the operationalization of the independent and dependent variables as well as the analytic strategy.

Chapter 5 presents the results of the analysis. The analysis includes the prevalence rates of PTSD symptomology and three logistic regression models examining the relationships between demographic characteristics, exposure to trauma and violence, social support and PTSD. Finally, chapter 6 provides a discussion of the findings, limitations of this research, and future directions for this line of inquiry. 


\section{CHAPTER 2. THEORETICAL OVERVIEW: STRESS AND PTSD}

\section{CORRECTIONAL OFFICER STRESS AND PTSD}

Stress is not new and has been a recognized phenomenon for centuries (Friedman, Keane, \& Resick, 2007; Turnbull, 1998); however, the term as it is known today was introduced by Hans Selye in 1936 (The American Institute of Stress, 2017). Selye proposed that the body experiences both positive (eustress) and negative stress (distress). Eustress is a manageable stress, may act as a motivating force, and could lead to growth and enhanced competence. Distress, however, is one that is uncontrollable, overwhelming, and prolonged (Selye, 1976).

Although some may use the terms post-traumatic stress disorder (PTSD) and stress interchangeably, they are two very distinct concepts. This section discusses the differences between stress and PTSD. Stress is not new and has been a recognized phenomenon for centuries (Friedman, Keane, \& Resick, 2007; Turnbull, 1998); however, the term as it is known today was introduced by Hans Selye in 1936 (The American Institute of Stress, 2017). Previously, the term was used in physics to explain elasticity, which is when an item is able to regain its original size after being stretched or compressed (Rosche, 2017). Selye proposed that the body experiences both positive (eustress) and negative stress (distress). Eustress is a manageable stress, may act as a 
motivating force, and could lead to growth and enhanced competence. Distress, however, is one that is uncontrollable, overwhelming, and prolonged (Selye, 1976).

Stress usually begins when an individual experiences either a positive or negative stressor which results in the start of the general adaptation syndrome (GAS) with the first stage of alarm. In this state, the body reacts with the fight or flight response.

Additionally, the nervous system is activated and an increase occurs in the heart rate, blood pressure, and the supply of blood sugar (Selye, 1976). This results in a burst of energy mobilizing the body's resources. The second stage is resistance (Selye, 1976) in which the body attempts to fight or resist the stressor. At this point, the individual may actually feel better as the early symptoms of alarm are reduced (Selye, 1976). This stage continues until the stress ends or resources have been depleted. If the stressor continues, the final stage is exhaustion. This occurs when the body has used all of its resources to fight the stressor, without a successful reduction of stressor. It is at this time that the individual becomes susceptible to illness and/or death (Selye, 1976). Over the course of a lifetime, the body experiences these stages many times which allows individuals to adapt to the demands of life (Selye, 1976).

Understanding the unique stressors of working in corrections has been a focus of academics, practitioners, and correctional administrators alike. Historically, working in correctional facilities has been identified as a stressful occupation with much of the research focusing on: a) the causes of stress; b) the reactions to stress; and c) the prevention and treatment of stress. The stressors are often classified into categories of: 1) task-related stressors; 2) organizational stressors; 3) external stressors; and 4) personal stressors. 
Task related stressors include physical danger which could include problematic inmate behavior (Armstrong \& Griffin, 2004; Cornelius, 1994; Finn, 1998; Harding \& Zimmermann, 1989; Kauffman, 1988; Martinez, 1997; Peeters, Schaufeli, \& Buunk, 1995; Schaufeli \& Peeters, 2000; Shamir \& Drory, 1982; Whitehead, 1989). Furthermore, a high workload and the level of responsibility have been identified as stressors (Dignam, Barrera, \& West, 1986; Dollard \& Winefeld, 1998; Kommer, 1990; Lasky,Gordon, \& Srebalus, 1986). Other task related stressors include role conflict and role ambiguity (Armstrong \& Griffin, 2004; Grossi \& Berg, 1991; Cheek \& Miller, 1983; Cullen, Link, Wolfe, \& Frank, 1985; Lindquist \& Whitehead, 1986; Lombardo, 1989; Rosefield, 1981; Schaufeli \& Peeters, 2000). Researchers reported that these conflicts occur may be due to the fact that staff are seen as both disciplinarians and rehabilitators.

Organizational stressors include staff shortage and inadequate pay (Brodsky, 1982; Cheek \& Miller, 1982; Finn, 1998; Harris, 1983; Tompson, 1994). Other organizational stressors include difficult physical conditions (Jacobs \& Crotty, 1983; Ostfeld, Kasl, D'Arti, \& Fitzgerald, 1987; Verhagen, 1986). Research has also indicated that the lack of supervisor support is an organizational stressor (Armstrong \& Griffin, 2004; Cheeseman, Kim, Lambert, \& Hogan, 2011; Cullen, Link, Wolfe, \& Frank, 1985; Dowden \& Tellier, 2004; Lambert, Hogan, \& Barton, 2002). Considering the recent reduction in correctional budgets as well as the increasing inmate population, these are particularly relevant issues.

External stressors, as opposed to organizational stressors, are those which originate from the world around them. These could include the negative attitudes held by the media and community about those who work in corrections (Brodsky, 1982; Cheek \& 
Miller, 1982; Shamir \& Drory, 1982; Stalgaitis, Meyers, \& Krisak, 1982). Examples include the media's portrayal of correctional staff as not intelligent or aggressive towards inmates (Brodsky, 1982; Cheek \& Miller, 1982).

Personal stressors are those generated by the work/family conflict, such as overtime, distance from home, and shift work (Armstrong, Atkin-Plunk, \& Wells, 2015; Cornelius, 1994; Kauffman, 1988; Lambert, Hogan, Barton, \& Camp, 2006). In particular, shift work has been found to result in fatigue, which hinders the individual's ability to perform on the job. One study quoted a corrections employee stating, "One day I pulled over to the side of the road because I couldn't remember whether I was going to work or going home" (Finn, 1998, p. 66).

In summary, stress in the corrections occupation is well documented. However, very little is known about how/if these stressors could lead to more significant issues such as PTSD symptomology which is classified as a very serious mental disorder.

Furthermore, if these stressors do produce symptomology, are there identifiable correlates for which this disorder could be managed or prevented? Before focusing on these questions, it is first important to identify the intricacies of PTSD, its history, and its known risk factors. The next section focuses on these topics and concludes with a discussion regarding its effects and possible interventions to mitigate symptomology. See Figure 1 below for sources of correctional staff stress. 


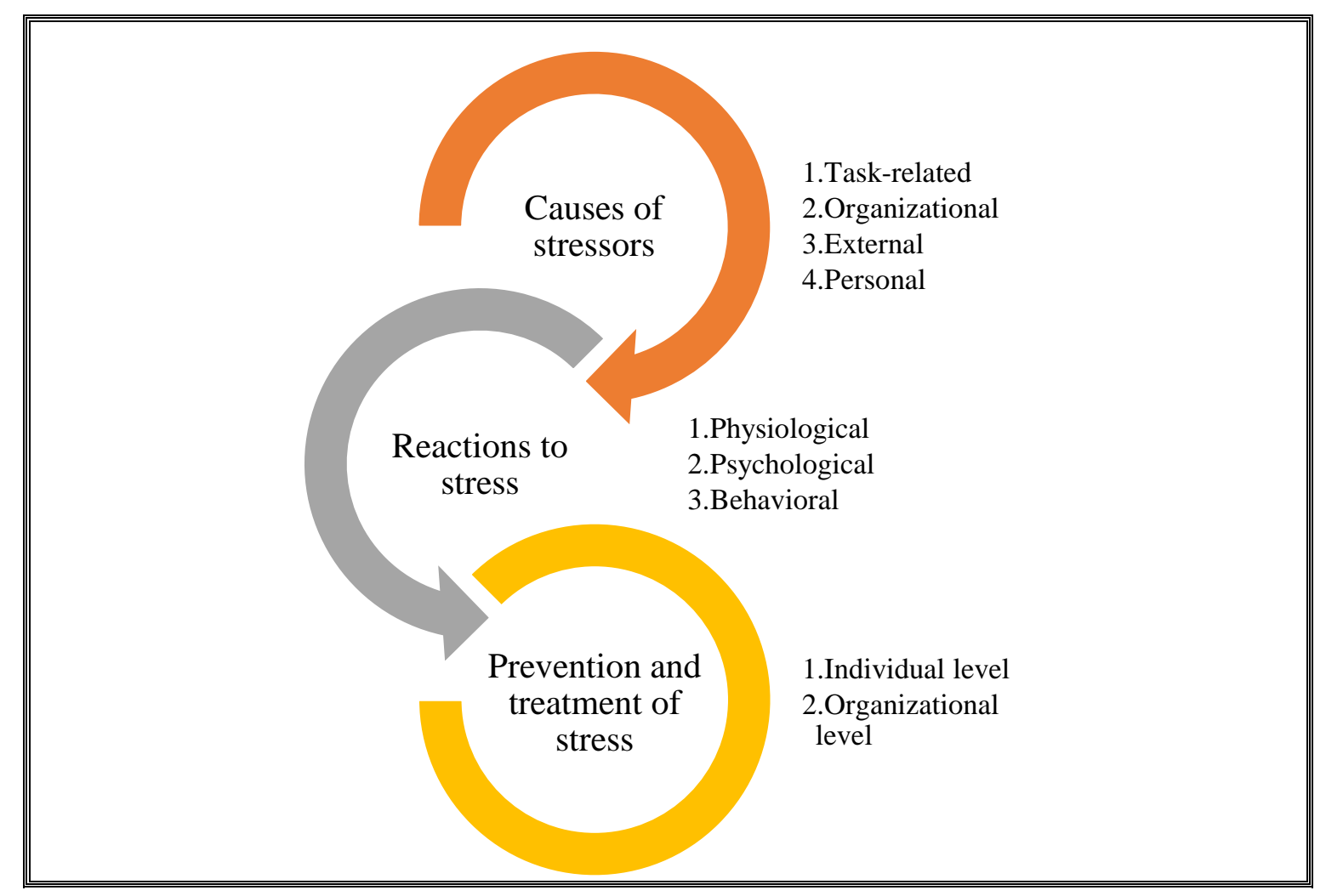

\section{IDENTIFICATION OF PTSD}

Although this dissertation provides a short overview of stress, it is important to note that this is only to distinguish it from PTSD which results "as a delayed or protracted response to a stressful event or situation (of either brief or long duration) of an exceptionally threatening or catastrophic nature, which is likely to cause pervasive distress in almost anyone" (World Health Organization, 2010, para. 37). It is classified in the Diagnostic and Statistical Manual of Mental Disorders as a trauma and stressor related disorder (American Psychiatric Association, 2013) and consists of eight components of which all should last more than one month to meet PTSD criteria (American Psychiatric Association, 2013). The first (group A) is the exposure to actual or threatened death, actual or threatened serious injury, or actual or threatened sexual 
violence. The death, serious injury, or sexual violence must occur in one of the following ways: direct experience; witnessing the incident in person; learning the incident happened to a close family member or friend (in these instances the actual or threatened death must have been accidental or violent); or experiencing repeated or extreme exposure to repulsive details of the incident (American Psychiatric Association, 2013). Repulsive details could include police officers exposed to child abuse and first responders collecting human remains (American Psychiatric Association, 2013).

The second component (group B) is that an individual has one or more intrusion symptoms associated with the incident and following the incident. These could include involuntary, repeated, and intrusive memories that are distressing; repeated dreams related to the incident; flashbacks in which the individual feels as though he/she is still experiencing the incident; intense or prolonged psychological distress at cues that resemble the incident, or marked physiological reactions to cues that resemble the incident (American Psychiatric Association, 2013).

In addition, the individual must have persistent avoidance of stimuli, which is associated with the incident (group C). This avoidance could include avoiding or attempting to avoid memories, thoughts, or feelings which are distressing, or avoiding or efforts to avoid reminders that bring about memories, thoughts, or feelings which are distressing (American Psychiatric Association, 2013).

The fourth component is negative change in thoughts and mood associated with the incident (group D). With this, at least two of the following should be present: 1) the inability to remember an important aspect of the incident (this could be due to amnesia not a head injury, alcohol, or drugs); 2) persistent and exaggerated negative beliefs or 
expectations about their self, others, or the world; 3) persistent and distorted cognitions about the cause or consequences of the incident that lead the individual to blame themselves; 4) persistent negative emotional state (to include fear, horror, anger, guilt, or shame); 5) marked diminished interest or participation in significant activities; 6) detachment or estrangement of others; 7) or persistent inability to experience positive emotions (such as the inability to experience satisfaction, loving feelings, and happiness) (American Psychiatric Association, 2013).

The fifth component includes marked changes in arousal and reactivity associated with the incident (group E). At least two of the following should occur: irritable behavior and angry outbursts, reckless or self-destructive behavior, hypervigilance, exaggerated startle response, problems with concentration, or sleep disturbance (American Psychiatric Association, 2013).

Finally, an individual should experience distress or impairment in social, occupational, or other significant functioning areas (group F) (American Psychiatric Association, 2013). This distress or impairment should not be due to physiological effects of a substance, such as drugs or alcohol, or an alternate medical condition (group G) (American Psychiatric Association, 2013). See Figure 2 below for a simplified explanation about PTSD. 
Figure 2. PTSD Simplified

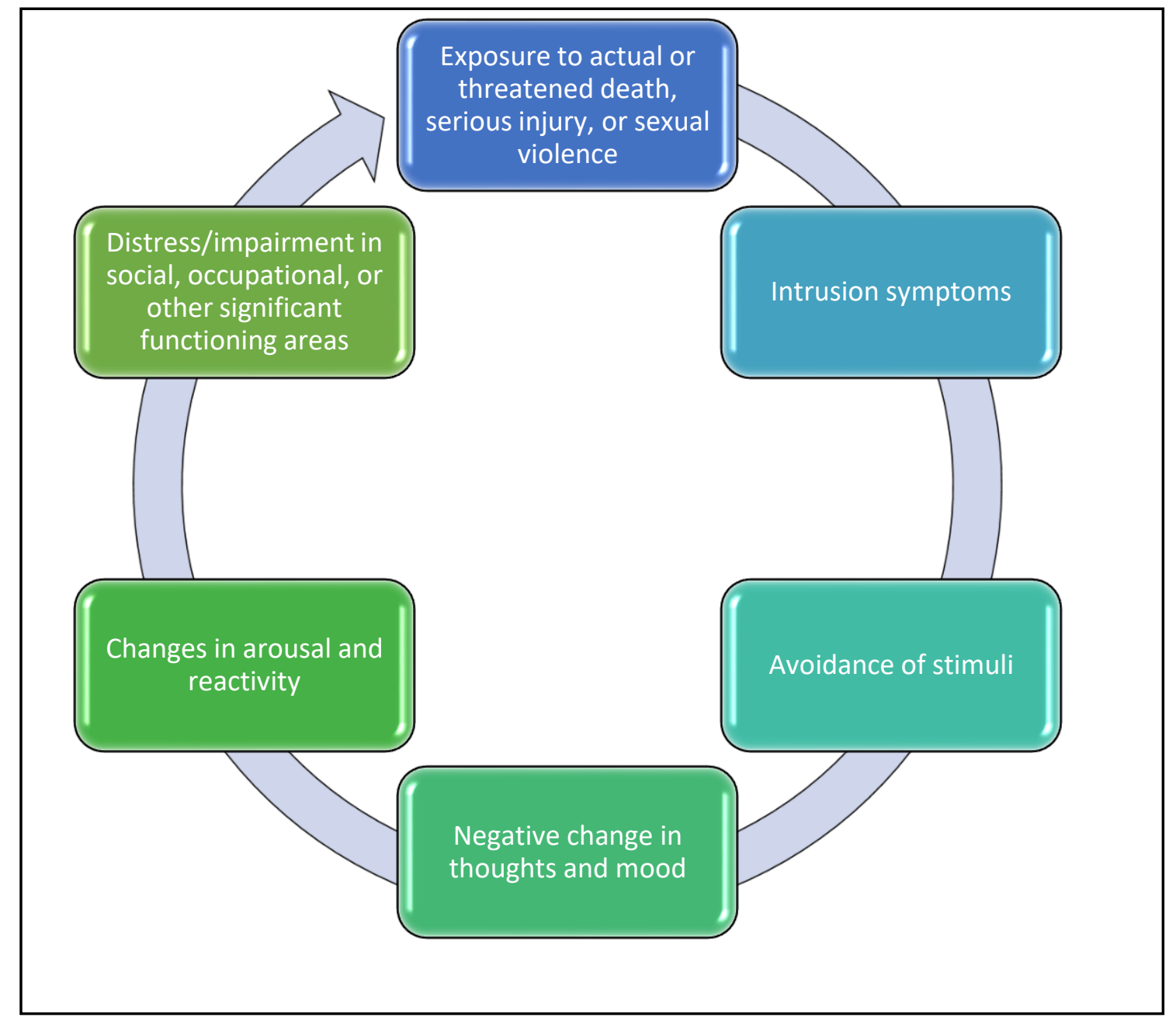

\section{HISTORY OF PTSD}

Although much is known about PTSD due to its formal classification in the DSM today, PTSD has evolved substantially since the first reports of PTSD like symptoms. It was first reported on the battlefield during the Civil War, when soldiers endured horrors due to combat, which was both concentrated and personal (Horwitz, 2015). The majority of battles were fought on foot with soldiers firing and being shot at close range. However, with the utilization of the accurate and deadly rifles in 1860 , soldiers could be cut down en masse resulting in body parts showering the survivors (Horwitz, 2015, para. 9). In 
addition to combat, many soldiers with injuries were treated with unsterilized instruments and given opiates for pain, which led to drug addictions. These conditions led to despair, homesickness, and listlessness, which were termed "nostalgia" by doctors (Horwitz, 2015). Although serious, "nostalgia" was blamed on "feeble will," "moral turpitude," and camp inactivity and was often treated with shaming.

Although military and medical personnel acknowledged post-battle psychiatric symptoms during the Civil War, it was not until the Russian-Japanese War of 1904-1905 that Russian psychiatrist, Dr. Avtocratov, began the first successful psychiatric treatment of post-combat soldiers (about 1500 were treated in 1904 and 2000 treated in 1905) (Crocq \& Crocq, 2000). In addition to Dr. Avtocratov, Dr. Honigman, a German physician, was also part of the treatment team and who would later use the phrase "war neurosis" for what was previously called "combat hysteria" and "combat neurasthenia" (Crocq \& Crocq, 2000).

World War I (WWI) brought a different type of warfare, one with industrial means, which advanced the knowledge of psychotraumatology. Very early in the war, psychiatric casualties were higher than expected with Dr. Gaupp, a German psychiatrist, reporting:

The big artillery battles of December 1914... filled our hospitals with a large number of unscathed soldiers and officers presenting with mental disturbances. From then on, that number grew at a constantly increasing rate. At first, these soldiers were hospitalized with the others ... but soon we had to open special psychiatric hospitals for them. Now, psychiatric patients make up by far the largest category in our armed forces ...The main causes are the fright and anxiety brought about by the explosion of enemy shells and mines, and seeing maimed or dead comrades ...The resulting symptoms are states of sudden muteness, deafness ... general tremor, inability to stand or walk, episodes of loss of consciousness, and convulsions. (Crocq \& Crocq, 2000, p. 49) 
Due to the large number of psychiatric casualties, treatment approaches changed. Rather than evacuating the casualty to a relaxed hospital environment separated from the battle, soldiers were treated in a frontline hospital and so benefitted from the support of their comrades as well as the military environment. Military and medical personnel surmised that this frontline treatment would lead to a return to the unit and less chronic symptoms in the future. Frontline treatment, also known as "proximity," became standard along with four other key principles identified by Dr. Salmon, an American physician. The principles were identified as immediacy (treatment provided as soon as possible), expectancy (positive expectation of prompt care), simplicity (simple treatments utilized such as rest, sleep, etc.), and centrality (organization of treatment so that frontline casualties were treated first) (Crocq \& Crocq, 2000).

Although World War II (WWII) was also an industrial war, it brought a different dynamic to psychiatric casualties due to the targeting of civilian populations, genocide of the Holocaust, air raids, and atomic bombs. Unfortunately, the lessons learned in WWI regarding the removal of casualties to base hospitals, went unheeded until 1943 (Crocq \& Crocq, 2000). Once implemented, about 50\% to $70 \%$ of soldiers were able to return to duty (Crocq \& Crocq, 2000). At the end of WWII, unlike WWI, the course and chronic nature of symptoms were studied extensively. American psychiatrists Dr. Grinker and Dr. Speigel examined 65 cases and ultimately distinguished between reactions to combat and reactions after combat (Crocq \& Crocq, 2000). Reactions after combat included "war neuroses" as well as passive-dependent states, psychosomatic states, guilt, depression, aggression, hostility, and psychotic-like states (Crocq \& Crocq, 2000). 
While Americans received extensive treatment from trained psychiatrists in frontline hospitals, the German military applied a different method. German soldiers suffering from combat stress were typically removed to a first aid station and provided chocolate, milk, and rest (Crocq \& Crocq, 2000). This is consistent with the German doctrine (of the time) that weak or degenerate individuals should be eliminated rather than allowing them to return and poison the community.

During the Vietnam War, the frontline treatment of psychiatric casualties was successful resulting in a low number of casualties, about 11.5 per 1,000 men per year, however, alcoholism, drug abuse, and delayed effects of combat exposure were significant as about 700,000 veterans required some form of psychological assistance (Crocq \& Crocq, 2000). The amount of delayed and chronic symptoms in the form of PTSD were surprising to medical personnel who had taken extensive measures to prevent such occurrences.

PTSD was again a focus preceding the wars in Iraq and Afghanistan. The Department of Veterans Affairs reported that $20 \%$ of Iraqi and $11 \%$ of Afghan war veterans reported PTSD symptoms (PTSD: A growing epidemic, 2009). The reason for the difference in the PTSD figures could be due to the exposure to more combat, as well as, the related trauma. As compared to the Afghan war, during the Iraqi war a higher percentage of veterans reported seeing dead bodies (95\% vs 39\%), being shot at (93\% vs. $66 \%$ ), being ambushed ( $89 \%$ vs. $58 \%$ ), and receiving mortar or rocket fire (86\% vs. $84 \%$ ) (U.S. Department of Veterans Affairs, n.d.-a). Additionally, more veterans reported knowing someone who was killed or seriously injured (86\% vs 43\%) (U.S. Department of Veterans Affairs, n.d.-a). 


\section{CAUSES OF PTSD}

\section{Natural Disasters}

PTSD symptomology has been identified in individuals after the occurrence of natural disasters such as tsunamis, hurricanes, and fires (U.S. Department of Veterans Affairs, n.d.-d). After the tsunami of 2004 that struck Indonesia, Sri Lanka, India, Thailand, and the Maldives, high levels of PTSD were found (National Climatic Data Center, 2008). Hurricane Katrina, which devastated the Gulf Coast in 2005 led to an increased prevalence of mental disorders over time (Kessler, Galea, Gruber, Sampson, Ursano, \& Wessely, 2008). After about two years, there remained a high rate of PTSD in the afflicted areas. Although wildfires are less frequent, wildfires have become more prevalent (U.S. Geological Survey, 2006). About 100,000 individuals were evacuated in 2003 as wildfires spread through southern California (U.S. Department of Veterans Affairs, n.d.-d). Data collected from survivors three years after the wildfire indicated that one-fourth had PTSD as a result of this traumatic event (Marshall, Schell, Elliott, Rayburn, \& Jaycox, 2007).

\section{Injuries}

PTSD is also prevalent in those with certain injuries which may arise from assault, falling, work environment, war, and transport (motorcycles, cars, etc.) (Bryant, Creamer, O’Donnell, Silove, Clark, \& McFarlane, 2009; Bryant, O’Donnell, Creamer, McFarlane, Clark, \& Silove, 2010; Hoge, McGurk, Thomas, Cox, Engel, \& Castro, 2008; Mayou, Black, \& Bryant, 2000; Vasterling, Brailey, Proctor, Kane, Heeren, \& Franz, 2012), For example, research has indicated that high impact incidents, causing mild traumatic brain injuries (mTBI), result in an increased prevalence of PTSD (Bryant et al., 
2009; Bryant et al., 2010; Hoge et al., 2008; Mayou et al., 2000; Vasterling et al., 2012). mTBI has been defined as when the head receives impact, consciousness is lost or altered for 30 minutes or less, posttraumatic amnesia occurs for less than 24 hours, and score of between 13 and 15 is indicated on the Glasgow Coma Scale (Bigler, 2008).

In addition to mTBI, other studies have found that loss of consciousness (Bryant, O’Donnell, Creamer, McFarlane, Clark, \& Silove, 2010; Hoge, McGurk, Thomas, Cox, Engel, \& Castro, 2008; Luethcke, Bryan, Morrow, \& Isler, 2011; Mayou, Black, \& Bryant, 2000; Vasterling, Brailey, Proctor, Kane, Heeren, \& Franz, 2012) and head injuries resulted in a higher rate of PTSD. For example, in a study of 1,260 accident survivors with head injuries, those who lost consciousness were found to have a higher prevalence of PTSD and higher levels of PTSD (Roitman, Gilad, Ankri, \& Shaley, 2013). Furthermore, the loss of consciousness resulted in a slower recovery time from PTSD symptoms (Roitman et al., 2013).

\section{Crime}

In addition to accidents and disasters, being a victim of a crime is also a common cause of PTSD. The PTSD caused by crime may differ from other causes of PTSD as PTSD may be more severe and last longer when the stressor is of human design (American Psychological Association, 1987).

\section{Mass Violence}

Mass violence, such as shootings at restaurants and schools, have been found to produce PTSD. After a cafeteria shooting in Texas in 1991, 28\% of the victims met the criteria for PTSD (North, Smith, McCool, \& Shea, 1989). Following a shooting at a California elementary school, PTSD symptoms were prevalent at the 1 month, 6 month, 
and 14-month follow-ups in children who were on the playground during the attack (Nader, Pynoos, Fairbanks, \& Frederick, 1990). In fact, the authors reported that $74 \%$ of the children on the playground during the attack continued to report symptoms of PTSD 14 months later, while $81 \%$ of those children who did not have direct exposure did not show symptoms of PTSD (Nader, Pynoos, Fairbanks, \& Frederick, 1990).

\section{Terror Attacks}

While natural disasters and mass violence have long produced survivors suffering from PTSD, terror attacks are relatively new traumas. Unfortunately, the mental health effects of these events appear to last longer than those of natural disasters (U.S. Department of Veterans Affairs, n.d.-c). Deliberate violence causes the community and survivors to feel as though an injustice was done to them, which could lead to anger, frustration, helplessness, fear, and a desire for revenge. Studies on those affected by terrorism consistently find that those who were closer to the attacks, injured, or knew someone who was killed or injured are at higher risk for developing PTSD (U.S. Department of Veterans Affairs, n.d.-c).

\section{Rape}

Research indicates that rape has been found to be related to higher rates of PTSD. In examining 1,007 young adults in the Detroit, Michigan area, Breslau, David, Andreski, and Peterson (1991) reported that 80\% of the females who reported rape had PTSD. Recent studies have found similar results with Rothbaum, Foa, Riggs, Murdock, and Walsh (1992) reporting a rate of $94 \%$ within one month of the rape, and $50 \%$ in the first 3 months following the rape. Likewise, Eklit and Christiansen (2010) reported that $45 \%$ of females met criteria for PTSD in the 3 months following the rape. 


\section{Torture}

Torture is often used to cause suffering and break resistance in an individual. Although controversy exists in the definition of torture, with some defining it as physical acts, which result in prolonged mental and physiological harm while others expand the definition to include degrading treatments and threats of harm. Since the beginning of the war on terrorism, multiple methods of torture have been used and developed, with extensive planning and calculation based on psychological principles. Consequently, it has become an additional focus of study for those interested in PTSD. One such study focused on the torture of 275 Palestinian male former prisoners in an attempt to determine if physical torture, sexual torture, sensory deprivation, or psychological torture affected the rate of PTSD (Punamaki, Qouta, \& El Sarraj, 2010). Physical torture and psychological torture were associated with increased PTSD symptoms both individually and when combined (Punamaki et al., 2010).

\section{EFFECTS OF PTSD}

The effects of PTSD are many and varied. They include physical consequences. For example, research indicates that those with PTSD have an increased risk for irritable bowel syndrome (Irwin, Falsetti, Lydiard, Ballenger, Brook, \& Brener, 1996), which often includes cramping, bloating, gas, diarrhea, and/or constipation. Similarly, fibromyalgia, which is characterized by pain, fatigue, memory issues, sleep issues, and mood issues, has also been found to be prevalent in those with PTSD (Amir, Kaplan, Neumann, Sharabani, Shani, \& Buskila, 1997). Furthermore, a higher likelihood has been found for those with PTSD to experience cardiovascular disease in which the blood vessels are blocked possibility leading to chest pain, stroke, and heart attack (Ahmadi, 
Hajsadeghi, Mirshkarlo, Budoff, Yehuda, \& Ebrahimi, 2011; Boscarino, 2008; Boscarino \& Chang, 1999; Boscarino, Galea, Adams, Ahern, Resnick, \& Vlahov, 2004; Coughlin, 2011; Cwikel, Abdelgani, Goldsmith, Quastel, \& Yevelson, 1997; Glaesmer, Brähler, Gündel, \& Riedel-Heller, 2011; Jordan, Miller-Archie, Cone, Morabia, \& Stellman, 2011; Kubzansky \& Koenen, 2009; Kubzansky, Koenen, Jones, \& Eaton, 2009; Kubzansky, Koenen, Spiro, Vokonas, \& Sparrow, 2007; Sibai, Armenian, \& Alam, 1989). Last, studies indicate those with PTSD are more likely to experience migraines which could include nausea, changes in vision, sensitivity to light and sound, and auras. These auras could render an employee unable to perform for up to 30 minutes (Mayo Foundation for Medical Education and Research. 2017). Consequently, these physical effects are not to be taken lightly as they could lead to employee absence, an employee unable to perform on the job, and/or the employee leaving the department.

In addition to physical consequences, studies indicate there are also mental and emotional issues which are more prevalent in those with PTSD. These include anger, paranoia, and depression (Kessler, Sonnega, Bromet, Hughes, \& Nelson, 1995; Kessler, Berglund, Demler, Jin, Merikangas, \& Walters, 2005). Also, studies have found that those with PTSD may result in difficulty maintaining employment and poor interpersonal relationships (Beck, Grant, Clapp, \& Palyo, 2009; Brewin, Andrews, \& Valentine, 2000; Olatunji, Cisler, \& Tolin, 2007; Ozer, Best, Lipsey, \& Weiss, 2003). These issues could result into an unstable and possibly dangerous work environment.

The consequences mentioned herein are all excellent motivations to consider PTSD a significant, and possibly, hazardous concern which should be carefully monitored within an entity. Perhaps with research combined with evidence based 
prevention and management methods, PTSD could be reduced among personnel, therefore reducing the possibility of physical, mental, and emotional consequences.

\section{SOCIAL SUPPORT AS A MITIGATOR FOR PTSD}

Considering the many and serious effects of PTSD symptomology, some studies have concentrated on questions of prevention as not all individuals who experience trauma will develop PTSD. Hence, if the development of PTSD symptomatology depends upon not only the intensity of the event, but also on factors occurring after the trauma, could specific interventions post-trauma affect PTSD? One intervention, improving social support, has been frequently studied to determine its effectiveness at preventing symptomology.

The fact that a lack of positive social support is a risk factor for PTSD has long been established by researchers, however how support acts as a mechanism to prevent the disorder has only been briefly addressed. Williams and Joseph (1999) likened social support to an active stress management strategy whereby it influences the individual's interpretation of the event. This reinterpretation serves to influence not only the appraisal cognitions, defined by Williams and Joseph (1999) as thoughts about the information and its meanings, but also reappraisals, which are thoughts obtained through alternative meanings to include the influence of others. Hence, social support allows the individual to essentially, reframe the event therefore lessening the impact. Consequently, some research has explored social support as a mechanism, which mitigates the impact of PTSD symptomology.

In examining the role of social support in adult male (118) and female (39) victims of sexual and non-sexual assault, the Crisis Support Scale (Joseph, Andrews, 
Williams, \& Yule, 1992) was used (Andrews, Brewin, \& Rose, 2003). The scale included questions regarding the availability of others, confiding in others, emotional support, practical support, negative response, and satisfaction with support. The participants are asked to rate the support questions on a 7-point scale ranging from never (1) to always (7) (Joseph et al., 1992). Positive social support did not affect PTSD symptoms; however, support satisfaction was significantly associated with PTSD symptoms (Andrews et al., 2003).

A later study focused on the relationship between PTSD symptomology, social support, and community victimization (Scarpa, Haden, \& Hurley, 2006). Community victimization was defined as being hit, threatened, stabbed, beaten/mugged, shot, chased, having their home broken into while the individual was home, and having their home broken into while the individual was not home (Scarpa et al., 2006). The social support scale asked participants to rate their family support on statements such as "My family is willing to help me make decisions," "My family really tries to help me," and "I can talk about my problems with my family" (Scarpa et al., 2006). In addition, support from friends was gauged by questions such as "I can talk about my problems with my friends," "My friends really try to help me out," and "I have friends with whom I can share my joys and sorrows" (Scarpa et al., 2006). While the severity of symptomology was related to family support, the success of friend support in reducing the severity of PTSD symptomology was dependent upon the level of victimization experienced. Specifically, individual experiences of increased levels of community violence resulted in diminished effects of supportive friends (Scarpa et al., 2006). 
Several factors have been examined to determine why some assault victims develop PTSD while others do not. Factors which affect symptomology include the type of assault (such as childhood victimization) (Weaver, Kilpatrick, Resnick, Best, \& Saunders, 1997); assailant identity (Cascardi, Riggs, Hearst-Ikeda, \& Foa, 1996); assault location (Cascardi, Riggs, Hearst-Ikeda, \& Foa, 1996); severity of initial PTSD symptoms (Riggs, Rothbaum, \& Foa, 1995); presence of depression following the assault (Shalev, Freedman, Peri, Brandes, Sahar, Orr, \& Pitman, 1997); anger following the assault (Koenen, Hearst-Ikeda, \& Caulfield, 1997; Riggs, Dancu, Gershuny, Greenberg, \& Foa, 1992); and degree of social support following the assault (Ullman \& Siegel, 1994).

In addition to victims of crime, social support has been shown to play a role in the symptomology among those who have experienced disasters. One year after the attacks of the World Trade Center Disaster, 2,368 adult New Yorkers participated in a study to determine if a lack of social support increased the likelihood of PTSD symptomology (Adams \& Boscarino, 2006). A modified version of the Medical Outcomes Study (MOS) Social Support Survey Instrument (Sherbourne \& Stewart, 1991) was used which included questions such as "Is someone available to help if you were confined to bed," to conceptualize social support. Low social support was found to have increased the likelihood of PTSD symptomology one year after the attacks; however, it did not affect the likelihood of PTSD when the individuals were examined one year after the initial study (Adams \& Boscarino, 2006).

Similarly, those experiencing an illness may also be more likely to experience symptomology. A study of 82 adults breast cancer survivors utilized the Duke-UNC 
Functional Social Support Questionnaire (DUKE-SSQ) to assess levels of social support. This questionnaire included statements such as "I get chances to talk to someone I trust about my personal or family problems," "I have people who care what happens to me," and "I get useful advice about important things in life" to which participants responded with 1 (much less than I would like) to 5 (as much as I would like) (Andrykowski \& Cordova, 1998). As expected, those with less social support reported greater PTSD symptoms (Andrykowski \& Cordova, 1998).

Not surprising, lack of social support has been identified as a PTSD risk factor among war veterans. However, research has also indicated that social support is a risk factors for those military personnel while they are serving during times of war. In a study of veterans, 1,198 males who served in the Vietnam theatre, defined as Vietnam or surrounding areas to include waters and airspace, were asked about their social support. This included questions about whether there was an individual the veteran could speak with, count on to help raise his spirits, and count on in case of an emergency (Fontana \& Rosenheck, 1994). The researchers found that low social support contributed directly to the development of PTSD symptoms (Fontana \& Rosenheck, 1994).

Vietnam veterans were again the focus of a study conducted by King, King, Fairbank, Keane, and Adams (1998) in which postwar social support was examined. Using a national sample of 1,632 veterans, both male and female, King et al. (1998) conceptualized social support into two categories: structural social support and functional social support. Structural social support included the responses to questions such as, "About how many voluntary groups or organizations (church, clubs, groups, etc.) do you belong to?" (King et al., 1998). Functional social support included responses to questions 
such as, "Among your friends and relatives, is there someone who would lend you a car or drive you to a doctor, the airport, shopping, or somewhere else if you really needed it?" (King et al., 1998). The reported findings were that structural social support predicts functional social support, and that functional social support predicts symptomology (King et al., 1998). Hence, the greater amount of functional social support, the lower the amount of symptomology. In a later study using the same demographics, 1,632 male and female Vietnam theater veterans, King, King, Foy, Keane, \& Fairbank (1999) did not find a relationship between structural social support, functional social support, and female veterans, however, for males, structural social support and functional social support were negatively correlated with symptomology (King et al., 1999). It could be that gender plays a significant role in whether certain types of social support are successful in reducing symptoms of PTSD.

These same social support conceptualizations would later be used to examine Vietnam veterans both at their homecoming from the war and at the time of the survey ${ }^{1}$ (Schnurr, Ford, Friedman, Green, Dain, \& Sengupta, 2000). The questions to assess social support included: "How many close friends/relatives do you have," "How often do you get together with friends," and "Does it seem that your family and friends understand you?" The research concluded that symptomology was associated with lower social support at homecoming as well as the time of the data collection for the study (Schnurr et al., 2004).

\footnotetext{
${ }^{1}$ This study utilized the National Vietnam Veterans Readjustment Study (NVVRS-299 participants) and the Hawaiian Vietnam Veterans Project (HVVP- 183 participants). For the NVVRS, the participants were interviewed an average of 26.9 years later (range was 23-33), and for the HVVP, the participants were interviewed an average of 19.2 years later (range was 14-24).
} 
The research on social support has assessed the relationship between symptomology and disclosure of traumatic events (Ford, Friedman, Green, Dain, \& Sengupta, 2000). Among a sample of World War I veterans exposed to mustard gas, the less an individual confided in a significant other about the experience or the more an individual was compelled by their superiors not to confide, the more that veteran was at risk to develop PTSD. Veterans who were unable to confide in significant others were unable to assimilate the trauma (Schnurr et al., 2000).

In addition to research about those who experienced violent and traumatic events from assault, illness, and war, some studies have focused solely on first responders and the role of social support. A 1999 study on routine duties of international firefighters (625) and American firefighters (203) found that in both populations, higher levels of family and at-work social support resulted in decreased rates of PTSD symptomology (Corneil et al., 1999). Similarly, the symptomology of 530 Dutch security guards was reduced by three types of support; emotional support in problem situations (support which helps an individual feel loved and cared for such as talking over a problem and providing feedback); instrumental support (help with childcare, housekeeping, transportation, etc.); and social companionship (availability of friends or companions) (Declercq, Vanheule, Markey, \& Willemsen, 2007). Social support was also identified as a reason for the difference in symptomology levels between male and female emergency medical technicians (EMTs). The males had a higher rate of symptomology than females which the authors attributed to the fact that perhaps females had either better access to, or greater, social support to assist with coping (Bennett, Williams, Page, Hood, \& Woollard, 2004). 
Studies of correctional staff have also produced results favorable to social support mitigating symptoms of PTSD. In discussing possible reasons for a $25.8 \%$ prevalence of symptoms within a sample of correctional workers, Stadnyk (2003), suggests that the rate may be due to employees feeling that supervisors were not supportive and encouraging and coworkers were unfriendly and provided little support. Similarly, lack of social support, defined as peer aggression, has been found to increase symptomology. Kunst, Bogaerts, and Winkel (2009) reported that Dutch correctional employees who were exposed to peer aggression which was defined as physical acts of aggression, intimidation, and unwanted sexual attention, were almost five and half times more likely to develop symptoms, as compared to inmate aggression. The increased symptomology was attributed to the fact that inmate aggression is the norm in these types of environments (Poole \& Regoli, 1981), however, peer aggression is abnormal in a culture that promotes "watching out for each other."

Correspondingly, PTSD has been studied among journalists with symptomology found to be affected by social support. Studies suggest that their symptomology rate of $30 \%$ among war journalists may be due to the lack of social support (Feinstein, Owen, \& Blair, 2002). Similarly, a later study examining 875 photojournalists found $6 \%$ had met the diagnosis for PSTD with social support reported to increase the risk of symptomology (Newman, Simpson, \& Handschuh, 2003).

In conclusion, the broader literature on PTSD and social support provides validation of social support as a promising intervention for PTSD symptomology among correctional staff. Symptomology decreased when social support increased in those who have experienced violent and traumatic events whether the events be assault, illness, war, 
or due to their occupation. Given the significance of social support in mitigating symptomology within these populations, that have been studied, could other criminal justice professionals benefit from increased social support? This dissertation explores this phenomenon as it relates to a particular group of criminal justice personnel who work in highly stressful environments, corrections staff. Should social support successfully mitigate symptomology, this could have tremendous implications for policy that could positively influence the quality of life for correctional staff.

\section{SUMMARY}

Often, people consider stress and PTSD to be the same and lump them into one category; however, they are very different. Although the term "stress" was first coined in relation to individuals in 1936 by Selye (The American Institute of Stress, 2017), PTSD has been diagnosed in some form since the Civil War with doctors labeling the condition “combat hysteria” (Crocq \& Crocq, 2000), "combat neurasthenia” (Crocq \& Crocq, 2000), "nostalgia” (Horwitz, 2015), and "war neurosis" (Crocq \& Crocq, 2000). Fortunately, knowledge about this condition has increased with its current label of PTSD recognized by the Diagnostic and Statistical Manual of Mental Disorders in 1980 (U.S. Department of Veteran Affairs, n.d.).

Currently PTSD has eight components; each of which should last more than one month to meet PTSD criteria (American Psychiatric Association, 2013). The first (group A) is exposure to actual or threatened death, serious injury, or sexual violence (American Psychiatric Association, 2013). The second and third components stipulate that an individual has one or more intrusion symptoms as well as persistent avoidance of stimuli (American Psychiatric Association, 2013). Additionally, the individual should have a 
negative change in thoughts and mood as well as a change in arousal and reactivity (American Psychiatric Association, 2013). Finally, an individual should experience distress or diminished functioning in social, occupational, or other areas (group F) (American Psychiatric Association, 2013).

The components generating PTSD symptoms are often associated with individuals who have experienced disasters, accidents, terror, and mass violence resulting in physical, mental, social, and financial issues; decreased quality of life; and substance abuse. However, not everyone exposed to these events exhibits the PTSD symptomology. Among those individuals who are exposed to the traumatic events, factors have been identified which mitigate the development of PTSD. One such factor, social support, acts as a type of filter whereby the individual's interpretation of the traumatic event may change. Studies have shown that the presence of social support reduces PTSD symptomology in sexual assault victims (Scarpa, Haden, \& Hurley, 2006), and in veterans (King et al., 1998, King et al., 1999). Other studies have found that low social support increases PTSD symptoms after exposure to disasters (Adams \& Boscarino, 2006), following an illness (Andrykowski \& Cordova, 1998), among Vietnam veterans (Fontana \& Rosenheck, 1994; Schnurr et al., 2000; Schnurr et al., 2004), among journalists (Feinstein et al., 2002; Newman et al., 2003), and among first responders (Bennett et al., 2004; Corneil et al., 1999; Declercq, 2007; Kunst et al., 2009; Stadnyk, 2003).

Although research indicates certain populations may have a higher prevalence of PTSD symptomology, the research is far from complete. The next chapter examines the existing research on PTSD symptomology by exploring the general population, as well as 
those in specific occupational groups such as social workers, trauma therapists, and first responders. Unfortunately, PTSD symptomology and social support has not been extensively studied among first responders and other criminal justice personnel.

However, given the findings report in the literature on PTSD symptomology primarily among police, firefighters, ambulance personnel, and security guards with more limited research on correctional staff, the findings suggest it is reasonable to hypothesize that stronger social support systems could ameliorate the negative effects of working in a chronically traumatic environment such as prison. This is the purpose of the current research, to assess the extent to which social support mitigates PTSD symptomology among correctional staff. 


\section{CHAPTER 3. PTSD: GENERAL POPULATION AND FIRST RESPONDERS}

\section{PTSD IN THE GENERAL POPULATION}

Recent PTSD statistics indicate that about $70 \%$ of United States adults have experienced trauma in their lifetime (PTSD United, 2013). Of these adults, about $20 \%$ of individuals develop PTSD, which equates to about 44.7 million individuals (PTSD United, 2013). Furthermore, about $8 \%$ of the population have PTSD at any one time, which equates to the population of Texas (PTSD United, 2013). Although these numbers are helpful in examining the overall prevalence of PTSD, it is also important to explore specific demographics in an attempt to determine possible correlates.

\section{Gender}

Studies focusing on symptomology by gender have been inconclusive. Studies have found rates of PTSD for females to range between 3\% (Stein et al., 1997) and 21.8\% (Breslau \& Davis, 1992). Some studies have reported that females, as compared to males, are twice as likely to report PTSD symptoms (Kessler, Chiu, Demler, \& Walters, 2005), have higher current or lifetime prevalence rates (Breslau, Kessler, Chilcoat, Schultz, Davis, \& Andreski, 1998; Norris, Perilla, Ibanez, \& Murphy, 2001; Stein, Walker, Hazen, \& Forde, 1997), more likely to have higher conditional current or lifetime prevalence rates (Norris, 1992), and more likely to have higher chronic rates of PTSD (Breslau \& Davis, 1992) than men. Although these studies suggest that PTSD 
symptoms are more prevalent among females, it is unclear why these differences exist. And, while some of the research literature finds a relationship between gender and PTSD, other research has found no relationship among the populations studied such as, young adults (Chung \& Breslau, 2008) and Operation Enduring Freedom and Operation Iraqi Freedom veterans (King, Street, Gradus, Vogt, \& Resick, 2013).

Age

Statistics tend to focus on adult PTSD; however, individuals of all ages, including senior citizens may be susceptible to PTSD symptoms. Research on PTSD symptomology prevalence in older individuals (those over 60), has been hindered due to the lack of examination of late onset cases in which the individual re-experiences the trauma after retirement or other changes (Aarts, op den Velde, Falger, Hovens, de Groen, \& van Duijn, 1996; Clipp, \& Elder, 1996; Tolin \& Foa, 2006). Additionally, older individuals tend to attribute symptoms of PTSD to physical conditions (Lyons \& McClendon, 1990) and physicians attribute it to depression or dysthymia (Averill \& Beck, 2000). However, PTSD symptoms may be prevalent in older individuals as they may experience a greater number of events that involve loss or medical emergencies. It may even be that senior citizens are subject to a higher risk of PTSD symptoms due to less social support and living in less favorable situations as compared to younger adults (van Zelst, de Beurs, Beekman, Deeg, \& van Dyck, 2003).

On the other hand, when Harris, Young, Rae, Jalaludin, and Solomong (2008) examined 355 individuals who visited a major metropolitan trauma center in Australia following an accidental injury. Within this sample, about $36 \%$ were classified as having 
PTSD symptoms (Harris et al., 2008) and those who were younger had higher PTSD symptomology scores.

\section{Race}

Research on the relationship between race and PTSD symptomology is inconclusive. Some researchers report higher symptomology rates for Hispanics among male combat veterans (Kulka, Schlesenger, Fairbank, Hough, Jordan, Marmar, \& Weiss, 1990), victims of Hurricane Andrew (Perilla, Norris, \& Lavizzo, 2002), and residents in New York City following the 9/11 terrorist attacks (Galea, Ahern, Resnick, Kilpatrick, Bucuvalas, Gold, \& Vlahov, 2002). Additionally, one study found Hispanic police officers had more severe PTSD symptoms than non-Hispanic police officers (Pole, Best, Weiss, Metzler, Liberman, Fagan, \& Marmar, 2001). Others report higher risks of PTSD symptomology among African Americans (Garrison, Bryant, Addy, Spurrier, Freedy, \& Kilpatrick, 1995; Roberts, Gilman, Breslau, \& Koenen, 2011; Shannon, Lonigan, Finch, \& Taylor, 1994). Still other studies have not found any relationship between race and PTSD symptoms (Breslau, Aguilar Gaxiola, Kendler, Su, Williams, \& Kessler, 2006; Ghafoori, Barragan, Tohidian, \& Palinkas, 2012).

Many studies have produced hypotheses to explain why symptomology rates vary by race. Some research suggests that among African Americans, the differences are due more to the relationship between race and the reporting of symptoms. The conclusion is that stigmatizing beliefs and negative judgement about mental illness, which reduces the likelihood of reporting, vary by race. In one study, an individual reported that their social circle would call them "crazy" (Alvidrez, Snowden, \& Kaiser, 2008). Additionally, other African Americans have mentioned reluctance to report due to the fear that it may 
perceived as though the family failed to handle issues internally (Williams, 2011). Others had negative attitudes about those who obtain mental health care and did not want to be one of "those people" (Williams, 2011). Differences in Hispanic symptomology has been attributed to suspected overreporting (Ortega \& Rosenheck, 2000). Hence, taken together, the research on the relationship between race and symptomology is inconclusive.

\section{Proximity to Trauma}

The existing literature indicates that geographical proximity to the trauma event may also affect the likelihood of symptomology. This is especially pertinent as trauma is experienced by correctional staff located within the same cell block unit. This has been confirmed by earlier studies, especially those examining the World Trade Center attacks. Of the 379 employees of the World Trade Center Companies interviewed, symptomology was found in $35 \%$ of those directly exposed as defined as a .1 mile radius (North, Pollio, Smith, King, Pandya, Suris, Hong, Dean, Wallace, Herman, Conover, Susser, \& Pfefferbaum, 2011).

In general, studies do not provide a consensus with findings unable to positively conclude that a specific gender, age, or race is more susceptible to PTSD symptomology. However, a close proximity to trauma has been shown to increase symptomology. Hence, further research is needed on whether specific demographics place individuals at a higher risk for experiencing PTSD symptoms. However, it may simply be that no one gender, age, or race is more likely to experience symptomology. 


\section{OCCUPATIONAL ENVIRONMENT}

\section{Primary Overview}

Similar to proximity to trauma, workers within certain occupational environments may be more apt to experience trauma that could produce PTSD symptoms. These include the generally recognized first responder populations of police, firefighters, ambulance personnel, and security guards. In addition to first responders, other occupations may also be susceptible to symptoms due to direct contact with trauma as well as indirect trauma referred to as secondary traumatic stress (STS) or vicarious traumatization. This next section discusses these occupational environments in more detail. These studies are divided into primary and secondary studies. Primary studies are those which focus on the first responder demographic. Secondary studies will follow with a discussion about social workers, trauma therapists, health care professionals, and journalists.

\section{Primary: Police}

Regular and ongoing exposure to traumatic situations, to include confrontations, violence, and potential harm, is part of the nature of police work. These traumatic situations may cause an officer to experience symptoms of PTSD. The studies examining this relationship between police work and PTSD show a wide range of PTSD symptomology rates, from a low of $2 \%$ (Carlier, Lamberts, Van Uchelen, \& Gersons, 1998) to a high of $49 \%$ (Kopel \& Friedman, 1997). The differences in rates could be due to the measurement tool utilized, sample size, the location of comparison groups (national vs. international), and the setting (routine duties vs. event specific duties). 
South Africa's Internal Stability Unit (ISU) was the focus of a 2008 study by Kopel and Friedman (1997). The ISU is part of the South African Police Force and functions as a specialist riot squad. They were typically located within black townships as the normal police were withdrawn due to increasing dangers. Utilizing the Impact of Events Scale (IES), 55 male ISU officers from the Pretoria, Witwatersrand, and Vereenining regions were queried about their symptoms (Kopel \& Friedman, 1997). Of the 55 male subjects, 49\% (27) met the criteria for a diagnosis of PTSD (Kopel \& Friedman, 1997). The most traumatic stressors identified were: seeing dead people in the townships (69\%), hearing colleagues talking about other South African Police members who had died or been wounded while doing township duty (64\%), seeing South African Police members wounded by a rock/stone throwing crowd (60\%), and being bothered by the sight of burning property of township residents (56\%). The least reported stressors (all less than 30\%) were, being wounded in the townships, collecting/ handling the corpses of South African Police members, encountering landmines and booby traps in the townships; and being part of a unit patrol which was ambushed (Kopel \& Friedman, 1997). Studies have found rates of PTSD for females to range between $3 \%$ (Stein et al., 1997) and 21.8\% (Breslau \& Davis, 1992). The finding of a high rate of symptomology was not considered unusual considering that South Africa has inequality in income, inequality in educational opportunities, persistent poverty, a severe HIV/AIDS pandemic, and violent crime (Bureau of Diplomatic Security, 2017).

Other research also employed the IES-R to determine prevalence of PTSD. Robinson et al. (1997) utilized this instrument in their examination of 100 Ohio police from Euclid, Lorain, and Cleveland Heights. In their conclusions, they reported about 
$13 \%$ of officers met the criteria for PTSD and the best predictors were exposure to death and the threatening of life (Robinson et al., 1997). Furthermore, those officers reporting 11 or less years on the force experienced more PTSD (Robinson et al., 1997) than those who had been on the force more than 11 years. The authors provided several reasons why less time on the job equates to more PTSD. First, younger officers may not have successful coping strategies to deal with critical incidents (Robinson et al., 1997). Second, younger officers may not be numb to intense stressors as compared to veteran officers (Robinson et al., 1997). Third, younger officers may report higher PTSD symptoms because they are more likely to be on street patrol, which puts them at greater risk for experiencing trauma as compared to a veteran officer who may have a desk job (Robinson et al., 1997). Last, younger officers may be more likely to overstate trauma (Robinson et al., 1997).

Darensburg, Andrew, Hartley, Burchfiel, Fekedulegn, and Violanti (2006) also utilized the IES-R to study 100 Buffalo, NY police officers. About $35 \%$ of officers reported moderate or severe PTSD symptoms with males and females having similar rates (36.6\% and 34.5\%) (Darensburg et al., 2006). Additionally, contrary to Robinson et al. (1997), the rate of PTSD seemed to increase with age (Darensburg et al., 2006).

Some studies expanded the focus from PTSD to other co-occurring disorders. Asmundson and Stapleton (2008) included anxiety sensitivity in their study of 138 Canadian police officers. A total of $31.9 \%$ of respondents tested positive for symptoms utilizing the PTSD Symptoms Checklist-Civilian Version (PCL-C). Those who tested positive had fewer years of education, were older, and spent more time in policing than those without symptoms. It is significant to know that the number of traumatic events 
reported did not statistically differ (6.9 for those without PTSD and 7.6 for those with PTSD) (Asmundson \& Stapleton, 2008).

Similarly, Stephens and Miller (2008) found that lack of education correlated with higher PTSD scores. Of the 527 New Zealand police officers who completed the Mississippi PTSD scale (M-PTSD), 13.6\% had symptoms when using the least conservative cut-off score (Stephens \& Miller, 2008). The events, which were most likely to be related to symptoms, included a known police officer's death, a robbery, mugging or hold-up, chronic distress at work and “other” experiences (Stephens \& Miller, 2008). “Other” experiences included 12 items such as being held hostage, body recoveries, crowds, riots, and child cot deaths (Stephens \& Miller, 2008).

Oehme, Donnelly, and Martin (2012) also focused on symptoms in a large sample. Their sample included police officers, agents from sheriff's departments and members of the highway patrol for a total of 853 participants. Additionally, the researchers examined how alcohol influenced domestic abuse. Utilizing the PTSD Checklist, the authors found that $17.7 \%$ of the law enforcement officers reported PTSD symptoms (Oehme, Donnelly, \& Martin, 2012). Additionally, those with symptoms were four times more likely to report using physical violence (Oehme, Donnelly, \& Martin, 2012).

Another study of a large sample included 3,817 South Korean police officers who completed the IES-R Korean Version. This study found that $41.11 \%$ had experienced PTSD following a traumatic event (Lee, Kim, Won, \& Roh, 2016). Those in the divisions of Intelligence and National Security and the Police Precinct had the highest frequency of PTSD symptoms at $43.6 \%$ and $43.5 \%$ (Lee et al., 2016). When examining rank, 
Inspectors and Assistant Inspectors had the highest frequencies (46\% and 42.7\%) (Lee et al., 2016). Additionally, a PTSD classification was common among older respondents aged $40(43.4 \%)$ and $50(48.38 \%)$ as compared to those in their 20s $(27.61 \%)$ and $30 \mathrm{~s}$ (29.51\%) (Lee et al., 2016). See Table 1 summarizing these studies.

Table 1: Police PTSD Studies to Date (Routine Duties)

\begin{tabular}{|c|c|c|c|c|}
\hline Source & Sample & Measurement Tool & PTSD Rate & Correlates of PTSD \\
\hline $\begin{array}{l}\text { Kopel \& Friedman, } \\
1997\end{array}$ & $\begin{array}{l}55 \text { Internal } \\
\text { Stability Unit } \\
\text { (ISU) of the South } \\
\text { African Police } \\
\text { Force }\end{array}$ & $\begin{array}{l}\text { Impact of Events Scale } \\
\text { (IES) }\end{array}$ & $49 \%$ & $\begin{array}{l}\text { Intrusion (-), } \\
\text { Avoidance (+) }\end{array}$ \\
\hline $\begin{array}{l}\text { Robinson, Sigman, \& } \\
\text { Wilson, } 1997\end{array}$ & $\begin{array}{l}100 \text { American } \\
\text { police }\end{array}$ & $\begin{array}{l}\text { Impact of Events- } \\
\text { Revised (IES-R) }\end{array}$ & $13 \%$ & $\begin{array}{l}\text { Exposure to Death and } \\
\text { Life Threat (+) }\end{array}$ \\
\hline $\begin{array}{l}\text { Darensburg, Andrew, } \\
\text { Hartley, Burchfiel, } \\
\text { Fekedulegn, \& } \\
\text { Violanti, 2006 }\end{array}$ & $\begin{array}{l}100 \text { Buffalo, NY } \\
\text { police }\end{array}$ & $\begin{array}{l}\text { Impact of Events Scale } \\
\text { (IES) }\end{array}$ & $35 \%$ & Age (+) \\
\hline $\begin{array}{l}\text { Asmundson \& } \\
\text { Stapleton, 2008 }\end{array}$ & $\begin{array}{l}138 \text { Canadian } \\
\text { police }\end{array}$ & $\begin{array}{l}\text { PTSD Symptoms } \\
\text { Checklist- Civilian } \\
\text { Version (PCL-C) }\end{array}$ & $31.9 \%$ & $\begin{array}{l}\text { Panic disorder (+), } \\
\text { Depressive symptoms } \\
(+), \text { Number of report } \\
\text { trauma (+), Anxiety } \\
\text { sensitivity somatic } \\
\text { concerns (+) }\end{array}$ \\
\hline $\begin{array}{l}\text { Stephens \& Miller, } \\
2008\end{array}$ & $\begin{array}{l}527 \text { New Zealand } \\
\text { police }\end{array}$ & $\begin{array}{l}\text { Mississippi PTSD scale } \\
\text { (M-PTSD) }\end{array}$ & $13.6 \%$ & $\begin{array}{l}\text { Education (-), Amount } \\
\text { of traumatic } \\
\text { experiences }(+), \text { A } \\
\text { known officer's death } \\
(+) \text {, robbery }(+) \text {, } \\
\text { mugging }(+), \text { chronic } \\
\text { distress at work }(+) \text {, } \\
\text { Trauma experienced } \\
\text { after joining police } \\
\text { rather than before }(+)\end{array}$ \\
\hline $\begin{array}{l}\text { Oehme, Donnelly, \& } \\
\text { Martin, } 2012\end{array}$ & $\begin{array}{l}853 \text { Florida law } \\
\text { enforcement agents } \\
\text { (police } \\
\text { departments, } \\
\text { sheriff's } \\
\text { departments, and } \\
\text { highway patrol) }\end{array}$ & PTSD Checklist (PCL) & $17.7 \%$ & $\begin{array}{l}\text { Using physical } \\
\text { violence }(+)\end{array}$ \\
\hline $\begin{array}{l}\text { Lee, Kim, Won, \& } \\
\text { Roh, } 2016\end{array}$ & $\begin{array}{l}3817 \text { South Korean } \\
\text { police }\end{array}$ & $\begin{array}{l}\text { Impact of Event Scale } \\
\text { (IES/Korean version) }\end{array}$ & $41.11 \%$ & Not Specified (N/S) \\
\hline
\end{tabular}


In addition to routine duties, studies have shown that police may be susceptible to PTSD symptoms following specific events such as shootings and disasters. In one of the earliest studies, Gersons (1989) questioned 37 officers who were involved in shooting incidents resulting in injury or death. Gersons (1989) began this research after his interest was piqued by an officer who asked for help. The officer stated that many other officers were suffering from PTSD; however, assistance was not available from within the department nor outside the department (Gersons, 1989). It was found that $46 \%$ (17) showed PTSD symptoms. Unfortunately, none of the officers with PTSD symptoms sought treatment from doctors, psychologists, or social workers within the police force (Gersons, 1989).

Regarding disasters, the findings are inconclusive. The rate of PTSD symptomology reported in an early study was low while a more recent study found a higher prevalence. The earlier study conducted by Carlier, Lamberts, Van Uchelen, and Gersons (1998) assessed police responding to a Boeing cargo plane crash into Amsterdam apartments in 1992. Eight months after the crash, the PTSD rates of 200 officers were evaluated to determine if debriefing affected the rates (Carlier et al., 1998). Utilizing the structured interview for PTSD (SI-PTSD), researchers found that $2 \%$ of the officers had PTSD, with one being debriefed and one not debriefed (Carlier et al., 1998). After 18 months, the results did not change; again 2\% of the officers had PTSD, with one being debriefed and one not debriefed (Carlier et al., 1998).

However, in examining a natural disaster, a more recent study, completed 10 years later, found higher rates of symptoms. West, Bernard, Mueller, Kitt, Driscoll, and Tak (2008) studied 912 New Orleans police who were surveyed 8 weeks after Hurricane 
Katrina. The respondents had performed a range of duties to include patrol duty (78\%) and looting control (59\%) (West et al, 2008). Symptoms were reported by $19 \%$ of the officers with predictors including injury after an assault, injury of a family member, involvement in crowd control, and body recovery (West et al, 2008).

Another study involving a manmade disaster, rather than a natural disaster, found a lower rate of symptoms. The focus for this study was 1,884 officers who responded to the attacks on the World Trade Center (WTC) on September 11, 2001 (Bowler, Kornblith, Adams, Gocheva, Schwarzer, \& Cone, 2016). These officers worked at least one shift during the rescue and recovery operations at the WTC, worked recovery operations at other sites, or were involved in debris transport. Of the 1,884 participants, 8\% (243) met criteria for PTSD symptoms (Bowler et al., 2016). See Table 2 below which summarizes the literature on these.

Table 2: Police PTSD Studies to Date (Event Specific Duties)

\begin{tabular}{|l|l|l|l|l|}
\hline \multicolumn{1}{|c|}{ Source } & \multicolumn{1}{|c|}{ Sample } & \multicolumn{1}{c|}{ Measurement Tool } & PTSD Rate & \multicolumn{1}{c|}{ Correlates/Predictors } \\
\hline Gersons, 1989 & $\begin{array}{l}\text { 37 American } \\
\text { police }\end{array}$ & Not identified & $46 \%$ & N/S \\
\hline $\begin{array}{l}\text { Carlier, Lamberts, } \\
\text { Van Uchelen, and } \\
\text { Gersons, 1998 }\end{array}$ & 200 Dutch police & $\begin{array}{l}\text { Structured Interview for } \\
\text { PTSD (SI-PTSD) }\end{array}$ & $2 \%$ & Disassociation (+) \\
\hline $\begin{array}{l}\text { West, Bernard, } \\
\begin{array}{l}\text { Mueller, Kitt, } \\
\text { 2riscoll, \& Tak, }\end{array}\end{array}$ & $\begin{array}{l}912 \text { American } \\
\text { police }\end{array}$ & PTSD Checklist (PCL) & $19 \%$ & $\begin{array}{l}\text { Recovery of bodies (+), } \\
\text { Crowd control (+), } \\
\text { Assault (+), Injury to a } \\
\text { family member (+) }\end{array}$ \\
\hline $\begin{array}{l}\text { Bowler, Kornblith, } \\
\text { Adams, Gocheva, } \\
\text { Schwarzer, \& Cone, } \\
\text { 2016 }\end{array}$ & 1,884 officers ${ }^{2}$ & $\begin{array}{l}\text { Posttraumatic Checklist- } \\
\text { Civilian Version (PCL-C) }\end{array}$ & $8 \%$ & $\begin{array}{l}\text { Hispanic (+), Income (-), } \\
\text { Physical injury on 9/11 } \\
(+), \text { Stress/trauma since } \\
9 / 11(+), \\
\text { Unemployment/retirement } \\
(+)\end{array}$ \\
\hline
\end{tabular}

\footnotetext{
${ }^{2}$ The article states that these were officers who responded to the disaster in NYC, however, it was not clearly identified if these were only NYC officers. The WTC Health Registry, which was used for this study, includes the US and 15 other countries. One of the authors of the study has been contacted to confirm only American officers.
} 


\section{Primary: Firefighters}

Among protective services personnel, firefighting has historically been ranked as one of the most dangerous. Per the Bureau of Labor Statistics (2015), the number of fatal work injuries among firefighters, although lower than previous years, is $35 \%$. This is not surprising considering they encounter multiple stressful situations and traumatic events which may require them to suppress fires, provide medical care, direct rescue efforts, engage in crowd control, and recover bodies (Del Ben, Scotti, Chen, \& Fortson, 2006). Studies of this demographic show a range of rates of symptomology from $6.5 \%$ (Haslam \& Mallon, 2003) to 26\% (Bryant \& Harvey, 1996).

Wagner, Heinrichs, and Ehlbert (1998) focused on these routine duties in examining professional firefighters in Germany. Utilizing the General Health Questionnaire, they found a symptomology rate of $18.2 \%$ and that symptoms were not related to specific functions in the department (Wagner et al., 1998). Furthermore, the likelihood of symptoms increased as the time on duty and participation in distressing missions increased (Wagner et al., 1998).

Corneil, Beaton, Murphy, Johnson, and Pike (1999) also focused on routine duties of international firefighters (625); however, they used these as a comparison group for American firefighters (203). They determined symptomology to be about $22 \%$ for the American respondents and $17 \%$ for Canadian respondents using the Impact of Events Scale (Corneil et al., 1999). Additionally, the researchers found that in the American sample, being married was associated with lower rates of PTSD symptomology, while in the Canadian sample, those with more than 15 years of service had increased rates of PTSD symptomology (Corneil et al., 1999). In both populations, higher levels of family 
and at-work social support resulted in decreased rates of PTSD symptomology (Corneil et al., 1999).

International professional firefighters were again the sample in a study of 31 United Kingdom fire service workers, which included 11 firefighters, 8 station officers, 4 sub officers, 4 leading firefighters, 2 fire control officers, and 2 area divisional officers (Haslam \& Mallon, 2003). The modified version of the Posttraumatic Stress Diagnostic Scale (PDS) revealed that only 2 (or about $6.5 \%$ ) of the respondents met the criteria for symptoms, however, the symptoms resulted from events that occurred outside of work (Haslam \& Mallon, 2003).

With respect to event specific trauma, symptomology has also resulted. North, Tivis, McMillen, Pfefferbaum, Cox, Spitznagel, Bunch, Schorr, and Smith (2002) utilized the Diagnostic Interview Schedule (DIS) to determine symptomology in 181 American professional firefighters who worked the area of the 1995 Oklahoma City bombing. The bombing was concentrated on the Alfred Murrah federal building and killed 168 people; 19 of those were children (Oklahoma City National Memorial and Museum, 2017). The symptomology rate was reported as $13 \%$ with the majority $(84 \%)$ reporting work in the "pit," the most unstable area surrounded by three-foot-high piles of debris, and (74\%) the "Mother Slab," a dangerously hanging 35,000-pound section of the roof (North et al., 2002). Firefighters reporting symptoms were less likely to get along with their supervisor and coworkers, less likely to acknowledge pride in their job, less likely to be satisfied with their job, and more likely to experience personal relationship changes (both negative and positive). Surprisingly, although reporting that the exposure to child victims was 
especially distressing, symptomology was not affected by contact with children's remains or affects.

In addition to professional firefighters, volunteer firefighters are also vulnerable to PTSD. In examining Australian firefighters, $17 \%$ reported significant post-traumatic stress related to firefighting duties, while $9 \%$ reported extreme post-traumatic stress (Bryant \& Harvey, 1996). Symptomology was not affected by the type of the stressor, but instead the severity and frequency of the stressor (Bryant \& Harvey, 1996). Furthermore, Bryant and Harvey (1996) found evidence to suggest that situations, which limit a firefighter's sense of personal control, increased the likelihood of symptomology. Table 3 below summarizes the significant studies to date. 
Table 3: Firefighter PTSD Studies to Date

\begin{tabular}{|c|c|c|c|c|c|}
\hline Source & Sample & $\begin{array}{c}\text { Measurement } \\
\text { Tool }\end{array}$ & Setting & PTSD Rate & $\begin{array}{l}\text { Correlates/ } \\
\text { Predictors }\end{array}$ \\
\hline $\begin{array}{l}\text { Bryant \& Harvey, } \\
1996\end{array}$ & $\begin{array}{l}651 \text { New South } \\
\text { Wales volunteer } \\
\text { firefighters }\end{array}$ & $\begin{array}{l}\text { Impact } \\
\text { of Event Scale } \\
\text { (IES) }\end{array}$ & $\begin{array}{l}\text { Routine } \\
\text { duties }\end{array}$ & $\begin{array}{l}17 \% \\
\text { significant } \\
9 \% \text { extreme } \\
---- \\
26 \%\end{array}$ & $\begin{array}{l}\text { Multiple events } \\
(+) \text {, Recent events } \\
(+)\end{array}$ \\
\hline $\begin{array}{l}\text { Wagner, } \\
\text { Heinrichs, \& } \\
\text { Ehlbert, } 1998\end{array}$ & $\begin{array}{l}402 \text { German } \\
\text { professional } \\
\text { firefighters }\end{array}$ & $\begin{array}{l}\text { General Health } \\
\text { Questionnaire \& } \\
\text { PTSD Symptom } \\
\text { Scale }^{3}\end{array}$ & $\begin{array}{l}\text { Routine } \\
\text { duties }\end{array}$ & $18.2 \%$ & $\begin{array}{l}\text { Longer job } \\
\text { experience (+), } \\
\text { Number of } \\
\text { distressing } \\
\text { missions in the } \\
\text { last month (+) }\end{array}$ \\
\hline \multirow[t]{2}{*}{$\begin{array}{l}\text { Corneil, Beaton, } \\
\text { Murphy, Johnson, } \\
\& \text { Pike, } 1999\end{array}$} & $\begin{array}{l}203 \text { American } \\
\text { professional } \\
\text { firefighters }\end{array}$ & $\begin{array}{l}\text { Impact of Event } \\
\text { Scale (IES) }\end{array}$ & $\begin{array}{l}\text { Routine } \\
\text { duties }\end{array}$ & $22 \%$ & $\begin{array}{l}\text { Married (-), Line } \\
\text { fire (-) }\end{array}$ \\
\hline & $\begin{array}{l}625 \text { Canadian } \\
\text { professional } \\
\text { firefighters }\end{array}$ & $\begin{array}{l}\text { Impact of Event } \\
\text { Scale (IES) }\end{array}$ & $\begin{array}{l}\text { Routine } \\
\text { duties/ }\end{array}$ & $17 \%$ & $\begin{array}{l}15+\text { years of } \\
\text { service }(+),\end{array}$ \\
\hline $\begin{array}{l}\text { North, Tivis, } \\
\text { McMillen, } \\
\text { Pfefferbaum, Cox, } \\
\text { Spitznagel, } \\
\text { Bunch, Schorr, } \\
\text { Smith, } 2002\end{array}$ & $\begin{array}{l}\text { 181 American } \\
\text { professional } \\
\text { firefighters }\end{array}$ & $\begin{array}{l}\text { Diagnostic } \\
\text { Interview } \\
\text { Schedule (DIS) }\end{array}$ & $\begin{array}{l}\text { Event } \\
\text { specific }\end{array}$ & $13 \%$ & $\mathrm{~N} / \mathrm{S}$ \\
\hline $\begin{array}{l}\text { Haslam \& } \\
\text { Mallon, 2003 }\end{array}$ & $\begin{array}{l}31 \text { United } \\
\text { Kingdom } \\
\text { professional fire } \\
\text { service workers }\end{array}$ & $\begin{array}{l}\text { Posttraumatic } \\
\text { Stress Diagnostic } \\
\text { Scale (PDS }\end{array}$ & $\begin{array}{l}\text { Routine } \\
\text { duties/ }\end{array}$ & $6.5 \%$ & $\begin{array}{l}\text { Children involved } \\
\text { in incident (+), } \\
\text { Serious injury or } \\
\text { pain to the } \\
\text { casualty (+), } \\
\text { Major incident (+) }\end{array}$ \\
\hline
\end{tabular}

${ }^{3}$ These scales were used together to determine a single prevalence rate. 


\section{Primary: Ambulance Personnel}

Emergency ambulance personnel are also at risk for PTSD as this may be a reaction to experiencing a traumatic event as well as helping or wanting to help a traumatized individual. However, the research on this professional group is sparse. The limited research indicates a range of symptomology from 5.6\% (Berger, Figueria, Maurat, Bucassio) to $22 \%$ (Bennett et al., 2004).

In studying 223 ambulance personnel in the region of Vastra Gotaland, Sweden, who reported experiencing a traumatic event, Jonsson, Segesten, and Mattsson (2003) employed two PTSD scales. The ambulance personnel reported a prevalence rate of $15.2 \%$ for the Impact of Events Scale (IES) and $12.1 \%$ on the Post Traumatic Symptom Scale (PTSD-10) (Jonsson et al., 2003). Furthermore, those with higher scores on the IES and PTSD-10 tended to be older, with more time in the ambulance service, and had less education (Jonsson et al., 2003).

International ambulance personnel were the sample in another study of 187 staff from the Dutch regional ambulance services (van der Ploeg \& Kleber, 2003). The Dutch version of the IES indicated a rate of $12 \%$ with $13 \%$ of the respondents reporting symptoms one year later (van der Ploeg \& Kleber, 2003). Firefighters responded that events involving children and hopeless patients were the most stressful (van der Ploeg \& Kleber, 2003).

Bennett et al. (2004) found a higher rate of $22 \%$ when using the Posttraumatic Diagnostic Scale (PDS) to examine 293 emergency medical technicians (EMTs) and paramedics in the United Kingdom. These staff served about three million people in both rural and urban settings. Although a difference between rates was not found between the EMTs and paramedics, males had a higher rate of symptomology than females (Bennett 
et al., 2004). The authors hypothesize that this may be attributed to the fact that resilient females join the ambulance service or perhaps females had either better access to, or greater, social support to assist with coping (Bennett et al., 2004).

Brazilian ambulance personnel were studied by Berger, Figueira, Maurat, Bucassio, Vieira, Jardim, Coutinho, Mari, and Mendlowicz (2007). These researchers sent questionnaires to 234 ambulance workers of the Group of Emergency Rescue (GSE) located in Rio de Janeiro, Brazil. The GSE is an elite division of the Fire Department of the State of Rio de Janeiro that supplies emergency medical assistance to urban areas. Since the GSE has a paramilitary structure, its members have military ranks; hence, physicians are commissioned officers while nurses are noncommissioned officers (Berger et al., 2007). In this population, full PTSD was found in 5.6\% of the respondents, and partial PTSD was found in 15\% (Berger et al., 2007). The authors hypothesized the low rates of PTSD were due to the physicians within the GSE. The physicians had higher socioeconomic and educational status which some studies hypothesize allow greater access to assistance and treatment therefore reducing the likelihood of PTSD. The authors also found that more men than women reported full PTSD (6.7\% vs. 1.9\%), while more women than men reported partial PTSD (13.3\% vs 20.4\%) (Berger et al., 2007). A statistically significant difference was found when examining marital status of those who reported partial and full PTSD (Berger et al., 2007). Those reporting full PTSD were more likely to be unmarried as compared to those without PTSD. Rather than significant, this was shown as "only a trend toward significance" when marital status was compared with partial PTSD (Berger et al., 2007, p. 3). Table 4 below summarizes the significant ambulance personnel studies to date. 
Table 4: Ambulance Personnel PTSD Studies to Date

\begin{tabular}{|c|c|c|c|c|}
\hline Source & Sample & $\begin{array}{l}\text { PTSD } \\
\text { Rate }\end{array}$ & $\begin{array}{c}\text { Measurement } \\
\text { Tool }\end{array}$ & $\begin{array}{l}\text { Correlates/ } \\
\text { Predictors }\end{array}$ \\
\hline \multirow[t]{2}{*}{$\begin{array}{l}\text { Jonsson, Segesten, \& } \\
\text { Mattsson, } 2003\end{array}$} & \multirow[t]{2}{*}{$\begin{array}{l}223 \text { Swedish } \\
\text { ambulance } \\
\text { personnel }\end{array}$} & $15.2 \%$ & $\begin{array}{l}\text { the Impact of } \\
\text { Events Scale (IES) }\end{array}$ & \multirow{2}{*}{$\begin{array}{l}\text { Lower sense of } \\
\text { coherence }(+), \text { Longer } \\
\text { job experience (+), } \\
\text { Physical and } \\
\text { psychological workload } \\
(+) \text {, Age (+) }\end{array}$} \\
\hline & & $12.1 \%$ & $\begin{array}{l}\text { Post Traumatic } \\
\text { Symptom Scale } \\
\text { (PTSD-10) }\end{array}$ & \\
\hline \multirow[t]{2}{*}{$\begin{array}{l}\text { van der Ploeg \& } \\
\text { Kleber, } 2003\end{array}$} & \multirow[t]{2}{*}{$\begin{array}{l}10 \text { Dutch } \\
\text { ambulance } \\
\text { personnel }\end{array}$} & $12 \%$ & $\begin{array}{l}\text { Dutch version of } \\
\text { the Impact of } \\
\text { Events Scale (IES) }\end{array}$ & \multirow[t]{2}{*}{$\begin{array}{l}\text { Lack of social support } \\
\text { at work }(+), \text { Poor } \\
\text { communication }(+)\end{array}$} \\
\hline & & $13 \%$ & $\begin{array}{l}\text { Dutch version of } \\
\text { the Impact of } \\
\text { Events Scale (IES) }\end{array}$ & \\
\hline $\begin{array}{l}\text { Bennett, Williams, } \\
\text { Page, Hood, \& } \\
\text { Woollard, } 2004\end{array}$ & $\begin{array}{l}293 \text { emergency } \\
\text { medical } \\
\text { technicians } \\
\text { (EMTs) and } \\
\text { paramedics }\end{array}$ & $22 \%$ & $\begin{array}{l}\text { Posttraumatic } \\
\text { Diagnostic Scale } \\
\text { (PDS) }\end{array}$ & Male (+) \\
\hline $\begin{array}{l}\text { Berger, Figueira, } \\
\text { Maurat, Bucassio, } \\
\text { Vieira, Jardim, } \\
\text { Coutinho, Mari, \& } \\
\text { Mendlowicz, } 2007\end{array}$ & $\begin{array}{l}234 \text { Brazilian } \\
\text { ambulance } \\
\text { personnel }\end{array}$ & $5.6 \%$ full $^{4}$ & $\begin{array}{l}\text { Posttraumatic } \\
\text { Stress Disorder } \\
\text { Checklist-Civilian } \\
\text { Version (PCL-C) }\end{array}$ & $\begin{array}{l}\text { Male (+), Not married } \\
(+), \text { Emotional } \\
\text { problems (+), Medical } \\
\text { visits (+) }\end{array}$ \\
\hline
\end{tabular}

${ }^{4} 15 \%$ partial 


\section{Primary: Security Guards}

Security guards are also at risk for PTSD due to the nature of their jobs. Unfortunately, there is little research on this group. In perhaps the only study of this security guards, Dutch researchers examined about 530 Dutch security guards to determine their level of PTSD as well as the nature and level of social support (Declercq, Vanheule, Markey, \& Willemsen, 2007). Utilizing the Dutch version of the Self-Rating Inventory for Posttraumatic Stress Disorder (SRIP), called the ZIL, researchers found that $10.9 \%$ of those who reported experiencing a critical incident $(41.5 \%)$ had a score indicative of PTSD (Declercq et al, 2007). Furthermore, only three types of support were positively significant utilizing the Social Support List (SSL). These forms of social support were: emotional support in problem situations (support which helps an individual feel loved and cared for such as talking over a problem and providing feedback); instrumental support (help with childcare, housekeeping, transportation, etc.); and social companionship (availability of friends or companions) (National Institutes of Health, \& Northwestern University, 2012; The Regents of the University of California, 2008).

\section{Primary: Compound Studies}

The studies discussed below are termed compound studies as their comparisons may concentrate on different responder groups as well as individual demographics. The frequency of symptomology for these studies ranged from a low rate of $4.6 \%$ (Slottje, Witteveen, Twisk, Smidt, Huizink, van Mechelen, \& Smid, 2008) to a high rate of $13.7 \%$ (Lilly, Pole, Best, Metzler, \& Marmar, 2009).

One such study focused on the role of gender on symptomology. Pole et al. (2001) compared male and female urban police officers $(n=655)$ conducting routine duties to 
determine whether gender was related to symptomology. Their study concluded that gender did not play a role in symptomology, however, ethnicity did with HispanicAmericans were more likely to report symptoms than Caucasians and African Americans (Pole et al., 2001).

Somewhat similarly, Lilly et al. (2009) compared 157 female police officers to 124 female civilians utilizing the Mississippi Scale (MS). Female officers reported less severe PTSD symptoms (13.7\%) as compared to the civilians (15\%) (Lilly et al., 2009). More severe PTSD symptoms were associated with lower income and more trauma exposure (Lilly et al., 2009). The authors hypothesized the difference in symptomology may result from the fact that females are minorities in the department and have enormous pressure to conform to male norms, hence they may have developed male attitudes, values, and behaviors over time (Marsden \& Kalleberg, 1993).

Other research has examined PTSD symptomology in multiple occupational categories such as police and firefighters. Slottje, Witteveen, Twisk, Smidt, Huizink, van Mechelen, and Smid (2008) reported a low rate of $4.6 \%$ with symptoms in the combined sample. The respondents $(1,996)$ completed the Dutch version of the Self-Rating Inventory for Post-traumatic stress disorder (SRIP) gauging symptoms following an El Al cargo aircraft crash into Amsterdam apartments (Slottje et al., 2008). Although a low rate was found for this population, Slottje et al. (2008) encourage caution when interpreting this rate as it was taken 8.5 years after the disaster. Hence, it could be speculated that the rate may have been higher if these individuals were examined more immediately following the disaster. 
A similar study focused on Portuguese police and firefighters. Lima, Maia, Ferreira, Magalhães, Nunes, Pinheiro, Ribeiro, Rodrigues, Santos, Santos, and Teles (2016) utilized the Posttraumatic Stress Disorder Checklist (PCL-5) to determine symptomology in 95 firefighters and municipal police officers. About $10 \%$ of the participants reported symptoms (Lima et al., 2016). Table 5 below summarizes the significant studies to date.

Table 5: Compound PTSD Studies to Date

\begin{tabular}{|c|c|c|c|c|c|}
\hline Source & Sample & $\begin{array}{c}\text { Measurement } \\
\text { Tool }\end{array}$ & Setting & $\begin{array}{l}\text { PTSD } \\
\text { Rate }\end{array}$ & $\begin{array}{l}\text { Correlates/ } \\
\text { Predictors }\end{array}$ \\
\hline $\begin{array}{l}\text { Pole, Best, } \\
\text { Weiss, Metzler, } \\
\text { Liberman, } \\
\text { Fagan, \& } \\
\text { Marmar, } 2001\end{array}$ & $\begin{array}{l}655 \text { police } \\
\text { officers }\end{array}$ & $\begin{array}{l}\text { Mississippi } \\
\text { Scale-Civilian } \\
\text { Version (MS- } \\
\text { CV). }\end{array}$ & Routine duties & -5 & Hispanic $(+)$ \\
\hline $\begin{array}{l}\text { Lilly, Pole, } \\
\text { Best, Metzler, } \\
\& \text { Marmar, } \\
2009^{6}\end{array}$ & $\begin{array}{l}157 \text { female } \\
\text { police officers } \\
124 \text { female } \\
\text { civilians }\end{array}$ & Mississippi Scale $^{7}$ & Routine duties & $\begin{array}{l}13.7 \% \\
15 \% \\
-28.7\end{array}$ & $\begin{array}{l}\text { Peritraumatic } \\
\text { emotional distress } \\
(+)\end{array}$ \\
\hline $\begin{array}{l}\text { Slottje, } \\
\text { Witteveen, } \\
\text { Twisk, Smidt, } \\
\text { Huizink, van } \\
\text { Mechelen, \& } \\
\text { Smid, 2008 } \\
\end{array}$ & $\begin{array}{l}528 \text { Dutch } \\
\text { firefighters } \\
1,468 \text { Dutch } \\
\text { police officers }\end{array}$ & $\begin{array}{l}\text { Self-Rating } \\
\text { Inventory for } \\
\text { Posttraumatic } \\
\text { Stress Disorder } \\
\text { (SRIP/Dutch } \\
\text { version) }\end{array}$ & Event specific & $4.6 \%$ & $\mathrm{~N} / \mathrm{S}$ \\
\hline $\begin{array}{l}\text { Lima, Maia, } \\
\text { Ferreira, } \\
\text { Magalhães, } \\
\text { Nunes, } \\
\text { Pinheiro, } \\
\text { Ribeiro, } \\
\text { Rodrigues, } \\
\text { Santos, Santos, } \\
\text { \& Teles, 2016 }\end{array}$ & $\begin{array}{l}95 \text { Portuguese } \\
\text { firefighters and } \\
\text { police officers }\end{array}$ & $\begin{array}{l}\text { Posttraumatic } \\
\text { Stress Disorder } \\
\text { Checklist (PCL-5) }\end{array}$ & Routine duties & $10 \%$ & $\mathrm{~N} / \mathrm{S}$ \\
\hline
\end{tabular}

\footnotetext{
${ }^{5}$ Did not report prevalence rate, however, it did report that female officers were less likely to have PTSD symptoms as compared to male officers.

${ }^{6}$ This study compared police with civilians.

${ }^{7}$ Adapted from the original Mississippi Scale for Combat-Related Posttraumatic Stress Disorder.
} 


\section{Secondary Overview}

These secondary studies are those in which the occupations are not considered first responders. Hence, while they may not experience as much direct exposure to traumatic events, they are still relevant to the present research due to their experience with indirect trauma, sometimes called secondary traumatic stress (STS) or vicarious traumatization. This next section will provide an overview of the literature, which addresses the occupational environments for social workers, trauma therapists, health care professionals, and journalists.

\section{Secondary: Social Workers}

Although typically associated with first responders, other occupations such as social work may be related to PTSD symptoms among individual professionals. Many studies suggest that secondary traumatic stress (STS) due to their work with traumatized individuals such as those who have been exposed to childhood abuse, domestic violence, violent crime, disasters, war and terrorism (Bride, 2007) may contribute to PTSD among social workers. Figley (1999) defined STS as "the natural consequent behaviors and emotions resulting from knowledge about a traumatizing event experienced by a significant other...the stress resulting from helping or wanting to help a traumatized of suffering person" (p. 10).

STS has symptoms identical to those of PTSD due to its intrusive imagery (Courtois, 1988; Danieli, 1988; Herman, 1992; McCann \& Pearlman, 1990), avoidant responses (Courtois, 1988, Haley, 1974), and physiological arousal (Figley, 1995; McCann \& Pearlman, 1990). Bride (2007) examined these in his study of 282 social workers. He reported that $97.8 \%$ of those interviewed reported that their clients 
experienced trauma and $70.2 \%$ experienced at least one STS symptom in the previous week (Bride, 2007). Furthermore, about $15.2 \%$ of the social workers met the criteria for a PTSD diagnosis (Bride, 2007). This finding could be applicable to those working in a correctional facility who may experience trauma indirectly.

\section{Secondary: Trauma Therapists}

Likewise, trauma therapists also experience vicarious traumatization (Arvay \& Uhlemann, 1996). Pearlman and Mac Ian (1995) examined self-identified trauma therapists and found that those with a history of personal trauma showed more negative effects resulting from the work. Furthermore, those with a history of personal trauma, and consequently, more negative effects, were not receiving supervision, had less experience working with trauma survivors, and worked in a hospital setting.

\section{Secondary: Health Care Professionals}

PTSD symptoms have also been found in health care professionals with exposure to violent patients (MacDonald, Karlinsky, Colotla, Flamer, British Columbia, \& University of British Columbia, 2003; Wykes \& Whittington, 1998). Emergency medical personnel who experienced an emotionally distressing work event, which produced either a direct threat to themselves or a witnessed threat to another, such as a patient, displayed similar levels of PTSD symptoms (Skogstad et al., 2013).

\section{Secondary: Journalists}

Journalists covering war also have an increased risk of PTSD. Due to their likelihood of observing death, injuries, and those who are mistreated, media employees who have been in war zones have more post-traumatic stress indicators when compared to those who have not been in war zones (Feinstein, Owen, \& Blair, 2002). Similarly, 
other studies have reported rates of 34\% and 35\% among Mexican journalists (Morales, Perez, \& Martinez, 2012; Morales, Perez, \& Martinez, 2014), 32\% among South African journalists (Marais \& Stuart, 2005), 13\% among U.S. and European journalists (Teegen \& Grotwinkel, 2001), and 12\% among Finnish journalists (Backholm \& Bjorkqvist, 2012). Research on this profession has indicated that the symptomology rate may be due to lack of PTSD treatment, depression, alcohol abuse, lack of social support, a culture of silence, and a lack of training about war zones (Feinstein, Owen, \& Blair, 2002).

\section{CORRECTIONAL STAFF}

Similar to the other occupational environments discussed previously, correctional staff experience many of the traumas and are officially recognized as first responders according to the National First Responders Organization (2014). However, studies on correctional officer PTSD symptomology are scarce. It has only been recently that this group has received attention as more individuals report PTSD and facilities begin to recognize the importance of diagnosing and treating this issue. Currently, of the seven studies identified for inclusion in this dissertation, four focus on international corrections and three focus on American corrections. The rates of PTSD symptomology noted in the American studies ranged from $7.9 \%$ (Tartaglini \& Safrari, 1997) to 33.7\% (Denhof \& Spinaris, 2016), while the rates identified in the international studies ranged from $15 \%$ (Kunst, Bogaerts, \& Winkel, 2009) to 60\% (Boudoukha, Altintas, Rusinek, FantiniHauwel, \& Hautekeete, 2013).

Since international studies seem to be more prevalent, these are discussed first. In 1992, one of the first studies examining PTSD rates in correctional staff was completed on 122 Canadian correctional officers employed in minimum and maximum facilities in 
Ontario (Rosine, 1992). In addition to PTSD rates, Rosine (1992) sought to determine the frequency of exposure to critical incidents to include riots, hostage situations, being shot at, shooting someone in the line of duty, finding murder and suicide victims, watching someone die and other grisly situations which coincide with PTSD. The sample was predominately male $(71 \%)$. The majority, $75 \%$, of those surveyed worked in male facilities (Rosine, 1992). Additionally, individuals employed in the minimum-security facilities had previous experience in either medium- or maximum-security facilities. Rosine (1992) reported that males experienced an average of 32 critical incidents, while females only experienced 16 . This difference was attributed to the fact that females had been employed in corrections for a shorter period (6 years vs 17 years) (Rosine, 1992). Furthermore, about $61 \%$ of officers reported receiving injuries at work and $43 \%$ of those resulted in at least one week off work (Rosine, 1992).

A total of $74 \%$ of officers experienced symptoms of PTSD with $17 \%$ having effects so severe that it could be labeled PTSD (Rosine, 1992). Of those reporting PTSD, about $81 \%$ indicated their symptoms disappeared in less than three years. Hence, among approximately $19 \%$ of the correctional officers, it took more than three years for the symptoms to subside. Rosine (1992) mentioned that the officers continued their work in the corrections field and hypothesized that they likely adapted. However, the adaptive behavior could have been maladaptive therefore creating issues at the facilities.

Rosine (1992) also reported exposure to critical incidents and subsequent PTSD affected the correctional officers' families. The officers' families experienced the officer's mood swings, anxiety, and irritability. Hence, the officers stated they did not 
discuss the events with family to reduce the family's worry as well as to shield them from the violence.

Another Canadian study based on a sample of 271 corrections employees from Saskatchewan was conducted in 2003. Participants were asked to complete a survey, which included the Posttraumatic Stress Diagnostic Scale (PDS) (Stadnyk, 2003). The sample was mainly female (49\% with $46 \%$ males and $5 \%$ not reporting), Caucasian (84\%), with an average age of about 42 years old (Stadnyk, 2003). The most frequent job assignment was a corrections worker in an urban setting. About $80 \%$ of the officers reported the experience of a traumatic event, and the average number was three events per employee within a six-month period (Stadnyk, 2003). In examining PTSD, Stadnyk (2003) reported that $25.8 \%$ of officers had symptoms indicative of PTSD with $16 \%$ of the PTSD being work related and $10 \%$ being not work related.

Stadnyk (2003) further addressed possible consequences related to PTSD. First, those with PTSD symptoms missed nearly five times more work in the period of a year than the annual average for corrections workers during the same time period (Stadnyk, 2003). Second, they drank almost twice as many alcoholic beverages as those without PTSD (Stadnyk, 2003). Last, they reported their supervisors were less supportive and encouraging, coworkers as unfriendly and providing little support, and the environment as unpleasant. Additionally, the consensus among those with PTSD symptoms was that there was a lack of planning and efficiency, concern for and commitment to the job, and emphasis on innovation (Stadnyk, 2003).

In addition to the U.S. and Canada, a study was also conducted in the Netherlands to determine PTSD prevalence among correctional workers. About 151 individuals 
participated in an interview, which utilized the Self-Rating Inventory (SRIP) for PTSD. The participants were mainly men (74\%), married (94\%), and with intermediate vocational education (87\%) (Kunst, Bogaerts, \& Winkel, 2009). The average years of service was 15 (Kunst, Bogaerts, \& Winkel, 2009). Results indicated 15\% of these correctional workers could be diagnosed with PTSD (Kunst, Bogaerts, \& Winkel, 2009).

Interestingly, Kunst, Bogaerts, and Winkel (2009) also explored the relationship between peer staff aggression and PTSD. A surprising number (34\%) of the participants stated that they had been exposed to colleague aggression while $42 \%$ stated they had been exposed to inmate aggression (Kunst, Bogaerts, \& Winkel, 2009). In comparing these experiences to the rates of PTSD, those exposed to peer aggression were almost five and half times more likely to develop symptoms of PTSD (Kunst, Bogaerts, \& Winkel, 2009). This relationship was deemed plausible because acts of aggression by inmates occur regularly and are in some ways a structural condition of prison, hence they should be less likely to cause distress PTSD (Poole \& Regoli, 1981). However, peer aggression is an abnormal occurrence especially in an environment that places an emphasis on employees watching out for each other.

One year later, a study assessed 240 French correctional staff and their risk of PTSD and burnout (Boudoukha, Altintas, Rusinek, Fantini-Hauwel, \& Hautekeete, 2013). This sample was mostly male (83\%), had a high school degree (79\%), with an average age of 38 (Boudoukha et al., 2013). Correctional personnel were classified as victimized because of the significant percentage who had experienced an assault (97\%), been confronted with another traumatic event during work (93\%), and had experienced indirect victimization such as witnessing assaults (95\%) (Boudoukha et al., 2013). The 
results indicate that $39 \%$ had a moderate risk of PTSD, and $22 \%$ had a high risk of PTSD (Boudoukha et al., 2013). Furthermore, age, gender, and seniority, contrary to their hypothesis, did not contribute to the risk of PTSD (Boudoukha et al., 2013).

Tartaglini and Safran (1997) examined U.S. corrections staff using the medical charts of 1029 urban jail officers who visited a department clinic over a two-year period and presented debilitating psychological distress in an attempt to determine the impact of psychiatric disorders. Of the total sample, about $7.9 \%$ had nonphobic anxiety disorders, which included PTSD, panic disorder, and generalized anxiety disorder (Tartaglini \& Safran, 1997).

Later, one of the most comprehensive studies conducted on U.S. correctional personnel was completed by Spinaris, Denhof, and Kellaway (2012). A web-based survey was advertised via a variety of venues and was completed by about 3,599 correctional personnel. The participants represented 49 states and 3 territories. The sample was mostly male (55\%), married or cohabitating (72\%), white (89\%), with an average age of 40 (Spinaris, Denhof, \& Kellaway, 2012). The most common job assignment was security/custody personnel (43.2\%) with an average of approximately 13 years of experience in corrections (Spinaris, Denhof, \& Kellaway, 2012).

The PTSD assessment tool was the Posttraumatic Stress Disorder ChecklistCivilian Version (PCL-C). The overall rate of PTSD in correctional personnel was found to be $27 \%$ (Spinaris, Denhof, \& Kellaway, 2012). The study then examined the rates by individual characteristics. Males were found to have a higher rates than females $(31 \%$ vs 22\%) (Spinaris, Denhof, \& Kellaway, 2012). Similarly, those with security job assignments had higher rates than those with other job assignments such as managerial 
staff, probation/parole personnel, and clerical staff (34\% vs 23\%) (Spinaris, Denhof, \& Kellaway, 2012). When examining the combination of gender and job assignment, rates of PTSD were higher for male security staff $(36 \%)$ as compared to female security staff $(30 \%)$.

In examining health conditions, Spinaris, Denhof, and Kellaway (2012) found that those with PTSD had higher rates of memory impairment, depression, difficulty sleeping, digestive problems, heart disease, skin conditions, and obesity. In fact, those with PTSD were more than $100 \%$ more likely to experience health conditions as compared to those without PTSD (Spinaris, Denhof, \& Kellaway, 2012). Similar to health conditions, those with PTSD reported more absenteeism per year, more alcoholic drinks per week, and more tobacco use (Spinaris et al., 2012). Unfortunately, health maintenance and coping behaviors such as exercise, social activities, and religious activities were also lower among those with PTSD (Spinaris et al., 2012).

Later, Denhof and Spinaris (2016) were commissioned to examine the prevalence of PTSD in Michigan correctional staff. The sample utilized the PTSD Checklist for DSM-5 (PCL-5) and included 991 correctional officers as well as forensic security assistants (Denhof \& Spinaris, 2016). A total of $33.7 \%$ of the sample were estimated to have PTSD with those working in high security areas having a 37\% greater risk of PTSD as compared to working in lower areas of security (39.3\% vs 28.8\%) (Denhof \& Spinaris, 2016). Table 6 below summarizes the significant studies to date. 
Table 6: Correctional Staff PTSD Studies to Date

\begin{tabular}{|c|c|c|c|c|}
\hline Source & Sample & Measurement Tool & PTSD Rate & $\begin{array}{l}\text { Correlates/ } \\
\text { Predictors }\end{array}$ \\
\hline Rosine, 1992 & $\begin{array}{l}122 \text { Ontario (CA) } \\
\text { corrections employees }\end{array}$ & $\begin{array}{l}\text { Diagnostic Interview } \\
\text { Schedule }\end{array}$ & $17 \%$ & $\mathrm{~N} / \mathrm{S}$ \\
\hline $\begin{array}{l}\text { Tartaglini \& Safrari, } \\
1997\end{array}$ & $\begin{array}{l}1029 \text { officers in a large } \\
\text { urban jail setting (U.S.- } \\
\text { Northeast) }\end{array}$ & Other $^{8}$ & $7.9 \%$ & $\mathrm{~N} / \mathrm{S}$ \\
\hline Stadnyk, 2003 & $\begin{array}{l}271 \text { Saskatchewan }(\mathrm{CA}) \\
\text { corrections employees }\end{array}$ & $\begin{array}{l}\text { Post traumatic stress } \\
\text { diagnostic scale }\end{array}$ & $25.8 \%$ & $\begin{array}{l}\text { Depression (+), Somatic } \\
\text { complaints }(+) \text {, Alcohol use } \\
(+), \text { Absence from work }(+), \\
\text { Used health care resources } \\
(+), \text { Negative perceptions of } \\
\text { workplace relationships with } \\
\text { coworkers and supervisors }(+)\end{array}$ \\
\hline $\begin{array}{l}\text { Kunst, Bogaerts, \& } \\
\text { Winkel, } 2009\end{array}$ & $\begin{array}{l}\text { 151 Dutch correctional } \\
\text { staff }\end{array}$ & $\begin{array}{l}\text { Self-Rating Inventory } \\
\text { for Post-Traumatic } \\
\text { Stress Disorder (SRIP) }\end{array}$ & $15 \%$ & Peer aggression exposure $(+)$ \\
\hline $\begin{array}{l}\text { Spinaris, Denhof, \& } \\
\text { Kellaway, } 2012\end{array}$ & $\begin{array}{l}3599 \text { Correctional staff } \\
\text { (U.S.- national) }\end{array}$ & $\begin{array}{l}\text { PTSD Checklist for } \\
\text { DSM-5 (PCL-5) }\end{array}$ & $27 \%$ & $\begin{array}{l}\text { Violence, injury, or death } \\
\text { (VID) emotions (+), More } \\
\text { types of VID (+), More VID } \\
\text { events (+), Physical assaults } \\
(+)\end{array}$ \\
\hline $\begin{array}{l}\text { Boudoukha, Altintas, } \\
\text { Rusinek, Fantini- } \\
\text { Hauwel, \& } \\
\text { Hautekeete, } 2013\end{array}$ & $\begin{array}{l}\text { 240 French correctional } \\
\text { staff }\end{array}$ & $\begin{array}{l}\text { Impact of Events Scale } \\
\text { Revised (IESR) }\end{array}$ & $\begin{array}{l}38 \% \text { (moderate) } \\
\frac{22 \% \text { (high) }}{60 \% \text { (total) }}\end{array}$ & Burnout (+) \\
\hline $\begin{array}{l}\text { Standing Committee } \\
\text { on Public Safety \& } \\
\text { National Security, } \\
2016\end{array}$ & $\begin{array}{l}\text { Canadian male } \\
\text { corrections officers }\end{array}$ & Unknown ${ }^{9}$ & $36 \%$ & $\mathrm{~N} / \mathrm{S}$ \\
\hline $\begin{array}{l}\text { Denhof \& Spinaris, } \\
2016\end{array}$ & $\begin{array}{l}991 \text { Correctional staff } \\
\text { and forensic security } \\
\text { assistants (U.S- } \\
\text { Michigan) }\end{array}$ & $\begin{array}{l}\text { PTSD Checklist for } \\
\text { DSM-5 (PCL-5) }\end{array}$ & $33.7 \%$ & $\begin{array}{l}\text { High security area }(+), \\
\text { Depression }(+), 10+\text { years in } \\
\text { corrections }(+)\end{array}$ \\
\hline
\end{tabular}

${ }^{8}$ Reviewed clinical charts of a department clinic.

${ }^{9}$ Quoted by Ms. Lori MacDonald, Assistant Deputy Minister, Emergency Management and Programs Branch, Department of Public Safety and Emergency Preparedness (Canada) in the Standing Committee on Public Safety and National Security meeting on May 3, 2016. 


\section{SUMMARY}

PTSD symptomology is an obvious concern for first responders, however, little research has been conducted as it pertains to symptomology in corrections staff. Only recently has this garnered attention from academia with a number of articles published in the last 25 years indicating a range of symptomology from 7.9\% (Tartaglini \& Safran, 1997) to $60 \%$ (Boudoukha et al., 2013). Furthermore, the majority of research focuses on international corrections, rather than the American population. However, the dearth in research should in no way diminish the seriousness of this issue. Instead, the dearth should be somewhat of a call to arms.

This dissertation seeks to answer that call, however, before beginning, it is important to ask, why should we determine symptomology and why is it important? The answer is actually a very simple one that is found in the KY DOC's mission: "To protect the citizens of the Commonwealth and to provide a safe, secure, and humane environment for staff and offenders..." (Commonwealth of Kentucky, 2017b, para. 1). PTSD creates problems for correctional workers, both personal and occupational. It can reduce their quality of life generally and, more specifically, their performance at work. Failure to perform well within the correctional setting may endanger the life and safety of both correctional officers and inmates. Therefore, the identification of the rate of PTSD symptomology among Kentucky correctional officers is important. Additionally, the identification of individual, familial and work-related factors that may increase or mitigate PTSD symptomology is important if we are to attempt to reduce PTSD symptoms among correctional workers. 
The factors that may affect the rate of PTSD symptoms among corrections staff included in the current analysis are: 1) the measure of the number of violent and traumatic events experienced in the last two years; 2) the amount of time spent working for the Department of Corrections (in months); 3) whether the staff member works a security assignment; and 4) whether they work in a maximum security facility. Additionally, demographic variables will be explored to include age, race, education, and gender.

Last, social support will be analyzed to determine if it could be effective as a means to reduce symptomology as research tells us that certain factors occurring post trauma could effectively prevent or reduce symptomology (Adams \& Boscarino, 2006; Andrews et al., 2003; Andrykowski \& Cordova, 1998; Bennett et al., 2004; Corneil et al., 1999; Declercq et al., 2007; Feinstein et al., 2002; Fontana \& Rosenheck, 1994; King et al., 1998; King et al., 1999; Kunst et al., 2009; Newman et al., 2003; Riggs, et al., 1995; Rothbaum et al., 1992; Scarpa et al., 2006; Schnurr et al., 2000; Schnurr et al., 2004; Stadnyk, 2003; Ullman \& Siegel, 1994). Social support is measured as marital status/the presence of a significant other (in lieu of a legal spouse), and perceived support from family, supervisor, and coworkers. Understanding the relationships between social support and PTSD symptomology could have tremendous implications for policy. 
The main research questions and hypotheses of this dissertation are as follows:

RQ1: What is the prevalence of PTSD symptomology among KYDOC correctional staff as measured by the trauma factor from the TSI-2?

H1: The PTSD symptomology rate in the KYDOC will be similar to that of Denhof and Spinaris (2012) which found $27 \%$.

RQ2: Are age, race, gender, or education associated with correctional staff experiencing PTSD symptoms.

H2: Due to limited research and inconsistent findings, the analysis on demographic correlates is exploratory.

RQ3: Do higher levels of exposure to violence and trauma measured by the duration of employment within the DOC, the number of violent and traumatic events, the current assignment of security, and working in a maximum security facility correlate with a higher likelihood of PTSD symptoms?

H3: A longer tenure in the KYDOC, exposure to a higher number of traumatic events, an assignment of security, and working in a maximum custody facility at time of data collection will increase the likelihood a staff member will report symptoms of PTSD.

RQ4: Do higher levels of perceived social support as measured by marriage/the presence of a significant other, or perceived support from family, supervisor, and 
coworkers significantly reduce the likelihood that corrections staff report PTSD symptoms?

H4: Staff who perceived higher social support are less likely to report symptoms of PTSD. In other words, those participants that are married or those that have a significant other, and those having better relationships with family, supervisors, and coworkers are less likely to demonstrate PTSD symptoms. 


\section{CHAPTER 4. METHODOLOGY}

Considering the information provided in the previous chapters, it is evident that PTSD symptomology in correctional staff is a significant, yet understudied occurrence. To bridge the gap in this knowledge, in collaboration with the Kentucky Department of Corrections (KY DOC), this dissertation seeks to determine the prevalence of PTSD symptomology and whether demographic characteristics and the exposure to violent and traumatic events are important correlates of PTSD symptomology. Further, this dissertation explores whether various social support factors mitigate its effects.

The data used for this dissertation come from a larger state-wide project funded by the Kentucky Department of Corrections titled, "Examining the Prevalence and Major Correlates of PTSD and Quality of Life Issues among Kentucky Department of Corrections Staff." This project began as a team effort in early 2015 with communication initiated by the present, now former, Department of Corrections Commissioner LaDonna Thompson. Commissioner Thompson recounted an article in which Oregon correctional staff had a higher rate of PTSD symptomology as compared to firefighters, deployed military, and the general public. Consequently, the Oregon Department of Corrections (ODOC) and Portland State University formed a collaboration to explore the issues surrounding this symptomology rate and discuss changes that could be implemented to 
reduce it in the correctional environment. The commissioner in turn reached out to a University of Louisville faculty member, Dr. Swartz, and the project development began.

During the summer of 2015, various research designs for assessing PTSD symptomology, with varying levels of depth, were developed and presented to the Commissioner. Levels were created ranging with the lowest level including prior PTSD diagnoses to the highest level, which included a formal PTSD symptomology instrument, coping mechanisms, workplace interventions, demographics, and facility infractions. Commissioner Thompson selected the highest level and provided suggestions for additional inclusions to the survey. Consequently, the survey not only measured PTSD symptomology but also factors that may influence that rate, including burnout, job satisfaction, positive/negative affect, and quality of life issues. This dissertation focuses on determining the prevalence of PTSD symptomology, demographic correlates that may be risk factors for PTSD, the impact of exposure to violence or trauma on PTSD symptomology, and whether social support insulates individuals from PTSD symptomology.

\section{DATA}

\section{Sample}

The analysis herein uses data from the TSI-2 administered to employees of the Kentucky Department of Corrections (KYDOC) along with self-report data regarding the respondents' demographics, correctional work history, the number of violent and traumatic events experienced while at work, and various measures of perceived social support. This is a prospective cross-sectional study that began May 2015 with the preparation of data collection and concluded in December 2016. 
The sample for this study is comprised of a subset of employees of the KYDOC. The KYDOC, as an entire organization, includes 10 departments: the commissioner's office, support services, office of adult institution, local jail facilities, corrections training, parole board, internal affairs, adult prison institutions, probation and parole, and correctional industries (Commonwealth of Kentucky, 2017a, p. 68). Only those individuals employed in adult corrections institutions who had contact with inmates were surveyed. This included employees from 12 adult facilities including the Bell County Forestry Camp, Blackburn Correctional Complex, Eastern Kentucky Correctional Complex, Green River Correctional Complex, Kentucky Correctional Institute for Women, Kentucky State Penitentiary, Kentucky State Reformatory, Little Sandy Correctional Complex, Luther Luckett Correctional Complex, Northpoint Training Center, Roederer Correctional Complex, and Western Kentucky Correctional Complex. Across the 12 facilities, Table 7 indicates 2,834 staff are employed with approximately 716 in contact with inmates. 
Table 7: KY DOC Adult Facilities

\begin{tabular}{|c|c|c|c|c|c|c|}
\hline Facility & $\begin{array}{c}\text { Security } \\
\text { Classification }\end{array}$ & $\begin{array}{l}\text { Total } \\
\text { Staff }\end{array}$ & $\begin{array}{c}\text { Total } \\
\text { Staff } \\
\text { Surveyed }\end{array}$ & $\begin{array}{l}\text { Total Staff } \\
\text { with } \\
\text { Inmate } \\
\text { Contact }\end{array}$ & $\begin{array}{c}\text { PTSD Of } \\
\text { Concern } \\
\text { Rate }\end{array}$ & $\begin{array}{c}\text { Survey } \\
\text { Response } \\
\text { Rate }\end{array}$ \\
\hline $\begin{array}{c}\text { Bell County } \\
\text { Forestry Camp }\end{array}$ & Minimum & 47 & 14 & 13 & $21.4 \%$ & $100 \%$ \\
\hline $\begin{array}{l}\text { Blackburn } \\
\text { Correctional } \\
\text { Complex }\end{array}$ & Minimum & 128 & 25 & 21 & $20.8 \%$ & $100 \%$ \\
\hline $\begin{array}{c}\text { Eastern } \\
\text { Kentucky } \\
\text { Correctional } \\
\text { Complex }\end{array}$ & Medium & 371 & 114 & 109 & $37.2 \%$ & $97 \%$ \\
\hline $\begin{array}{c}\text { Green River } \\
\text { Correctional } \\
\text { Complex }\end{array}$ & $\begin{array}{l}\text { Minimum and } \\
\text { Medium }\end{array}$ & 254 & 59 & 57 & $17.3 \%$ & $100 \%$ \\
\hline $\begin{array}{l}\text { Kentucky } \\
\text { Institute for } \\
\text { Women }\end{array}$ & $\begin{array}{l}\text { Minimum, } \\
\text { Medium, and } \\
\text { Maximum }\end{array}$ & 182 & 67 & 58 & $14.9 \%$ & $100 \%$ \\
\hline $\begin{array}{c}\text { Kentucky } \\
\text { State } \\
\text { Penitentiary }\end{array}$ & Maximum & 318 & 107 & 98 & $58.5 \%$ & $100 \%$ \\
\hline $\begin{array}{c}\text { Kentucky } \\
\text { State } \\
\text { Reformatory }\end{array}$ & Medium & 393 & 69 & 64 & $31.7 \%$ & $100 \%$ \\
\hline $\begin{array}{c}\text { Little Sandy } \\
\text { Correctional } \\
\text { Complex }\end{array}$ & $\begin{array}{l}\text { Medium, and } \\
\text { Maximum }\end{array}$ & 230 & 69 & 62 & $17.4 \%$ & $100 \%$ \\
\hline $\begin{array}{l}\text { Luther Luckett } \\
\text { Correctional } \\
\text { Complex }\end{array}$ & $\begin{array}{l}\text { Minimum and } \\
\text { Medium }\end{array}$ & 192 & 55 & 51 & $23.8 \%$ & $100 \%$ \\
\hline $\begin{array}{l}\text { Northpoint } \\
\text { Training } \\
\text { Center }\end{array}$ & Medium & 282 & 84 & 78 & $22.2 \%$ & $100 \%$ \\
\hline $\begin{array}{c}\text { Roederer } \\
\text { Correctional } \\
\text { Complex }\end{array}$ & $\begin{array}{l}\text { Medium, and } \\
\text { Maximum }\end{array}$ & 224 & 42 & 36 & $23.1 \%$ & $100 \%$ \\
\hline $\begin{array}{c}\text { Western } \\
\text { Kentucky } \\
\text { Correctional } \\
\text { Complex }\end{array}$ & Medium & 213 & 70 & 69 & $35.3 \%$ & $100 \%$ \\
\hline
\end{tabular}


As of 2015, the KY DOC had more than 4000 employees (Commonwealth of Kentucky, 2017c), however, in 2016, only 3400 employees were reported (Commonwealth of Kentucky, 2017d). The goal of the data collection was to gather responses from approximately $30 \%$ of the employees, which resulted in 800 surveys from staff representing the roles of custody, treatment, assessment, and medical. Furthermore, a representation of all shifts was also present. 775 were completed and comprise the sample for this study.

The data collection process began with the Principle Investigator (PI), Dr. Kristin Swartz, scheduling facility visits. Once scheduled, survey materials were gathered and taken to all facilities. Although staff from all facilities were surveyed, with the PI being present for $100 \%$ of surveys completed, this author was only able to visit seven of the 12 facilities. The staff were typically in a conference room or break room with space to complete the survey. Once staff were present, the PI provided an overview of the survey including the purpose, instructions on how to complete the survey, and the University of Louisville's Institutional Review Board (IRB) guidelines. During the informed consent process, certain guidelines were highlighted including that participation was optional and staff were not required to complete it, confidential and identifying information would not be shared with the DOC, and compensation from the UofL would not be given for the completion of the survey. Staff were then allowed to begin the survey with the understanding that we were available for questions at any time. Once completed, staff were directed to fold and drop the survey in a locked wooden box which would then be transported to the university by the PI. Once surveys were returned to the university, surveys were held in a locked cabinet in a locked office. Data entry was completed at the 
university, on encrypted computers belonging to the university. No identifiers were included in the database. The next section includes a detailed discussion of the variables used in the analysis of this dissertation.

\section{Measures of Variables}

Dependent Variable. While there are many PTSD scales and assessments available, the Trauma Symptom Inventory 2 (TSI-2) was utilized as the measure of PTSD symptomology. The TSI-2, created by Briere (2011) is considered a valid instrument to determine PTSD symptomology due to its internal consistency, multiple setting options, and requirement of only a $5^{\text {th }}$ grade reading level. It (in the assessment of PTSD) has been used extensively in research and clinical contexts (Elhai, Gray, Kashdan, \& Franklin, 2005), and demonstrates strong psychometric properties with alpha values ranging from .84 to .87 . Predictive validity has also been very high, as $91 \%$ of patients diagnosed with PTSD are correctly classified using the TSI (Briere, Elliott, Harris, \& Cotman, 1995; Edens, Otto, \& Dwyer, 1998). Additionally, its validity scales may determine an individual's tendency to deny symptoms, which may be an issue when examining a correctional population (Briere, 2011).

The TSI-2 consists of 136 self-report items, which allow researchers to measure symptomology related to the factors of self-disturbance, externalization, and somatization. Predictive validity has also been very high, as $91 \%$ of patients diagnosed with PTSD are correctly classified using the TSI (Briere, Elliott, Harris, \& Cotman, 1995; Edens, Otto, \& Dwyer, 1998). Additionally, its validity scales may determine an individual's tendency to deny symptoms, which may be an issue when examining a correctional population (Briere, 2011). 
Here the focus is on the TRAUMA factor and use it as a proxy for the dependent variable. Individuals with elevated TRAUMA scores suggest a significant likelihood that the individual will meet the criteria for PTSD (Briere, 2011). More about the scales and subscales are below. The TRAUMA factor, for PTSD as I refer to hereafter, is comprised of four scales: anxious arousal (AA), intrusive experiences (IE), defensive avoidance (DA), and dissociation (DIS), as well as the subscales of anxious arousal-anxiety and anxious arousal-hyperarousal (Briere, 2011). See Figure 3 for more about the scale and subscales.

\section{Figure 3: TSI-2 and Factors}

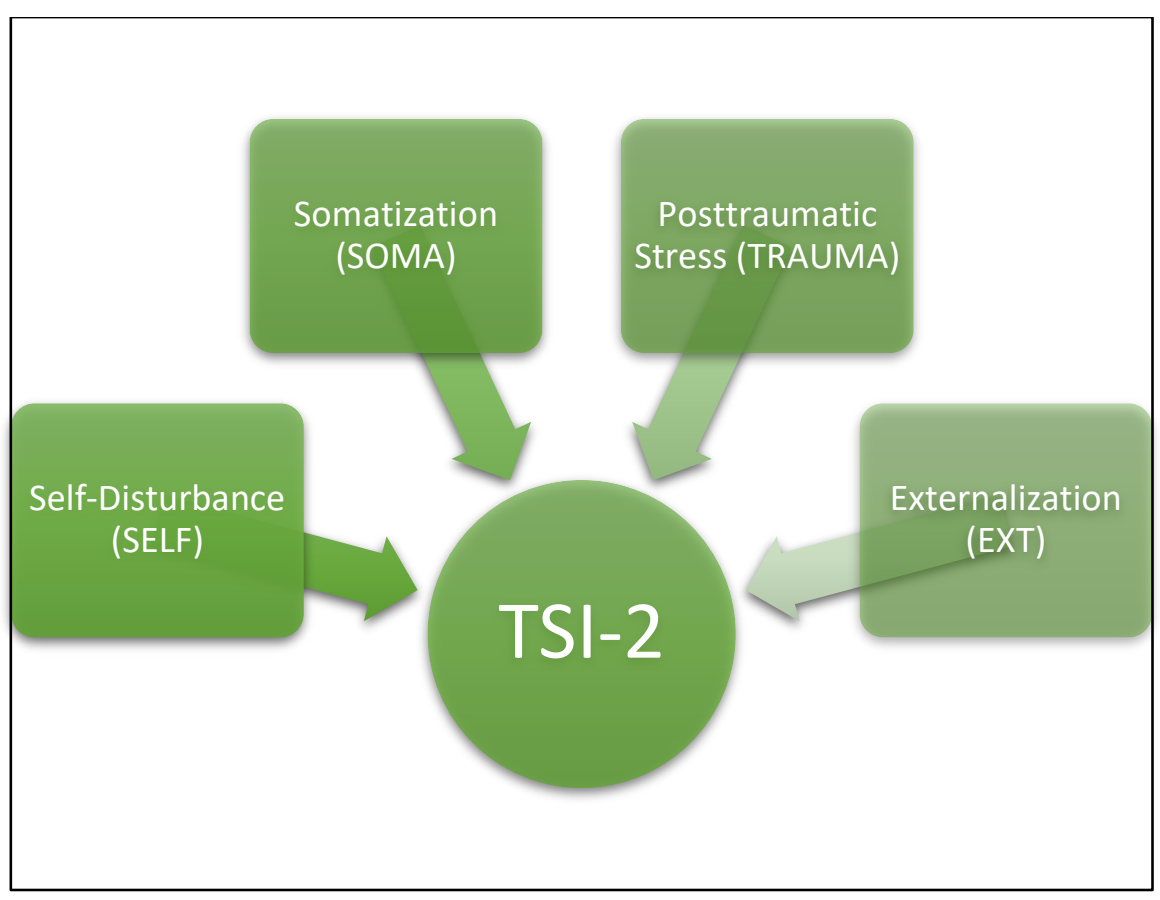

The first scale of anxious arousal (AA) reflects the individual's experience of anxiety to include hyper alertness, panic, phobias, fears, tension, and jumpiness (Briere, 2011). High rates of anxiety have been linked to those who have been abused, assaulted, or exposed to disasters (Briere, 2011). Unlike the original TSI, the TSI-2 included two subscales of anxious arousal, anxious arousal-anxiety (AA-A) and anxious arousal- 
hyperarousal (AA-H) (Briere, 2011). AA-A evaluates indices of anxiety to include worrying, nervousness, fears of death or injury, and irrational fears (Briere, 2011). AA-H includes symptoms which are associated with the nervous system such as hypervigilance, jumpiness, sleep disturbances, and irritability (Briere, 2011). AA-H directly relates to group D in the DSM-V which is negative changes in thoughts and mood associated with the incident (American Psychiatric Association, 2013). A high score on this subscale (AA-H) indicates an individual may utilize avoidance strategies to include substances such as drugs and alcohol (Briere, 2011).

The defensive avoidance (DA) scale includes avoidances in an attempt to manage posttraumatic distress (Briere, 2011). These actions could include an attempt to repress memories or painful thoughts and an attempt to avoid events, which may trigger the memory of a traumatic event (Briere, 2011). Furthermore, elevated DA scores could result in the decreased willingness to discuss or process traumatic events in therapy (Briere, 2011).

The dissociation (DIS) scale is an unconscious change in awareness which is developed as an avoidance. It "measures the extent to which the respondent experiences dissociative symptomology" (Briere, 2011, p. 16).

To calculate the dependent variable, the TSI-2 Professional Manual directed the researcher to utilize the scoring sheet to sum specific items. After summing, the scorer was to use the raw scores calculation tables to determine subscale scores, scale scores, and factor scores. Next, using the appendix in the manual, the raw scores are converted to t-scores based upon the individual's demographics. The demographics may change an individual's t-score. For example, a male aged 18-54 years scoring a 40 on the trauma 
scale has a t-score of 54, while a female aged 18-54 years scoring a 40 on the trauma scale has a t-score of 52 (Briere, 2011). See Figure 4 for more information about the TRAUMA factor, scales, and subscales.

\section{Figure 4: TRAUMA Factor Scales and Subscales}

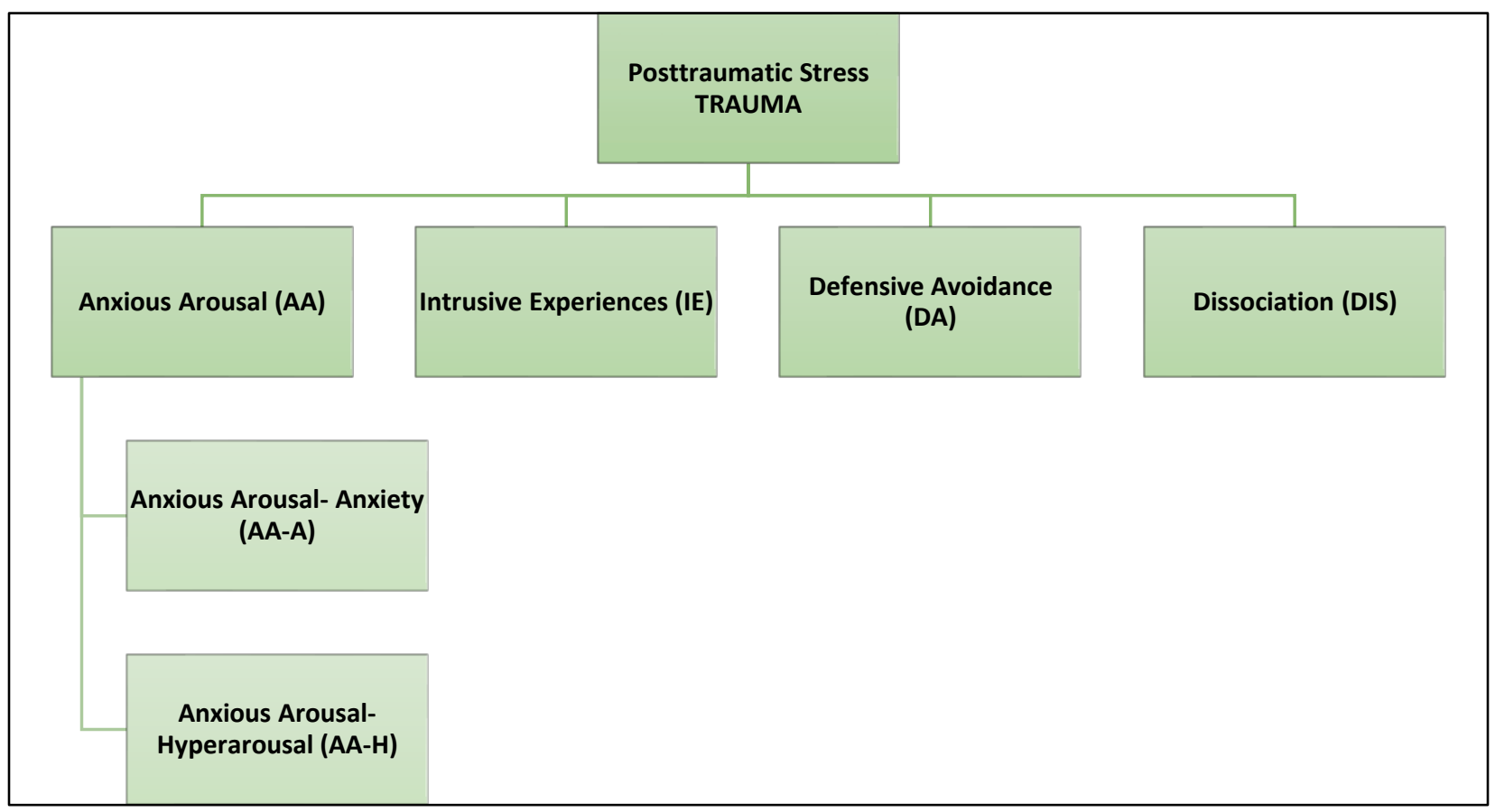

Once determined, the raw TRAUMA factor scores (t-scores) were analyzed by recoding them (ranging from 36 to 88) into categories as defined by Briere (2011) as normal, problematic, or clinically elevated. T-scores ranging from 33 to 59 were recoded as normal (0), scores ranging from 60-64 were recoded as problematic (1), and scores ranging from 65 to 88 were recoded as clinically elevated (2) (Briere, 2011, p. 13).

To further clarify, PTSD symptomology, the symptomology range was revised further so that an individual was either in the normal range or of PTSD concern. Hence, those with t-scores in the normal range (33-59) were recoded to 0 , and those in the problematic and clinically elevated range (60 to 88) were recoded as 1 and will be called "of PTSD concern." About 30\% of the scores were of PTSD concern while those, which 
were normal, equaled $70 \%$. The average was .30 . The standard deviation was .46 . See

Table 8 for more details about the symptomology ranges.

\section{Table 8: TRAUMA Symptomology Range}

\begin{tabular}{|l|l|l|}
\hline TRAUMA Score & Symptomology Range & \multicolumn{1}{c|}{ Interpretation } \\
\hline $\mathrm{T}=\leq 59$ & Normal & Normal range. \\
\hline $\mathrm{T}=60-64$ & Problematic & Likely to have clinical implications. \\
\hline $\mathrm{T}=\geq 65$ & Clinically Elevated & $\begin{array}{l}\text { Sufficient extremity representing a significant } \\
\text { concern. }\end{array}$ \\
\hline
\end{tabular}


Table 9: Descriptive Statistics, Variables, and Scales

\begin{tabular}{|c|c|c|c|c|c|}
\hline Variables & Scale & Mean & S.D. & Range & $\mathbf{N}$ \\
\hline \multicolumn{6}{|l|}{ Dependent Variable } \\
\hline Trauma Score & $\begin{array}{l}(0=\text { Normal, } \\
1=\text { Of PTSD } \\
\text { Concern })\end{array}$ & 0.30 & 00.46 & $0-1$ & 756 \\
\hline \multicolumn{6}{|l|}{ Demographic Variables } \\
\hline Age & $\begin{array}{l}\text { (Age in } \\
\text { years) }\end{array}$ & 39.5 & 11.4 & $21-73$ & 772 \\
\hline Race & $\begin{array}{l}(0=\text { Nonwhite }, \\
1=\text { White })\end{array}$ & $90 \%$ & $30 \%$ & $0-1$ & 773 \\
\hline Gender & $\begin{array}{l}(0=\text { Female } \\
1=\text { Male })\end{array}$ & $60 \%$ & $50 \%$ & $0-1$ & 775 \\
\hline Education & $\begin{array}{l}(1=0.39 \% \\
2=33.81 \% \\
3=30.06 \% \\
4=26.45 \% \\
5=2.58 \% \\
6=6.71 \%)\end{array}$ & & & $1-6$ & 775 \\
\hline \multicolumn{6}{|c|}{ Exposure to Violence and Trauma Independent Variables } \\
\hline Traumatic Events & $\begin{array}{l}\text { (Number of } \\
\text { traumatic } \\
\text { events) }\end{array}$ & 15.9 & 48.1 & $0-733$ & 741 \\
\hline Duration in $\mathrm{DOC}^{10}$ & $\begin{array}{l}\text { (Months in } \\
\text { KY DOC) }\end{array}$ & 90.4 & 79.9 & $0-432$ & 775 \\
\hline Custodial Staff & $\begin{array}{l}(0=\text { No, } \\
1=\text { Yes })\end{array}$ & 00.66 & 00.47 & $0-1$ & 694 \\
\hline Facility Security Level & $\begin{array}{l}(0=\text { Max } \\
1=\text { Not } \\
\text { Max })\end{array}$ & 0.14 & 0.35 & $0-1$ & 775 \\
\hline \multicolumn{6}{|c|}{ Social Support Independent Variables } \\
\hline $\begin{array}{l}\text { Marriage/Presence } \\
\text { of Sig. Other }\end{array}$ & $\begin{array}{l}(0=\text { Single, } \\
1=\text { Married/Sig. } \\
\text { Other })\end{array}$ & 0.83 & 0.37 & $0-1$ & 728 \\
\hline
\end{tabular}




\begin{tabular}{|c|c|c|c|c|c|}
\hline Variables & Scale & Mean & S.D. & Range & $\mathbf{N}$ \\
\hline \multicolumn{6}{|c|}{ Independent Variables } \\
\hline Family Support & $\begin{array}{l}\text { (Summed } \\
\text { Score, 1= } \\
\text { Strongly } \\
\text { Disagree to } \\
\text { 4= Strongly } \\
\text { Agree) }\end{array}$ & 16.69 & 4.35 & $6-24$ & 765 \\
\hline Supervisor Support & $\begin{array}{l}\text { (Summed } \\
\text { score, } \\
1=\text { Strongly } \\
\text { Disagree to } \\
4=\text { Strongly } \\
\text { Agree) }\end{array}$ & 21.83 & 4.60 & $8-32$ & 726 \\
\hline Coworker Support & $\begin{array}{l}\text { (Summed } \\
\text { Score, 1= } \\
\text { Strongly } \\
\text { Disagree to } \\
\text { 4= Strongly } \\
\text { Agree) }\end{array}$ & 20.75 & 4.22 & $8-32$ & 739 \\
\hline
\end{tabular}




\section{Independent Variables: Demographic Characteristics}

Several demographic variables that have previously been researched in conjunction with PTSD were included in the models. These included age, race, education, and gender. The age of the respondent was left open-ended. Respondents indicated a

range from 21 to 73 years. The average age was 39.5. The standard deviation was 11.4. For more about these, see Table 9.

The respondent's race was measured as a dichotomous measure of white (0) and nonwhite (1). Although ethnicity is usually divided into more categories, the survey utilized only two categories for race as this follows how the KY DOC has recorded their staff member's ethnicities. The sample was $92 \%$ white. This is representative of the KY DOC's staff population of which $92 \%$ are white and only $8 \%$ are minorities (K. Swartz, personal communication, June 25, 2017).

An indicator for respondent's gender was included and included options of three response choices (male, female, and transgender). Since none of the staff responded as being transgendered, this was recoded into a dichotomous variable $(0=$ male; $1=$ female). The sample was $63.9 \%$ male. This is representative of the KY DOC's staff population of which $64 \%$ are male and only $36 \%$ are female (K. Swartz, personal communication, June 25, 2017).

Education was measured using the average of 6 responses ranging from some high school to graduate degree $(1=$ some high school, $2=$ high school degree/GED, $3=$ some college, $4=$ college degree, $5=$ some graduate work, $6=$ graduate degree). The largest proportion of respondents indicated a high school degree (33.8\%), while 30\% had 
some college, $26.5 \%$ had a college degree, $6.7 \%$ had a graduate degree, and $2.6 \%$ had some graduate school.

\section{Independent Variables: Violent and Traumatic Exposure}

The first cluster of key independent variables includes a variety of self-report measures that capture the respondents' exposure to violence and trauma (EVT). EVT is operationalized as three items: 1) the measure of the number of violent and traumatic events experienced in the last two years; 2) the amount of time spent working for the Department of Corrections (in months); 3) the assignment of security; and 4) the security level of the facility (maximum security).

The number of violent and traumatic events is a summed measure of 17 different types of violent or traumatic events that the staff had been involved in the past 2 years. These included whether the staff member had experienced the event as a result of the actions by a staff member, experienced the event due to actions by an inmate, or witnessed the event in which the action was taken by an inmate or other staff member. Some of the items included were hostage taking, physical and sexual assault, slashing, spitting, and stabbing. Staff reported experiencing from 0 events (perhaps those who are

new the KY DOC) to 733 events. The average was 15.9 events and the standard deviation was 48.1 See Table 10 for the sum of each type of event for the sample. 
Table 10: Violent and Traumatic Occurrences in the Past 2 Years

\begin{tabular}{|l|c|c|}
\hline \multicolumn{1}{|c|}{ Violent and Traumatic Event } & $\begin{array}{c}\text { Number of Occurrences for } \\
\text { Entire Sample }\end{array}$ & Mean for Sample \\
\hline Physical Assault & 3123 & 0.53 \\
\hline Excessive Force & 2604 & 3.60 \\
\hline Suicide Attempt & 1168 & 1.60 \\
\hline Slashing & 785 & 0.90 \\
\hline Sexual Assault & 661 & 0.20 \\
\hline Life Threatening Letter & 146 & 0.18 \\
\hline Potential to Shoot Another & 132 & 0.16 \\
\hline Completed Suicide & 118 & 0.16 \\
\hline Other & 99 & 0.09 \\
\hline Murder & 63 & 0.06 \\
\hline Life Threatening Phone Call & 43 & 0.05 \\
\hline Riot & 11 & \\
\hline Hostage Taking & & \\
\hline
\end{tabular}

The amount of time spent working for the Department of Corrections (in months) was compiled from two parts of the survey. First, the staff were asked how many years and months they had worked in the KY DOC. The amount of time spent working in corrections ranged from zero months (new employee) to 430 months (almost 36 years). The average amount of time spent in the KY DOC was 90.4 months, or about 7.5 years. The standard deviation was 79.9.

The staff's current assignment of security was recoded. This variable was taken from the question inquiring about the staff's current assignment with the choices of $1=$ 
CERT, 2= Clerical Staff, 3=Education, 4=Hostage Negotiation Team, 5=Medical, 6=Psychological, 7=Security/Custody Personnel, 8=Social Worker, 9=

Treatment/Programming Personnel, and 10=Other. Those with security assignments $(1,4$, and 7) were recoded as a 1 . Those without security assignments were recoded into $0(2,3$, $5,6,8,9$, and 10$)$. About $60 \%$ of staff were working in security assignments $(\mathrm{M}=.60$; $\mathrm{SD}=.49)$

Last, the facility's security level was dichotomized. Those with a minimum or medium classification were recoded as a 1 . Those with a maximum security classification were recoded as a 0 . Some facilities have multiple classifications, such as Roederer, etc. Those facilities were recoded to 1 as their staff did not always work in the maximum security facility. $14 \%$ of staff reported working in a maximum security facility $(\mathrm{M}=.14$; $\mathrm{SD}=.35)$

\section{Independent Variables: Social Support}

The second cluster of key independent variables in this dissertation serve as measures of social support including marital status/the presence of a significant other, and three perceived social support scales including social support from family, supervisor, and coworkers.

Marital status/the presence of a significant other was measured taking the response from the following categories $(1=$ single, $2=$ married, $3=$ widower, $4=$ divorced, $5=$ separated) and recoded into a dichotomous variable with 1 representing married and those that are single, widowed, divorced, and separated recoded to 0. Next, the presence of a significant other was analyzed with the respondents answering, "If not married, do you have a significant other?" The answer choices were yes, no, and not 
applicable. These choices were then recoded into a dichotomous variable with 0 being "no" and 1 being "yes." The third choice of not applicable was removed from the recode. These two dichotomous variables were then combined and recoded with those who were married or had a significant other were coded as a "1" and those that were not married and did not have a significant other were coded as a " 0. ." The number of participants who were married or had a significant other was about $83 \%$.

Perceived support from family, supervisors, and coworkers focused on emotional support (support which helps an individual feel loved and cared for) and social companionship (availability of individuals). Family support was measured by providing respondents a total of six statements and asking their level of agreement. Three of these statements were positively keyed and respondents were asked to select from a scale of 1=Strongly Disagree to 4=Strongly Agree. These included: 1) "I have people in my family that I can talk to about the problems I have at work;" 2) "When my job gets me down, I always know that I can turn to my family and get the support I need to feel better;" and 3) "It's a good thing that I have my spouse (or girlfriend/boyfriend) around when things aren't going well at work." The remaining three statements were negatively keyed with the scale of $1=$ Strongly Agree to $4=$ Strongly Disagree. These were statements such as: 4) "No one in my family can really understand how tough my job can be;" 5) "There is really no one in my family that I can talk to about my job;" and 6) "My spouse (or girlfriend/boyfriend) can't really help me much when my job gets me tense.” These three variables were then reversed coded so that they followed the scale of $1=$ Strongly Disagree to 4=Strongly Agree. Finally, the first three variables and the newly recoded 
variables were summed, with higher values associated with more support. The average was 16.69. The standard deviation was 4.35. The Cronbach's alpha was .81 .

Supervisor support was gauged based on the summed responses to five positively keyed statements and four negatively keyed statement. The positively keyed statements include: 1) "My supervisors often encourage the people I work with to think of better ways of getting the work done which may never have been thought of before;" 2) "My supervisors often encourage us to do the job in a way that we really would be proud of;" 3) "When my supervisors have a dispute with somebody on the force, they usually try to handle it in a friendly manner;" 4) "My supervisors often encourage the people I work with if they do their job well;" and 5) "I like my supervisor." The scale ranged from 1= Strongly Disagree to $4=$ Strongly Agree. Four negatively keyed statements were included as well such as: 6) "My supervisor is unfair to me;" 7) "My supervisor shows too little interest in the feelings of subordinates;" 8) "The people I work with often have the importance of their job stressed to them by their supervisors;" and 9) "My supervisors often blame others when things go wrong, which are possibly not the fault of those blamed." These four variables were then reversed coded so that they followed the scale of 1=Strongly Disagree to 4=Strongly Agree. All variables were then summed resulting in an average of 21.83. The standard deviation was 4.59. The Cronbach's alpha was .81 .

For social support from coworkers, six positively keyed statements were included which were: 1) "My coworkers often compliment someone who has done his/her job well;" 2) "My coworkers often encourage each other to do the job in a way that we would really be proud of;" 3) "My coworkers often encourage each other to think of better ways of getting the work done which may never have been thought of before;" 4) "My 
coworkers are loyal to me;" 5) "I have good relationships with my co-workers;" and 6) "I like the people I work with.” The respondents replied using a scale in which $1=$ Strongly Disagree to 4= Strongly Agree. Negatively keyed statements were included as well such as: 7) "There is too much fighting among staff at work;" and 8) "My coworkers often blame each other when things go wrong." The responses were then recoded into a summed variable. The average was 21.75 . The standard deviation was 4.22 . The Cronbach's alpha was .82. A higher score indicates higher levels of perceived social support.

\section{Analytic Strategy}

To address the first research question regarding prevalence of PTSD symptomology, the raw TRAUMA factor scores (t-scores from 36-88) will be recoded into categories as defined by Briere (2011) as normal (33-59), problematic (60-64), or clinically elevated (65-88). These scores will then be further divided into two categories with those scoring in the normal range (33-59) recoded to 0 , and those in the problematic and clinically elevated range (60 to 88 ) recoded to 1 . Those recoded to 1 will be termed "of PTSD concern." Since this results in a dichotomized dependent variable, logistic regression will be utilized for determine the results for models 1 through 3 .

Prior to presenting the results from the logistic regression models, the prevalence rates of PTSD symptomology are provided. The first model examines whether age, race, gender, or education are important correlates of PTSD symptomology. The second model, while controlling for the demographics, examines the relationships between exposure to violence and trauma and PTSD symptomology. The third model includes the demographic variables, the exposure to violence and trauma variables, and the social 
support variables to examine whether those staff who perceive higher levels of social support are less likely to demonstrate PTSD symptoms. 


\section{CHAPTER 5. ANALYSES AND RESULTS}

This chapter presents and discusses the analyses and results of this dissertation. First, the frequency is provided to report the percentage of those staff who are of PTSD concern. Second, the bivariate correlations among all variables are provided and discussed. Next, 3 logistic regression models are presented. The first model which examines the dependent variable against the demographic variables (age, race, gender, or education). The second model subsequently follows with the addition of the exposure to violence and trauma variables. Last, the third model includes the demographic variables, the exposure to violence and trauma variables, and the social support variables to examine their relationships with symptomology. In this section, each of the research questions is addressed.

\section{PREVALENCE OF PTSD SYMPTOMOLOGY}

To calculate symptomology, the TSI-2 scoring sheet was used to sum specific items leading to a conversion from a raw score to a t-score. These $\mathrm{t}$-scores were then recoded into categories as defined by Briere (2011) as normal (33-59), problematic (60$64)$, or clinically elevated (65-88). Of the 756 scores, $69.8 \%$ were normal, $9.8 \%$ were problematic, and $20.4 \%$ were clinically elevated. To further clarify, these ranges were recoded and divided into two categories; normal range (33-59) and those in the 
problematic and clinically elevated range (60 to 88$)$. Those in the problematic and clinically elevated range are considered "of PTSD concern." About $30.2 \%$ of the scores were of PTSD concern while those, which were normal, equaled $69.8 \%$.

\section{Table 11: Prevalence Rates Of PTSD Concern}

\begin{tabular}{|c|c|c|}
\hline PTSD Score & Recode (\#1) & Recode (\#2) \\
\hline $33-59$ & Normal (69.8\%) & Normal (69.8\%) \\
\hline $60-64$ & Problematic (9.8\%) & \multirow{2}{*}{ Of PTSD Concern (30.2\%) } \\
\hline $65-88$ & Clinically Elevated (20.4\%) & \\
\hline
\end{tabular}

\section{BIVARIATE ANALYSIS}

Table 11 provides the bivariate correlations among all variables. As previous research indicates, the demographic variables of age, race, gender, and education are not correlated with PTSD symptomology. However, in examining the exposure to trauma variables, the assignment of security (0.12) and the faculty custody level $(0.25)$ were positively correlated with PTSD symptomology at the probability level of $p<0.01$. This correlation is in the expected direction with previous research indicating as these increase, so too does symptomology. Several of the social support variables were also statistically significantly associated with PTSD symptomology. The variables of family social support (-0.27), supervisor social support (-0.17), and coworker social support $\quad$ (0.22 ) were all negative and statistically significant, indicating that as social support increases, experiencing PTSD symptomology is less likely. See Table 12 below with the bivariate correlations. 
Table 12: Bivariate Correlations

\begin{tabular}{|c|c|c|c|c|c|c|c|c|c|c|c|c|c|}
\hline & 1 & 2 & 3 & 4 & 5 & 6 & 7 & 8 & 9 & 10 & 11 & 12 & 13 \\
\hline $\begin{array}{l}\text { 1. Of PTSD } \\
\text { Concern }\end{array}$ & 1.00 & & & & & & & & & & & & \\
\hline 2. Age & -0.05 & 1.00 & & & & & & & & & & & \\
\hline 3. Ethnicity & -0.04 & -0.05 & 1.00 & & & & & & & & & & \\
\hline 4. Gender & 0.05 & $-0.09^{* *}$ & -0.03 & 1.00 & & & & & & & & & \\
\hline 5. Education & -0.03 & 0.02 & $0.09^{* *}$ & $-0.23^{* *}$ & 1.00 & & & & & & & & \\
\hline $\begin{array}{l}\text { 6. Sum of traumatic } \\
\text { events }\end{array}$ & 0.06 & -0.02 & -0.02 & -0.03 & -0.04 & 1.00 & & & & & & & \\
\hline $\begin{array}{l}\text { 7. Duration in } \\
\text { KYDOC }\end{array}$ & 0.04 & $0.56^{* *}$ & -0.06 & -0.05 & -0.05 & 0.04 & 1.00 & & & & & & \\
\hline $\begin{array}{l}\text { 8. Assignment of } \\
\text { security }\end{array}$ & $0.12^{* *}$ & $-0.24^{* *}$ & -0.01 & $0.36^{* *}$ & $-0.42^{* *}$ & 0.01 & $-0.27^{* *}$ & 1.00 & & & & & \\
\hline $\begin{array}{l}\text { 9. Maximum } \\
\text { custody facility }\end{array}$ & $0.25^{* *}$ & -0.01 & -0.03 & 0.04 & 0.02 & -0.01 & 0.04 & -0.02 & 1.00 & & & & \\
\hline $\begin{array}{l}10 . \\
\text { Married/Presence } \\
\text { of SO }\end{array}$ & 0.00 & -0.06 & -0.03 & $0.10^{*}$ & -0.06 & 0.04 & 0.00 & -0.02 & 0.00 & 1.00 & & & \\
\hline $\begin{array}{l}\text { 11. Family social } \\
\text { support }\end{array}$ & $-0.27^{* *}$ & -0.01 & 0.04 & $-0.12^{* *}$ & $0.10^{* *}$ & -0.01 & -0.05 & $-0.16^{* *}$ & -0.05 & $0.09^{*}$ & 1.00 & & \\
\hline $\begin{array}{l}\text { 12. Supervisor } \\
\text { social support }\end{array}$ & $-0.17^{* *}$ & 0.03 & 0.01 & -0.06 & $0.09^{*}$ & -0.04 & -0.04 & $-0.14^{* *}$ & 0.00 & -0.05 & $0.21^{* *}$ & 1.00 & \\
\hline $\begin{array}{l}\text { 13. Coworker social } \\
\text { support }\end{array}$ & $-0.22^{* *}$ & 0.04 & -0.04 & -0.02 & $0.07^{*}$ & -0.05 & -0.04 & $-0.10^{* *}$ & -0.05 & -0.01 & $0.24^{* *}$ & $0.66^{* *}$ & 1.00 \\
\hline
\end{tabular}




\section{MULTIVARIATE ANALYSES}

This next section presents the multivariate analyses utilizing logistic regression. Logistic regression is based on loglinear procedures and is designed for use with dichotomous dependent variables when the independent variables are a mixture of continuous and categorical.

The analyses begin with the first model (demographics: age, race, gender, and education), moves to the second model (exposure to trauma: sum of violent and traumatic events experienced, duration in DOC, security assignment, and prison custody level), and concludes with the third model (social support: marital status/presence of a significant other, family support, supervisor support, and coworker support).

\section{First Model: Demographics}

The first model included the demographic variables to include age, race, education, and gender. This analysis shows that none of these demographics were statistically significantly associated with PTSD symptomology.

\section{Second Model: Exposure to Violence and Trauma}

The second model, in which the exposure to violence and trauma variables were added, resulted in little change for the demographic variables, as they remained insignificant. However, three of the four exposure to trauma and violence variables (the duration of employment in the KY DOC, the assignment of security, and working in a maximum custody facility) were significantly and positively correlated with PTSD symptomology at the probability level of $\mathrm{p}<0.05$. Further, those who worked security were 2.8 times more likely to be of PTSD concern and those who worked in a maximum security facility were 4.6 times more likely to be of PTSD concern than those not 
working in a maximum security facility. See Table 13 with the results from the regression.

\section{Third Model: Social Support}

The third model includes the social support variables (marital status/presence of a significant other, as well as support from family, supervisor, and coworkers). Similar to previous models, age, race, and education variables remained non-significant. However, gender becomes significant and negative at the 0.05 level $(-0.55)$ meaning that females have a higher likelihood of symptomology.

Regarding the exposure to violence variables, the assignment of security (1.05) and work in a maximum custody facility (1.90) were positive and significant. The most robust effect of symptomology was produced by those who worked in a maximum security facility, with those staff being 6 times more likely to be of PTSD concern.

In examining the social support variables, marital status/presence of a significant other was not significant; however, family social support (-0.12) and coworker social support (-0.08) were significant and negative. Hence, as family and coworker social support increases, PTSD symptomology decreases.

It is important to note that with this model, the $\mathrm{R}^{2}$ is $20 \%$. In previous models, only $1 \%($ model 1$)$ and $10 \%($ model 2$)$ of variance were explained. Hence, this last model is the best fit for the data as it explains the most variance. 


\section{Table 13: Regression Models}

\begin{tabular}{|c|c|c|c|c|c|c|c|c|c|}
\hline & Coefficient & S.E. & $\operatorname{Exp}(B)$ & Coefficient & S.E. & $\operatorname{Exp}(B)$ & Coefficient & S.E. & $\operatorname{Exp}(B)$ \\
\hline Age & -0.01 & 0.01 & 0.99 & -0.02 & 0.01 & 0.98 & -0.01 & 0.01 & 0.99 \\
\hline Race & -0.36 & 0.33 & 0.70 & -0.41 & 0.36 & 0.66 & -0.38 & 0.41 & 0.69 \\
\hline Education & -0.03 & 0.07 & 0.97 & 0.11 & 0.09 & 1.12 & 0.15 & 0.10 & 1.16 \\
\hline Gender & 0.16 & 0.17 & 1.17 & -0.12 & 0.19 & 0.88 & $-0.55^{*}$ & 0.23 & 0.58 \\
\hline $\begin{array}{l}\text { Sum of } \\
\text { violent/traumatic } \\
\text { events } \\
\text { Duration of } \\
\text { employment with }\end{array}$ & & & & 0.00 & 0.00 & 1.00 & 0.00 & 0.00 & 1.00 \\
\hline $\begin{array}{l}\text { KYDOC } \\
\text { Assignment of }\end{array}$ & & & & $0.01 * *$ & 0.00 & 1.00 & 0.00 & 0.00 & 1.00 \\
\hline $\begin{array}{l}\text { Security } \\
\text { Maximum custody }\end{array}$ & & & & $0.00 * *$ & 0.23 & 2.78 & $1.05^{* *}$ & 0.27 & 2.85 \\
\hline $\begin{array}{l}\text { facility } \\
\text { Marital }\end{array}$ & & & & $0.00 * *$ & 0.23 & 4.62 & $1.90 * *$ & 0.26 & 6.66 \\
\hline $\begin{array}{l}\text { status/Presence of SO } \\
\text { Family Social }\end{array}$ & & & & & & & 0.07 & 0.27 & 1.07 \\
\hline $\begin{array}{l}\text { Support } \\
\text { Supervisor Social }\end{array}$ & & & & & & & $-0.23^{* *}$ & 0.02 & 0.89 \\
\hline $\begin{array}{l}\text { Support } \\
\text { Coworkers Social }\end{array}$ & & & & & & & -0.01 & 0.02 & 0.99 \\
\hline Support & & & & & & & $-0.08 * *$ & 0.03 & 0.92 \\
\hline $\begin{array}{l}* * \mathrm{p}=<.01 \\
* \mathrm{p}=<.05\end{array}$ & $\mathrm{R}^{2} .01$ & $\mathrm{~N}=752$ & & $\mathrm{R}^{2} .10$ & $\mathrm{~N}=719$ & & $\mathrm{R}^{2} .20$ & $\mathrm{~N}=628$ & \\
\hline
\end{tabular}




\section{SUMMARY}

This chapter provided the bivariate relationships between the variables as well as a discussion of the multivariate analyses. In the first model, the analysis indicated that none of the demographic variables were significant. The second model indicated three of the four exposure to violence and trauma variables affected symptomology (duration in the KY DOC, assignment of security, and employment in a maximum custody facility). In the third model, gender became significant, two of the exposure to violence and trauma variables remained significant (assignment of security and employment in a maximum custody facility), and family and coworker social support affected symptomology. Table 14 presents an overview of the findings.

Consequently, this analysis provides mixed results for the research hypotheses. A more detailed discussion of the results is provided in the subsequent chapter.

Table 14: Overview of the Findings

\begin{tabular}{|c|c|c|c|}
\hline Of PTSD Concern & Model 1 & Model 2 & Model 3 \\
\hline Age & NS & NS & NS \\
\hline Ethnicity & NS & NS & NS \\
\hline Education & NS & NS & NS \\
\hline Gender & NS & NS & - \\
\hline Sum of VTEs & & NS & NS \\
\hline Duration in KYDOC & & + & NS \\
\hline Security assignment & & + & + \\
\hline Maximum custody facility & & + & + \\
\hline Marital status/Presence of significant other & & & NS \\
\hline Family social support & & & - \\
\hline Supervisor social support & & & NS \\
\hline Coworker social support & & & - \\
\hline
\end{tabular}




\section{CHAPTER 6: DISCUSSION AND CONCLUSION}

This final chapter provides a summary of the findings from the analysis. It also includes a discussion about whether the analysis supports the research hypotheses. Furthermore, implications for policy and practice are presented as well as limitations and directions for future research.

\section{SUMMARY OF FINDINGS}

Table 16 provides a summary of the findings in relation to the hypotheses of this dissertation with the focus on the relationship between variables in all models. First, the rate of PTSD concern was $30.2 \%$. In the first model, none of the demographics were significant when examined against those with symptomology. In the second model, none of the demographics were significant, however, three of the exposure to trauma and violence variables were significant and positive (duration in KY DOC, assignment of security, and employment in a maximum security facility). In the final model, which contained all variables, age, race, and education, were not significant. However, gender became significant and negative, indicating that female correctional staff were more likely to be of PTSD concern. In reviewing the exposure to violence and trauma variables in this model, the assignment of security and employment in a maximum security facility were significant and positive. Last, this model indicated that family social support and 
coworker social support were significant and negative, indicating that those correctional staff with higher levels of family and coworker social support were less likely to be of PTSD concern. See Table 16 for how the findings of this dissertation compare to the hypotheses.

\section{Hypothesis I: PTSD Symptomology}

It was hypothesized that the prevalence rate of PTSD symptomology would be similar to the $27 \%$ as found by Spinaris et al. (2012) in their national study. The results of this research are consistent with that figure as $30 \%$ of the staff employed in the Kentucky Department of Corrections reported PTSD of concern. Hence, about $30 \%$ of individuals scored in either the problematic or clinically elevated range of the TSI-2. This percentage is similar to other studies such as Boudouka et al. (2013) (38\% moderate) and Denhof and Spinaris (2016) (33.7\%). Hypothesis I was supported.

\section{Hypothesis II: Model 1 (Demographic Variables)}

This model concentrated on demographic variables (age, race, education, and gender) to determine whether they were associated with PTSD symptomology. Since previous research has resulted in inconsistent findings, this model was exploratory rather than hypothesizing a certain relationship. The results of the analysis presented in this dissertation are that demographic characteristics are not associated with PTSD symptomology. This follows previous studies with a few exceptions. First, studies of other first responder populations have found that as age increases, so too does symptomology (Darrensburg et al., 2006; Jonsson et al., 2003). Second, Bowler et al. (2016) and Pole et al. (2001) found a relationship as it relates to ethnicity with Hispanics 
having an increased likelihood of symptoms. Third, Stephens and Miller (2008) found that education was a predictor of symptomology among officers with those having less of an education having a higher rate of symptomology. Finally, gender has been reported in some studies to predict a higher rate of symptomology among male ambulance personnel (Bennett et al., 2004; Burger et al., 2007).

\section{Hypothesis III: Model 2 (Exposure to Violence and Trauma)}

The second model included the demographic variables (age, race, education, and gender) and added in the exposure to violence and trauma variables (the sum of violent and traumatic events, duration of work in the KY DOC, the assignment of security, and working in a maximum custody facility). Similar to the first model, none of the demographic variables were significant. However, three of the exposure to violence and trauma variables were significant and positive (duration of employment in KY DOC, assignment of security, and work in a maximum custody facility), indicating that as exposure to trauma and violence increases, so does PTSD symptomology. This is consistent with previous studies (Corneil et al., 1999; Denhof \& Spinaris, 2016; Jonsson et al., 2003; Spinaris et al., 2012; Wagner et al., 1998).

Although the sum of violent and traumatic event was not significant in these model, many studies of first responder populations have found this to be significant. Spinaris et al. (2012) reported that corrections personnel who experienced more types of violence, injury, or death (VID), more VID events, and more physical assaults had a higher rate of symptomology. Similar results in which the number of traumatic events experienced increases symptomology have been reported by studies focusing on Australian volunteer firefighters (Bryant \& Harvey, 1996), New Zealand police (Stephens 
\& Miller, 2008), American police (Robinson et al., 1997), and Canadian police (Asmundson \& Stapleton, 2008). Thus, hypothesis III is partially supported.

\section{Hypothesis IV: Model 3 (Social Support)}

In the third and final model, most of the demographic variables (age, race, and education) remain insignificant. However, gender becomes significant and negative, meaning that females have a higher likelihood of symptomology. This contrasts with a finding reported by Spinaris et al. (2012) which reported that male security staff had a higher prevalence of PTSD (36\%) as compared to females (30\%).

Next, three of the exposure to violence and trauma variables remain significant and positive (duration of work in the KY DOC, the assignment of security, and working in a maximum custody facility).

Regarding the duration of work in the KY DOC, the assignment of security, and working in a maximum custody facility, it is important to discuss what parts of these produce symptomology. First, the duration of work in the KY DOC, as previously noted has been found significant in earlier studies, may best be examined in the context of

stress, specifically stress on corrections staff produced by organizational factors. These could include a lack of staff, inadequate pay, and difficult physical conditions.

Considering the recent reduction in correctional budgets as well as the increasing inmate population, these are particularly relevant issues.

Second, the assignment of security and working in a maximum security facility could be causing those who work in corrections to experience symptomology due to the "what if" factor. Recent articles about symptomology in corrections staff have mentioned that officers are always on guard and feel they must "watch their back" constantly due to 
the possibility of an attack. Hence, this hypervigilance could be a reason why these variables are related to symptomology.

Moving to the social support variables, marital status/presence of a significant other was not significant. This is in contrast to earlier studies indicating marriage in first responders (Berger et al., 2007; Corneil et al., 1999) and the presence of a significant other in survivors of assault (Mgoqi-Mbalo, Zhang, \& Ntuli, 2017) may reduce symptomology.

Although it was somewhat unexpected that supervisor social support was not significant, the finding that coworker affected the likelihood of symptomology is not surprising. Previous studies have supported this finding with Stadnyk (2003) reporting that coworker social support reduced symptomology for corrections staff and van der Ploeg \& Kleber (2003) concluding something similar for ambulance personnel. Furthermore, the correctional environment places a high value on teamwork. This is evidenced when during a violent incident, the staff run toward the event to help other officers rather than away. Administration typically monitors staff closely who distance themselves from coworkers as it may be a sign that the staff member is being manipulated by an inmate, which could be disastrous (Michigan Department of Corrections, 2015).

Similar to coworker social support, family social support was significant and negative. This is consistent with other studies which examined first responders, veterans, and the general population. For example, both international and American firefighters were found to have reduced symptomology due to family social support (Corneil et al., 1999). Similarly, Vietnam veterans with higher levels of family social support were 
found to have lower rates at both their homecoming from the war and a few decades later (Schnurr et al., 2004). Victims of community violence (Scarpa et al., 2006) and breast cancer survivors (Andrykowski \& Cordova, 1998) have also found to have benefited from family social support as they reported less PTSD symptoms. Thus, hypothesis IV is partially supported. See Table 15 comparing the results for the hypotheses. 
Table 15: Support for Hypotheses

\begin{tabular}{|c|c|c|c|}
\hline Hypothesis & $\begin{array}{l}\text { Supported/Not } \\
\text { Supported }\end{array}$ & $\begin{array}{l}\text { Consistent with Previous } \\
\text { Research }\end{array}$ & $\begin{array}{l}\text { Extends Previous } \\
\text { Research }\end{array}$ \\
\hline $\begin{array}{l}\text { H1: The rate of } \\
\text { PTSD } \\
\text { symptomology } \\
\text { will be similar to } \\
\text { that of Spinaris et } \\
\text { al. (2012) of } \\
27 \% \text {. }\end{array}$ & $\begin{array}{l}\text { This hypothesis was } \\
\text { supported. }\end{array}$ & $\begin{array}{l}\text { This analysis is consistent with } \\
\text { previous research conducted by } \\
\text { Spinaris et al. (2012) with } 30 \% \\
\text { of KY DOC staff reporting } \\
\text { symptomology of concern. }\end{array}$ & $\begin{array}{l}\text { This research reveals } \\
\text { that Kentucky has a } \\
\text { rate similar to a } \\
\text { national study of } \\
\text { corrections personnel. }\end{array}$ \\
\hline $\begin{array}{l}\text { H2/Model 1: } \\
\text { Demographic } \\
\text { characteristics } \\
\text { (age, race, } \\
\text { gender, and } \\
\text { education) may } \\
\text { place staff at an } \\
\text { increased risk of } \\
\text { symptomology. }\end{array}$ & $\begin{array}{l}\text { This hypothesis was } \\
\text { exploratory and } \\
\text { resulted in } \\
\text { inconsistent support. }\end{array}$ & $\begin{array}{l}\text { This analysis was exploratory as } \\
\text { previous research indicated age, } \\
\text { race, and gender did not } \\
\text { influence symptomology. }\end{array}$ & $\begin{array}{l}\text { This analysis } \\
\text { extended previous } \\
\text { research by focusing } \\
\text { on demographic } \\
\text { variables that have } \\
\text { historically been } \\
\text { inconclusive in } \\
\text { predicting } \\
\text { symptomology. }\end{array}$ \\
\hline $\begin{array}{l}\text { H3/ Model 2: The } \\
\text { increase in the } \\
\text { exposure to } \\
\text { violence and } \\
\text { trauma variables } \\
\text { will increase } \\
\text { symptomology. }\end{array}$ & $\begin{array}{l}\text { This hypothesis is } \\
\text { supported. The } \\
\text { duration of } \\
\text { employment in the } \\
\text { KY DOC, assignment } \\
\text { of security, and } \\
\text { employment in a } \\
\text { maximum custody } \\
\text { facility were } \\
\text { significant for } \\
\text { symptomology. }\end{array}$ & $\begin{array}{l}\text { These results are partially } \\
\text { consistent with previous } \\
\text { research. } \\
\text { Although the sum of violent and } \\
\text { traumatic events was not } \\
\text { significant in this model, } \\
\text { previous research has indicated a } \\
\text { relationship (Asmundson \& } \\
\text { Stapleton, 2008; Bryant \& } \\
\text { Harvey, 1996; Robinson et al., } \\
\text { 1997; Spinaris et al., 2012; } \\
\text { Stephens \& Miller, 2008). } \\
\text { Second, the resulting relationship } \\
\text { between symptomology and the } \\
\text { duration of employment } \\
\text { contrasts with the finding by } \\
\text { Boudoukha et al. (2013). } \\
\text { Third, the finding that an } \\
\text { assignment of security increases } \\
\text { the chances of symptomology is } \\
\text { similar to that of Spinaris et al. } \\
\text { (2012). } \\
\text { Last, the finding of an increased } \\
\text { likelihood of symptomology for } \\
\text { those working in a maximum } \\
\text { custody facility is consistent } \\
\text { (Spinaris et al., 2012). }\end{array}$ & $\begin{array}{l}\text { This analysis extends } \\
\text { research by } \\
\text { disaggregating two } \\
\text { variables that could be } \\
\text { contributing to } \\
\text { symptomology which } \\
\text { are the amount of } \\
\text { traumatic and violent } \\
\text { events and the time } \\
\text { spent working in the } \\
\text { KY DOC. }\end{array}$ \\
\hline
\end{tabular}




\begin{tabular}{|c|c|c|c|}
\hline $\begin{array}{l}\text { H4/ Model 3: } \\
\text { Higher levels of } \\
\text { social support } \\
\text { reduces } \\
\text { symptomology }\end{array}$ & $\begin{array}{l}\text { This hypothesis is } \\
\text { only partially } \\
\text { supported. } \\
\text { First, most of the } \\
\text { demographic variables } \\
\text { were insignificant } \\
\text { except for gender } \\
\text { which became } \\
\text { significant (negative). } \\
\text { Second, two of the } \\
\text { exposure to trauma } \\
\text { and violence variables } \\
\text { were significant and } \\
\text { positive (assignment } \\
\text { of security and work } \\
\text { in a maximum } \\
\text { custody facility). } \\
\text { Third, only family and } \\
\text { coworker social } \\
\text { support had a } \\
\text { significant } \\
\text { relationship } \\
\text { (negative). }\end{array}$ & $\begin{array}{l}\text { This analysis is only partially } \\
\text { consistent with research. } \\
\text { First, the demographic variables } \\
\text { were insignificant except for } \\
\text { gender which was negative. The } \\
\text { research on this is mixed. } \\
\text { Second, the finding that the } \\
\text { assignment of security is } \\
\text { consistent with previous } \\
\text { research. However, the finding } \\
\text { that the amount of violent and } \\
\text { traumatic events was not } \\
\text { significant contrasts with } \\
\text { previous research (Asmundson \& } \\
\text { Stapleton, 2008; Bryant \& } \\
\text { Harvey, 1996; Robinson et al., } \\
\text { 1997; Spinaris et al., 2012; } \\
\text { Stephens \& Miller, 2008). } \\
\text { Third, the significance of family } \\
\text { and coworker social support was } \\
\text { significant which is consistent } \\
\text { with previous findings } \\
\text { (Andrykowski \& Cordova, 1998; } \\
\text { Corneil et al., 1999; Scarpa et al., } \\
\text { 2006; Schnurr et al., 2004). }\end{array}$ & $\begin{array}{l}\text { This analysis extends } \\
\text { previous research by } \\
\text { focusing on the role of } \\
\text { social support which } \\
\text { are disaggregated to } \\
\text { allow for greater } \\
\text { differentiation } \\
\text { between variables. }\end{array}$ \\
\hline
\end{tabular}




\section{LIMITATIONS OF STUDY}

While there are numerous advantages to the current study, a few limitations do exist with the most obvious being that the survey measures self-report data and whether the PTSD symptoms experienced were experienced while working in a KY DOC prison facility. Self-report data relies on the honesty of the participants and the ability to accurately respond to questions. Since individuals interpret words and phrases differently, this could result in a sort of inconsistency between individuals in the data. Additionally, although the TSI-2 was introduced as a measure to determine symptomology from only work related violent and traumatic events, it is difficult to confirm that all responses followed this directive.

Second, the violent and traumatic events occurred in the past, hence, the employee's psychological state at the time of the survey may affect how they report prior trauma. This could mean that the individual underestimates or overestimates the amount of trauma, however the TSI-2 has two validity scales which assess the respondent's tendency to underreport or overreport symptoms (Briere, 2011).

Third, this dissertation utilizes cross sectional data, which is an excellent starting point in which to explore symptomology. However, in the future, it may be beneficial to gather longitudinal data to identify any changes over time. Additionally, this would allow for an evaluation of programs implemented as a result of this dissertation.

Fourth, self-report data comprised the material for this dissertation, however, it may be worthwhile to seek access to the KY DOC's records. This would allow researchers to corroborate the exposure to violence and trauma therefore lending an additional legitimacy to the results. 


\section{IMPLICATIONS FOR POLICY, PRACTICE, AND FURTHER RESEARCH}

Although this dissertation provided distinctive and relevant information about a

first responder population which has long been neglected, the ultimate result is a call for increased attention and additional research. First, it may be worthwhile for the KY DOC to further explore the relationship between male and female staff and an increased likelihood of symptomology. Specifically, what actions are taken by males to decrease the symptomology? Furthermore, could these actions be taken by females with success?

Second, the KY DOC should look closely at the variables which were significant (security assignment and maximum security facility) and determine if there are policies and procedures the department could implement to alleviate these. Regarding security assignments, while the KY DOC currently rotates these assignments, perhaps the DOC should trial a shorter amount of time in security. This rotation plan could later be evaluated on effectiveness as it relates to symptomology.

Next, since family and coworker social support were significant, the KY DOC should review any current family and coworker social support programs offered to staff. This author was unable to find any formal information about these programs offered to staff, however, recent Facebook posts have shown that facilities will have family events with food and activities. These should continue on a regular basis. Additionally, KY DOC should begin to research the feasibility of offering workshops and support groups for families as these can increase the family's feeling of competence in the provided support, reduce the sense of isolation, increase the connection between families with similar experiences, and provide opportunities for families to seek support (Family Support Program, 2017). For example, the U.S. Department of Veterans Administration 
offers programs for those who are the caregiver for an individual with PTSD, those who are seeking assistance on how to encourage an individual to seek help, and for children who have a parent with PTSD. Furthermore, research also supports not only group sessions but individual sessions conducted in the home (Korfmacher, O'Brien, Hiatt, \& Olds, 1999).

In addition to those variables which were significant, the KY DOC should also examine those which were not significant. For example, regarding the sum of violent and traumatic events, the KY DOC should carefully examine the violent and traumatic events, not in terms of number but in terms of type. For example, could a single type of event such as suicide attempt, result in increased symptomology as opposed to multiple threatening letters?

While the recommendations for policies and procedures are necessary, some may question how could an entity implement some of these with such a tight budget. There are many ways the KY DOC could implement these beginning with the utilization of an oft neglected resource- academia. This author encourages a collaborative communication between the KY DOC and the higher education institutions in Kentucky. Through this collaboration, the KY DOC could receive some much-needed resources for a fraction of the cost, such as interns to staff prisons, statisticians to further examine violent and traumatic events, and medical personnel to design and implement family social support programs.

Another recommended resource to offset the costs of these recommendations is that the KY DOC apply for grants. The federal government often advertises grants 
whereby the money could be used to implement preventive PTSD programs.

Furthermore, these grants may also cover the evaluation of such programs.

Last, the KY DOC should attempt to integrate the local community to help offset costs. Perhaps businesses could be used in an effort to sponsor some of the family days. This could provide multiple benefits to include advertising company to staff and increasing the company's exposure to other possible clients. This is a valuable tactic utilized by many as evidenced by sponsorship shirts, etc.

Although this dissertation makes recommendations regarding symptomology at the department level, Kentucky should ultimately work to reduce symptomology with a bill which would offer almost immediate access to PTSD resources. This would be similar to the Canadian provinces of Ontario and Manitoba which took a giant step forward in 2016 with the passage of Bill 163. This bill amended the Workplace Safety and Insurance Act to include PTSD. It is called Supporting Ontario's First Responders Act and recognizes not only the typical first responders (fire, police) but also corrections staff thereby allowing them to receive treatment for PTSD much faster. If an individual is diagnosed with PTSD by a psychiatrist or psychologist, their claims to be eligible for

benefits from the Workplace Safety and Insurance Board (WSIB) are expedited. The key here is that the individual does not need to prove a link between the PTSD and the job, instead, it is presumed to be work related unless the opposite is shown.

\section{CONCLUSION}

Research on the general population regarding PTSD symptomology is prolific, however, first responders have not had the same amount of exposure. One of these first responder groups, correctional staff, have been consistently shown to be exposed to 
repeated trauma due to their work in a confined environment housing violent and mentally ill offenders. Unfortunately, only the mainstream media has begun to explore the significance of this issue. Academic research has been slow to follow.

This dissertation sought to remedy this deficit by first, examining responses from staff from the Kentucky Department of Corrections adult facilities to determine to what extent PTSD is an issue among their staff. Second, the symptomology rate was determined allowing a comparison of other first responder prevalence rates. Next, this this dissertation focused on exposure to violence and trauma variables to determine whether they are associated with symptomology. Finally, an examination of social support variables was conducted. It was hypothesized that these social support variables would help to mitigate symptomology and allow the KY DOC to utilize this information to implement preventive and management measures. Although only two of these social support variables, family and coworker social support, mitigated symptomology, this still has tremendous implications for the KY DOC.

It is this author's hope that this dissertation has in some small way assisted those who work in the KY DOC. Currently, correctional staff seem to be the ghosts of law enforcement. They are often behind walls; easily forgotten. However, they are "brothers in blue" and perform a noble and honest profession. They protect and serve the community. Consequently, they should be provided preventive and management resources when their duties require them to encounter violence and trauma which results in PTSD symptomatology. However, to be successful this must be a group effort. As Amaral (2017) stated, "We are all united in our losses and therefore united in our battle to change the culture of corrections to get staff the help they deserve" (para. 19). 


\section{REFERENCES}

Aarts, P. G. H, op den Velde, W., Falger, P. R. J., Hovens, J. E., de Groen, J. H. M., \& van Duijn, H. (1996) Late onset of posttraumatic stress disorder in aging resistance veterans in the Netherlands. In P. E. Ruskin \& J. A. Talbott (Eds.), Aging and Posttraumatic Stress Disorder. (pp. 53-76). Washington, DC: American Psychiatric Press.

Ahmadi, N., Hajsadeghi, F., Mirshkarlo, H. B., Budoff, M., Yehuda, R., \& Ebrahimi, R. (2011). Post-traumatic stress disorder, coronary atherosclerosis, and mortality. The American Journal of Cardiology, 108(1), 29-33. doi:10.1016/j.amjcard.2011.02.340

Alvidrez, J., Snowden, L. R., \& Kaiser, D. M. (2008). The experience of stigma among black mental health consumers. Journal of Health Care for the Poor and Underserved, 19(3), 874-93. doi:10.1353/hpu.0.0058

Amaral, N. (2017). Post-traumatic stress and suicide in corrections: How PA DOC is addressing the issue. Retrieved from http://inpublicsafety.com/2017/08/posttraumatic-stress-and-suicide-in-corrections/

American Psychiatric Association. (2013). Diagnostic and statistical manual of mental disorders (5th ed.). Arlington, VA: American Psychiatric Publishing.

Amir, M., Kaplan, Z., Neumann, L., Sharabani, R., Shani, N., \& Buskila, D. (1997). Posttraumatic stress disorder, tenderness and fibromyalgia. Journal of Psychosomatic Research, 42(6), 607-613. doi:10.1016/S0022-3999(97)00009-3 
Andrews, B., Brewin, C. R., \& Rose, S. (2003). Gender, social support, and PTSD in victims of violent crime. Journal of Traumatic Stress, 16(4), 421-427. doi:10.1023/A:1024478305142

Andrykowski, M. A., \& Cordova, M. J. (1998). Factors associated with PTSD symptoms following treatment for breast cancer: Test of the Andersen model. Journal of Traumatic Stress, 11(2), 189-203. doi:10.1023/A:1024490718043

Armstrong, G. S., Atkin-Plunk, C. A., \& Wells, J. (2015). The relationship between work-Family conflict, correctional officer job stress, and job satisfaction. Criminal Justice and Behavior, 42(10), 1066-1082. doi: $10.1177 / 0093854815582221$

Armstrong, G. S., \& Griffin, M. L. (2004). Does the job matter? Comparing correlates of stress among treatment and correctional staff in prisons. Journal of Criminal Justice, 32(6), 577-592. doi:10.1016/j.jcrimjus.2004.08.007

Arvay, M. J., \& Uhlemann, M. R. (1996). Counsellor Stress in the Field of Trauma: A Preliminary Study. Canadian Journal of Counselling, 30(3), 193-210.

Asmundson, G. J., \& Stapleton, J. A. (2008). Associations between dimensions of anxiety sensitivity and PTSD symptom clusters in active-duty police officers. Cognitive Behaviour Therapy, 37(2), 66-75. doi:10.1080/16506070801969005

Averill, P. M., \& Beck, J. G. (2000). Posttraumatic stress disorder in older adults: A conceptual review. Journal of Anxiety Disorders, 14(2), 133-156.

Backholm, K., \& Björkqvist, K. (2012). The mediating effect of depression between exposure to potentially traumatic events and PTSD in news journalists. European Journal of Psychotraumatology, 3(1), 183-88. 
Beck, J. G., Grant, D. M., Clapp, J. D., \& Palyo, S. A. (2009). Understanding the interpersonal impact of trauma: contributions of PTSD and depression. Journal of Anxiety Disorders, 23(4), 443-50. doi:10.1016/j.janxdis.2008.09.001

Bennett, P., Williams, Y., Page, N., Hood, K., \& Woollard, M. (2004). Levels of mental health problems among UK emergency ambulance workers. Emergency Medicine Journal, 21(2), 235-236

Berger, W., Figueira, I., Maurat, A. M., Bucassio, E. P., Vieira, I., Jardim, S. R., Coutinho, E. S. F., Mari, J. J., \& Mendlowicz, M. V. (2007). Partial and full PTSD in Brazilian ambulance workers: prevalence and impact on health and on quality of life. Journal of Traumatic Stress, 20(4), 637-642.

Bigler, E. D. (2008). Neuropsychology and clinical neuroscience of persistent postconcussive syndrome. Journal of the International Neuropsychological Society, 14(1), 1-22. doi:10.1017/S135561770808017X

Boscarino, J. A. (2008). A prospective study of PTSD and early-age heart disease mortality among Vietnam veterans: implications for surveillance and prevention. Psychosomatic Medicine, 70(6), 668-76. doi:10.1097/PSY.0b013e31817bccaf

Boscarino, J. A., \& Chang, J. (1999). Electrocardiogram abnormalities among men with stress-related psychiatric disorders: Implications for coronary heart disease and clinical research. Annals of Behavioral Medicine, 21(3), 227-234.

doi:10.1007/BF02884839

Boscarino, J. A., Galea, S., Adams, R. E., Ahern, J., Resnick, H., \& Vlahov, D. (2004). Mental health service and medication use in New York City after the September 11, 2001, terrorist attack. Psychiatric Services (Washington, D.C.), 55(3), 274-83. 
Boudoukha, A. H., Altintas, E., Rusinek, S., Fantini-Hauwel, C., \& Hautekeete, M. (2013). Inmates-to-staff assaults, PTSD and burnout: profiles of risk and vulnerability. Journal of Interpersonal Violence, 28(11), 2332-50. doi:10.1177/0886260512475314

Bowler, R. M., Kornblith, E. S., Li, J., Adams, S. W., Gocheva, V. V., Schwarzer, R., \& Cone, J. E. (2016). Police officers who responded to 9/11: Comorbidity of PTSD, depression, and anxiety 10-11 years later. American Journal of Industrial Medicine, 59(6), 425-36. doi:10.1002/ajim.22588

Breslau, J., Aguilar-Gaxiola, S., Kindler, K. S., Su, M., Williams, D., \& Kessler, R. C. (2006). Specifying race-ethnic differences in risk for psychiatric disorder in a USA national sample. Psychological Medicine, 36(1), 57-68.

Breslau, N., \& Davis, G. C. (1992). Posttraumatic stress disorder in an urban population of young adults: Risk factors for chronicity. The American Journal of Psychiatry, $149(5), 671-675$.

Breslau, N., Davis, G. C., Andreski, P., \& Peterson, E. (1991). Traumatic events and posttraumatic stress disorder in an urban population of young adults. Archives of General Psychiatry, 48(3), 216-22.

Breslau, N., Kessler, R. C., Chilcoat, H. D., Schultz, L. R., Davis, G. C., \& Andreski, P. (1998). Trauma and posttraumatic stress disorder in the community: The 1996 Detroit area survey of trauma. Archives of General Psychiatry, 55(7), 626-32. Brewin, C. R., Andrews, B., \& Valentine, J. D. (2000). Meta-analysis of risk factors for posttraumatic stress disorder in trauma-exposed adults. Journal of Consulting and Clinical Psychology, 68(5), 748-66. 
Briere, J. (2011). Trauma Symptom Inventory- 2 (TSI-2). Lutz, FL: Psychological Assessment Resources, Inc. Retrieved from http://www4.parinc.com/Products/Product.aspx?ProductID=TSI-2

Briere, J., Elliott, D. M., Harris, K., \& Cotman, A. (1995). Trauma symptom inventory: Psychometrics and association with childhood and adult victimization in clinical samples. Journal of Interpersonal Violence, 10(4), 387-401.

Brodsky, C. M. (1982). Work stress in correctional institutions. Journal of Prison and Jail Health, 2(2), 74-102.

Bryant, R. A., Creamer, M., O’Donnell, M., Silove, D., Clark, C. R., \& McFarlane, A. C. (2009). Post-traumatic amnesia and the nature of post-traumatic stress disorder after mild traumatic brain injury. Journal of the International Neuropsychological Society, 15(6), 862-867. doi:10.1017/S1355617709990671

Bryant, R. A., \& Harvey, A. G. (1996). Posttraumatic stress reactions in volunteer firefighters. Journal of Traumatic Stress, 9(1), 51-62. doi:10.1002/jts.2490090106

Bryant, R. A., O’Donnell, M. L., Creamer, M., McFarlane, A. C., Clark, C. R., \& Silove, D. (2010). The psychiatric sequelae of traumatic injury. American Journal of Psychiatry, 167(3), 312-320. doi:10.1176/appi.ajp.2009.09050617

Bureau of Diplomatic Security. (2017). South Africa 2017 Crime \& Safety Report. United States Department of State. Retrieved from Bureau of Labor Statistics. (2015). National Census of Fatal Occupational Injuries in 2014. U.S. Department of Labor. Retrieved from http://www.bls.gov/news.release/pdf/cfoi.pdf 
Carlier, I. V., Lamberts, R. D., Van Uchelen, A. J., \& Gersons, B. P. (1998). Disasterrelated post-traumatic stress in police officers: a field study of the impact of debriefing. Stress Medicine, 14(3), 143-148. doi:10.1002/(SICI)10991700(199807)14:3<143::AID-SMI770>3.0.CO;2-S

Cascardi, M., Riggs, D. S., Hearst-Ikeda, D., \& Foa, E. B. (1996). Objective ratings of assault safety as predictors of PTSD. Journal of Interpersonal Violence. 11(1), 65-78.

Cheek, E. E., \& Miller, M. (1982). Prisons of life. Washington, DC: American Federation of State County and Municipal Employees.

Cheek, E. E., \& Miller, M. (1983). The experience of stress for correctional officers: A double bind theory of correctional stress. Journal of Criminal Justice, 11(2), 105130.

Cheeseman, K., Kim, B., Lambert, E., \& Hogan, N. (2011). Correctional officer perceptions of inmates and overall job satisfaction. Journal of Crime and Justice, 34(2), 81-102. doi:10.1080/0735648X.2011.580515

Chung, H., \& Breslau, N. (2008). The latent structure of post-traumatic stress disorder: Tests of invariance by gender and trauma type. Psychological Medicine, 38(4), 563-573. doi: 10.1017/S0033291707002589

Clipp, E. C., \& Elder, G. H. Jr. (1996). The aging veteran of world war II: Psychiatric and life course insights. In P. E. Ruskin \& J. A. Talbott (Eds.), Aging and Posttraumatic Stress Disorder. (pp. 79-100). Washington, DC: American Psychiatric Press. 
Commonwealth of Kentucky. (2017a). Directory of Services. Kentucky Department of Corrections. Retrieved from http://corrections.ky.gov/depts/Pages/default.aspx Commonwealth of Kentucky. (2017b). Kentucky Department of Corrections Home. Kentucky Department of Corrections. Retrieved from http://corrections.ky.gov/Pages/default.aspx

Commonwealth of Kentucky. (2017c). Kentucky Department of Corrections Annual Report, 2015. Kentucky Department of Corrections. Retrieved from http://corrections.ky.gov/about/Documents/Research\%20and\%20Statistics/Annua 1\%20Reports/2015\%20Annual\%20Report.pdf

Commonwealth of Kentucky. (2017d). Kentucky Department of Corrections Annual Report, 2016. Kentucky Department of Corrections. Retrieved from http://corrections.ky.gov/about/Documents/Research\%20and\%20Statistics/Annua 1\%20Reports/2016\%20Annual\%20Report\%20APPROVED.pdf

Corneil, W., Beaton, R., Murphy, S., Johnson, C., \& Pike, K. (1999). Exposure to traumatic incidents and prevalence of posttraumatic stress symptomatology in urban firefighters in two countries. Journal of Occupational Health Psychology, $4(2), 131-141$.

Cornelius, G. F. (1994). Stressed out: Strategies for living and working with stress in correction. Laurel, MD: American Correctional Association.

Coughlin, S. S. (2011). Post-traumatic stress disorder and cardiovascular disease. The Open Cardiovascular Medicine Journal, 5(1), 164-170. doi:10.2174/1874192401105010164 
Courtois, C. A. (1988). Healing the incest wound: Adult survivors in therapy. New York, NY: W.W. Norton

Crocq, M.-A., \& Crocq, L. (2000). From shell shock and war neurosis to posttraumatic stress disorder: a history of psychotraumatology. Dialogues in Clinical Neuroscience, 2(1), 47-55.

Cullen, F., Link, B., Wolfe, N., \& Frank, J. (2006). The social dimensions of correctional officer stress. Justice Quarterly, 2(4), 505-533. doi:10.1080/07418828500088711

Cwikel, J., Abdelgani, A., Goldsmith, J. R., Quastel, M., \& Yevelson, I. I. (1997). Twoyear follow-up study of stress-related disorders among immigrants to Israel from the Chernobyl area. Environmental Health Perspectives Supplements, 105.

Danieli, Y. (1988). Confronting the unimaginable: Psycho therapists' reactions to victims of the Nazi Holocaust. In J. P. Wilson, Z. Harel, \& B. Kahana (Eds.), Human adaptation to extreme stress: From the Holocaust to Vietnam (pp. 219-238). New York, NY: Plenum Press

Darensburg, T., Andrew, M., Hartley, T., Burchfiel, C., Fekedulegn, D., \& Violanti, J. (2006). Gender and age differences in posttraumatic stress disorder and depression among Buffalo police officers. Traumatology, 12(3), 220-228.

Declercq, F., Vanheule, S., Markey, S., \& Willemsen, J. (2007). Posttraumatic distress in security guards and the various effects of social support. Journal of Clinical Psychology, 63(12), 1239-46.

Del Ben, K. S., Scotti, J. R., Chen, Y.-C., \& Fortson, B. L. (2006). Prevalence of posttraumatic stress disorder symptoms in firefighters. Work \& Stress, 20(1), 3748. doi:10.1080/02678370600679512 
Denhof, M.D., \& Spinaris, C. G. (2016). Prevalence of Trauma-Related Health Conditions in Correctional Officers: A Profile of Michigan Corrections Organization Members. Retrieved from http://www.mcoseiu.org/files/2016/05/MCO-Paper_FINAL.pdf

Dignam, J. T., Barrera, M., \& West, S. G. (1986). Occupational stress, social support and burnout among correctional officers. American Journal of Community Psychology, 14(2), 701-724.

Dollard, M. F., \& Winefield, A. H. (1998). A test of the demand-control/support model of work stress in correctional officers. Journal of Occupational Health Psychology, 3(3), 243-264.

Dowden, C., \& Tellier, C. (2004). Predicting work-related stress in correctional officers: A meta-analysis. Journal of Criminal Justice, 32(1), 31-47. doi:10.1016/j.jcrimjus.2003.10.003

Edens, J. F., Otto, R. K., \& Dwyer, T. J. (1998). Susceptibility of the trauma symptom inventory to malingering. Journal of Personality Assessment, 71(3), 379-92.

Elhai, J. D., Gray, M. J., Kashdan, T. B., \& Franklin, L. C. (2005). Which instruments are most commonly used to assess traumatic event exposure and posttraumatic effects? A survey of traumatic stress professionals. Journal of Traumatic Stress 18(5), 541-545.

Family Support Program. (2017). What is family support? University of North Carolina. School of Social Work. Retrieved from http://fsp.unc.edu/what-is-family-support Feinstein, A., Owen, J., \& Blair, N. (2002). A hazardous profession: war, journalists, and psychopathology. The American Journal of Psychiatry, 159(9), 1570-5. 
Figley, C. R. (1995). Compassion fatigue as secondary traumatic stress disorder: An overview. In C. R. Figley (Ed.), Compassion fatigue: Coping with secondary traumatic stress disorder in those who treat the traumatized (pp. 1-20). New York: Brunner/Mazel

Figley, C. R. (1999). Compassion fatigue: Toward a new understanding of the costs of caring. In B. H. Stamm (Ed.), Secondary traumatic stress: Self-care issues for clinicians, researchers, \& educators (2nd ed., pp. 3-28). Lutherville, MD: Sidran

Finn, P. (1998). Correctional officer stress: A cause for concern and additional help. Federal Probation, 62(2), 65-74.

Fontana A, \& Rosenheck R. (1994). Posttraumatic stress disorder among Vietnam theater veterans. A causal model of etiology in a community sample. The Journal of Nervous and Mental Disease, 182(12), 677-84.

Friedman, M. J., Keane, T. M., \& Resick, P. A. (2007). Handbook of PTSD: Science and practice. New York: Guilford Press.

Galea, S., Ahern, J., Resnick, H., Kilpatrick, D., Bucuvalas, M., Gold, J., \& Vlahov, D. (2002). Psychological sequelae of the September 11 terrorist attacks in New York City. New England Journal of Medicine, 13(3), 982-987.

Garrison, C. Z., Bryant, E. S., Addy, C. L., Spurrier, P. G., Freedy, J. R., \& Kilpatrick, D. G. (1995). Posttraumatic stress disorder in adolescents after hurricane Andrew. Journal of the American Academy of Child \& Adolescent Psychiatry, 34(9), $1193-$ 1201. doi:10.1097/00004583-199509000-00017 
Gersons, B. (1989). Patterns of PTSD among police officers following shooting incidents: A two-dimensional model and treatment implications. Journal of Traumatic Stress, 2(3), 247-257. doi:10.1007/BF00976230

Ghafoori, B., Barragan, B., Tohidian, N., \& Palinkas, L. (2012). Racial and Ethnic Differences in Symptom Severity of PTSD, GAD, and Depression in TraumaExposed, Urban, Treatment-Seeking Adults. Journal of Traumatic Stress, 25(1), 106-110. http://doi.org/10.1002/jts.21663

Glaesmer, H., Brähler, E., Gündel, H., \& Riedel-Heller, S. G. (2011). The association of traumatic experiences and posttraumatic stress disorder with physical morbidity in old age: a German population-based study. Psychosomatic Medicine, 73(5), 4016. doi:10.1097/PSY.0b013e31821b47e8

Grossi, W., \& Berg, B. (1991). Stress and job dissatisfaction among correctional officers: An unexpected finding. International Journal of Offender Therapy and Comparative Criminology, 35(1), 73-81.

Haley, S. A. (1974). When the patient reports atrocities: Specific treatment considerations of the Vietnam veteran. Archives of General Psychiatry, 30(2), 191

Harding, T. W., \& Zimmermann, F. (1989). Psychiatric symptoms, cognitive stress and vulnerability factors: A study in a remand prison. British Journal of Psychiatry, 155(1), 36-43.

Harris, G. (1983). Stress in corrections. Boulder, CO: National Institute of Corrections.

Harris, I. A., Young, J. M., Rae, H., Jalaludin, B. B., \& Solomon, M. J. (2008). Predictors of post-traumatic stress disorder following major trauma. ANZ Journal of Surgery, 78(7), 583-7. doi:10.1111/j.1445-2197.2008.04578.x 
Haslam, C., \& Mallon, K. (2003). A preliminary investigation of post-traumatic stress symptoms among firefighters. Work \& Stress, 17(3), 277-285.

Herman, J. (1992). Complex PTSD: A syndrome in survivors of prolonged and repeated trauma. Journal of Traumatic Stress, 5, 377-391.

Hoge, C. W., McGurk, D., Thomas, J. L., Cox, A. L., Engel, C. C., \& Castro, C. A. (2008). Mild traumatic brain injury in U.S. Soldiers re- turning from Iraq. New England Journal of Medicine, 358(20), 453-463. doi:10.1056/NEJMoa072972

Irwin, C., Falsetti, S. A., Lydiard, R. B., Ballenger, J. C., Brock, C. D., \& Brener, W. (1996). Comorbidity of posttraumatic stress disorder and irritable bowel syndrome. The Journal of Clinical Psychiatry, 57(12), 576-8.

Jacobs, J. B., \& Crotty, N. (1983). The guard's world. In J. B. Jacobs (Ed.), New perspectives on prison and imprisonment (133-141). Ithaca, NY: Cornell University Press.

James, D.J., \& Glaze, L.E. (2006). Mental Health Problems of Prison and Jail Inmates. U.S. Department of Justice, Office of Justice Programs. Washington, DC: Author. Retrieved from https://www.bjs.gov/content/pub/pdf/mhppji.pdf

Jonsson, A., Segesten, K., \& Mattsson, B. (2003). Post-traumatic stress among Swedish ambulance personnel. Emergency Medicine Journal, 20(1), 79-84.

Jordan, B. K., Marmar, C. R., Fairbank, J. A., Schlenger, W. E., Kulka, R. A., Hough, R. L., \& Weiss, D. S. (1992). Problems in families of male Vietnam veterans with posttraumatic stress disorder. Journal of Consulting and Clinical Psychology, 60(6), 916-926. 
Jordan, H. T., Miller-Archie, S. A., Cone, J. E., Morabia, A., \& Stellman, S. D. (2011). Heart disease among adults exposed to the September 11, 2001 World Trade Center disaster: results from the World Trade Center Health Registry. Preventive Medicine, 53(6), 370-6. doi:10.1016/j.ypmed.2011.10.014

Joseph, S., Andrews, B., Williams, R., \& Yule. W. (1992). Crisis support and psychiatric symptomatology in adult survivors of the Jupiter cruise ship disaster. British Journal of Clinical Psychology, 31, 63-73.

Kauffman, K. (1988). Prison officers and their world. Cambridge, MA: Harvard University Press.

Kessler, R. C., Chiu, W. T., Demler, O., \& Walters, E. E. (2005). Prevalence, severity, and comorbidity of 12-month DSMIV disorders in the National Comorbidity Survey Replication. Archives of General Psychiatry, 62(7), 617-627.

Kessler, R. C., Galea, S., Gruber, M. J., Sampson, N. A., Ursano, R. J., \& Wessely, S. (2008). Trends in mental illness and suicidality after hurricane Katrina. Molecular Psychiatry, 13(4), 374-384.

Kessler, R. C., Sonnega, A., Bromet, E., Hughes, M., \& Nelson, C. B. (1995). Posttraumatic stress disorder in the National Comorbidity Survey. Archives of General Psychiatry, 52(12), 1048-60.

Kessler, R. C., Berglund, P., Demler, O., Jin, R., Merikangas, K. R., \& Walters, E. E. (2005). Lifetime prevalence and age-of-onset distributions of DSM-IV disorders in the National Comorbidity Survey Replication. Archives of General Psychiatry, 62(6), 593-602. 
Kim, K., Becker-Cohen, M, \& Serakos, M. (2015). The Processing and Treatment of Mentally Ill Persons in the Criminal Justice System. The Urban Institute. Retrieved from http://www.urban.org/research/publication/processing-andtreatment-mentally-ill-persons-criminal-justice-system/view/full_report

King, L. A., King, D. W., Fairbank, J. A., Keane, T. M., \& Adams, G. A. (1998). Resilience-recovery factors in post-traumatic stress disorder among female and male Vietnam veterans: hardiness, postwar social support, and additional stressful life events. Journal of Personality and Social Psychology, 74(2), 420-34.

King, D. W., King, L. A., Foy, D. W., Keane, T. M., \& Fairbank, J. A. (1999). Posttraumatic stress disorder in a national sample of female and male Vietnam veterans: risk factors, war-zone stressors, and resilience-recovery variables. Journal of Abnormal Psychology, 108(1), 164-70.

King, M. W., Street, A. E., Gradus, J. L., Vogt, D. S., \& Resick, P. A. (2013). Gender differences in posttraumatic stress symptoms among OEF/OIF Veterans: An item response theory analysis. Journal of Traumatic Stress, 26, 175-183. doi:

$10.1002 / \mathrm{jts} .21802$

Koenen, K., Hearst-lkeda, D., \& Caulfield, M. B. (1997). The relationship of anger and coping to PTSD symptoms in traumatized women. Poster session presented at the annual meeting of the Association for the Advancement of Behavior Therapy. Miami. FL.

Kommer, M. M. (1990). Working with people: A study on the working environment and the functioning of COs. The Hague, the Netherlands: Ministry of Justice (Dutch). 
Kopel, H., \& Friedman, M. (1997). Posttraumatic symptoms in South African Police exposed to violence. Journal of Traumatic Stress, 10(2), 307-317. doi:10.1002/jts.2490100211

Korfmacher, J., O'Brien, R., Hiatt, S., \& Olds, D. (1999). Differences in program implementation between nurses and paraprofessionals in prenatal and infancy home visitation: A randomized trial. American Journal of Public Health. 89(12), $1847-1851$

Kubzansky, L. D., \& Koenen, K. C. (2009). Is posttraumatic stress disorder related to development of heart disease? An update. Cleveland Clinic Journal of Medicine, 76, S60-5. doi:10.3949/ccjm.76.s2.12

Kubzansky, L. D., Koenen, K. C., Jones, C., \& Eaton, W.W. (2009). A prospective study of posttraumatic stress disorder symptoms and coronary heart disease in women. Health Psychology: Official Journal of The Division of Health Psychology, American Psychological Association, 28(1), 125-30. doi:10.1037/02786133.28 .1 .125

Kubzansky, L. D., Koenen, K. C., Spiro, A., Vokonas, P. S., \& Sparrow, D. (2007). Prospective study of posttraumatic stress disorder symptoms and coronary heart disease in the Normative Aging Study. Archives of General Psychiatry, 64(1), 109-16.

Kulka, R. A., Schlesenger, W. E., Fairbank, J. A., Hough, R. L., Jordan, B. K., Marmar, C. R., \& Weiss, D. S. (1990). Trauma and the Vietnam war generation: Report of findings from the national Vietnam veterans readjustment study (Brunner/Mazel psychosocial stress series, no. 18). New York, NY: Brunner/Mazel. 
Kunst, M. J. J., Bogaerts, S., \& Winkel, F. W. (2009). Peer and inmate aggression, type D-personality and post-traumatic stress among Dutch prison workers. Stress and Health, 25(5), 387-395. doi:10.1002/smi.1247

Lambert, E., Hogan, N., \& Barton, S. (2002). Building commitment among correctional staff: The issue of feedback, promotional opportunities, and organizational fairness. Corrections Compendium, 27(3), 1-5, 24-28.

Lambert, E., Hogan, N., Barton, S., \& Ventura, L. (2006). The impact of work-family conflict on correctional staff: A preliminary study. Criminology \& Criminal Justice, 6(4), 371-387. doi:10.1177/1748895806068572

Lasky, G. L., Gordon, B. C., \& Srebalus, D. J. (1986). Occupational stressors among federal correctional different security levels. Criminal Justice and Behavior, 13(3), 317-327.

Lee, J. H., Kim, I., Won, J. U., \& Roh, J. (2016). Post-traumatic stress disorder and occupational characteristics of police officers in Republic of Korea: A crosssectional study. BMJ Open, 6(3), E009937. doi:10.1136/bmjopen-2015-009937

Lilly, M. M., Pole, N., Best, S. R., Metzler, T., \& Marmar, C. R. (2009). Gender and PTSD: What can we learn from female police officers? Journal of Anxiety Disorders, 23(6), 767-74. doi:10.1016/j.janxdis.2009.02.015

Lima, C., Maia, A., Ferreira, R., Magalhães, A., Nunes, H., Pinheiro, S., Ribeiro, L., Rodrigues, C., Santos, P., Santos, V., \& Teles, R. (2016). PTSD and quality of life among firefighters and municipal police forces. European Psychiatry:

Supplement, 33(1), 513-513. doi:10.1016/j.eurpsy.2016.01.1895 
Lindquist, C. A., \& Whitehead, J. T. (1986). Burnout, job stress and job satisfaction among southern correctional officers. Journal of Offender Counseling Services and Rehabilitation, 10(4), 5-26.

Lisitsina, D. (2015). 'Prison guards can never be weak': The hidden PTSD crisis in America's jails. The Guardian. Retrieved from https://www.theguardian.com/usnews/2015/may/20/corrections-officers-ptsd-american-prisons

Lombardo, L. X. (1989). Guards imprisoned: Correctional officers at work. Atlanta, GA: Elsevier.

Lopez, O. (2014). Prison officers need help, but they won't ask for it. Newsweek. Retrieved from http://www.newsweek.com/2014/06/06/prison-officers-need-helpthey-wont-ask-it-252439.html

Luethcke, C. A., Bryan, C. J., Morrow, C. E., \& Isler, W. C. (2011). Comparison of concussive symptoms, cognitive performance, and psychological symptoms between acute blast versus non-blast induced mild traumatic brain injury. Journal of the International Neuropsychological Society, 17(1), 36-45. doi:10.1017/S1355617710001207

Lyons, J., \& McClendon, O. (1990) Changes in posttraumatic stress disorder: Symptomatology as a function of aging. Nova-Psychology Newsletter, 8(1), 3-18.

MacDonald, H., Karlinsky, H., Colotla, V., Flamer, S., British Columbia, \& University of British Columbia. (2003). Posttraumatic stress disorder (PTSD) in the workplace: A descriptive study of workers experiencing PTSD resulting from work injury. Victoria, B.C.: Workers' Compensation Board. Retrieved from 
http://www.worksafebc.com/about_us/resources/library_services/online_publicati ons/wcb_research/assets/pdf/99FS-62.pdf

Marais, A. \& Stuart, A. (2005). The role of temperament in the development of posttraumatic stress disorder amongst journalists. South African Journal of Psychology, 35(1), 89-105.

Marsden, P. V., Kalleberg, A. L., \& Cook, C. R (1993). Gender differences in organizational commitment: Influences of work positions and family roles. Work and Occupations, 20(3), 368-390.

Marshall, G.N., Schell, T. L., Elliott, M. N., Rayburn, N. R., \& Jaycox, L. H. (2007). Psychiatric disorders among adults seeking emergency disaster assistance after a wildland-urban interface fire. Psychiatric Services 58(4): 509-514.

Martinez, A. R. (1997). Correctional officer: The "other" prisoner. The Keeper's Voice, $18(1), 8-11$.

Mayo Foundation for Medical Education and Research. (2017). Video: Migraine aura. Retrieved from http://www.mayoclinic.org/diseases-conditions/migraine-withaura/multimedia/migraine-aura/vid-20084707

Mayou, R. A., Black, J., \& Bryant, B. (2000). Unconsciousness, amnesia and psychiatric symptoms following road traffic accident injury. The British Journal of Psychiatry, 177(6), 540-545. doi:10.1192/bjp.177.6.540

McCann, I. L., \& Pearlman, L. A. (1990). Vicarious traumatization: A framework for understanding the psychological effects of working with victims. Journal of Traumatic Stress, 3(1), 131-149. 
McFarlane, A. C. (1986). Posttraumatic morbidity of a disaster: A study of cases presenting for psychiatric treatment. Journal of Mental and Nervous Disorders, 174(1), 4-14.

Mendlowicz, M. V., \& Stein, M. B. (2000). Quality of life in individuals with anxiety disorders. The American Journal of Psychiatry, 157(5), 669-82.

Merikangas, K. R., He, J.-p., Burstein, M., Swanson, S. A., Avenevoli, S., Cui, L., Benjet, C., Georgiades, K., \& Swendsen, J. (2010). Lifetime Prevalence of Mental Disorders in U.S. Adolescents: Results from the National Comorbidity Survey Replication-Adolescent Supplement (NCS-A). Journal of the American Academy of Child \& Adolescent Psychiatry, 49(10), 980-989. doi:10.1016/j.jaac.2010.05.017

Mgoqi-Mbalo, N., Zhang, M., \& Ntuli, S. (2017). Risk factors for PTSD and depression in female survivors of rape. Psychological Trauma: Theory, Research, Practice and Policy, 9(3), 301-308. doi:10.1037/tra0000228

Michigan Department of Corrections. (2017). Overfamiliarity. Is your team at risk? Retrieved from http://www.michigan.gov/corrections/0,4551,7-119-1441_1476136016--,00.html

Morales, R. F., Perez, V. R., \& Martinez, L. (2012). Posttraumatic stress symptoms in Mexican journalists covering the drug war. Suma Psicológica, 19(1), 7-17.

Morales, R. F., Perez, V. R., \& Martinez, L. (2014). The psychological impact of the war against drug-trafficking on Mexican journalists. Revista Colombiana de Psicología, 23(1), 177-193. 
Nader, K., Pynoos, R., Fairbanks, L., \& Frederick, C. (1990). Children's PTSD reactions one year after a sniper attack at their school. American Journal of Psychiatry, 147(1), 1526-1530.

National Climatic Data Center. (2008). US tornado climatology. Asheville, NC: US Department of Commerce. Retrieved from http://www.ncdc.noaa.gov/oa/climate/severeweather/tornadoes.html

National First Responders Organization. (2014). Who is a first responder? Retrieved from http://www.nfro.org/who.html

National Institutes of Health, \& Northwestern University. (2012). Social Relationships. NIH Toolbox. Retrieved from http://www.nihtoolbox.org/WhatAndWhy/Emotion/SocialRelationships/Pages/def ault.aspx

Newman, E., Simpson, R., \& Handschuh, D. (2003). Trauma exposure and post-traumatic stress disorder among photojournalists. Visual Communication Quarterly, 10(1), $4-13$

Norris, F. H. (1992). Epidemiology of trauma: Frequency and impact of different potentially traumatic events on different demographic groups. Journal of Personality and Social Psychology, 60(3), 409-418.

Norris, F. H., Perilla, J. L., Ibanez, G. E., \& Murphy, A. D. (2001). Sex differences in symptoms of posttraumatic stress: Does culture play a role? Journal of Traumatic Stress, 14(1), 7-28.

North, C. S., Pollio, D. E., Smith, R. P., King, R. V., Pandya, A., Suris, A. M., Hong, B. A., Dean, D. J., Wallace, N. E., Herman, D. B., Conover, S., Susser, E. \& 
Pfefferbaum, B. (2011). Trauma exposure and posttraumatic stress disorder among employees of New York City companies affected by the September 11, 2001 attacks on the World Trade Center Disaster Medicine and Public Health Preparedness, Vol 5 ((Supplement 2)) (September 2011). (10th anniversary of 9/11; Original research).

North, C. S., Smith, E. M., McCool, R. E., \& Shea, J. M. (1989). Short-term psychopathology in eyewitnesses to mass murder. Hospital and Community Psychiatry, 40(1), 1293-1295.

North, C. S., Tivis, L., McMillen, J. C., Pfefferbaum, B., Cox, J., Spitznagel, E. L., Bunch, K., Schorr, J., Smith, E. M. (2002). Coping, functioning, and adjustment of rescue workers after the Oklahoma City bombing. Journal of Traumatic Stress, 15(3), 171-175. doi:10.1023/A:1015286909111

Oehme, K., Donnelly, E. A., \& Martin, A. (2012). Alcohol abuse, PTSD, and officercommitted domestic violence. Policing, 6(4), 418-430.

Oklahoma City National Memorial and Museum. (2017). Those who were killed. Retrieved from https://oklahomacitynationalmemorial.org/people/

Olatunji, B. O., Cisler, J. M., \& Tolin, D. F. (2007). Quality of life in the anxiety disorders: A meta-analytic review. Clinical Psychology Review, 27(5), 572-581. doi:10.1016/j.cpr.2007.01.015

Ortega, A. N., \& Rosenheck, R. (2000). Posttraumatic stress disorder among Hispanic Vietnam veterans. American Journal of Psychiatry, 157(4), 615-619. 
Ostfeld, A. M., Kasl, S. V., D’Arti, O. A., \& Fitzgerald, E. F. (1987). Stress, crowding and blood pressure in prison. Hillsdale, NJ: Lawrence Erlbaum.

Ozer, E. J., Best, S. R, Lipsey, T. L., \& Weiss, D. S. (2003). Predictors of posttraumatic stress disorder and symptoms in adults: a meta-analysis. Psychological Bulletin, $129(1), 52-73$.

PAR Inc. (2012). Trauma Symptom Inventory- 2 (TSD-2). Retrieved from http://www4.parinc.com/Products/Product.aspx?ProductID=TSI-2

Pearlman, L. A., \& Mac Ian, P. S. (1995). Vicarious traumatization: An empirical study of the effects of trauma work on trauma therapists. Professional Psychology: Research and Practice, 26(6), 558-565.

Peled, E., \& Davis, D. (1995). Groupwork with children of battered women. Thousand Oaks, CA: Sage.

Peeters, M. C. W., Schaufeli, W. B., \& Buunk, B. P. (1995). The role of attributions in the cognitive appraisal of work related stressful events: An event recording approach. Work and Stress, 9(4), 463-474.

Perilla, J. L., Norris, F. H., \& Lavizzo, E. A. (2002). Ethnicity, culture, and disaster response: Identifying and explaining ethnic differences in PTSD six months after Hurricane Andrew. Journal of Social and Clinical Psychology, 21(1), 20-45.

Pole, N., Best, S. R., Weiss, D. S., Metzler, T., Liberman, A. M., Fagan, J., \& Marmar, C. R. (2001). Effects of gender and ethnicity on duty-related posttraumatic stress 
symptoms among urban police officers. The Journal of Nervous and Mental Disease, 189(7), 442-8

Poole, E. D., \& Regoli, R. M. (1981). Alienation in prison. An examination of the work relations of prison guards. Criminology, 19(2), 251-270. doi:10.1111/j.17459125.1981.tb00415.x

PTSD: A growing epidemic. (2009). National Institutes of Health. Retrieved from https://medlineplus.gov/magazine/issues/winter09/articles/winter09pg10-14.html

PTSD United. (2013). PTSD Statistics. Retrieved from http://www.ptsdunited.org/ptsdstatistics-2/

Punamäki, R. L., Qouta, S. R., \& El Sarraj, E. (2010). Nature of torture, PTSD, and somatic symptoms among political ex-prisoners. Journal of Traumatic Stress, 23(4), 532-6. doi:10.1002/jts.20541

Riggs, D. S., Dancu, C. V., Gershuny, B. S., Greenburg, D., \& Foa, E. B. (1992). Anger and post-traumatic stress disorder in female crime victims. Journal of Traumatic Stress, 5(4), 613-625. doi:10.1002/jts.2490050410

Riggs, D. S., Rothbaum, B. O., \& Foa, E. B. (1995). A prospective examination of symptom of post traumatic stress disorder in victim of nonsexual assault. Journal of Interpersonal Violence. 10(2), 201-214.

Roberts, A. L., Gilman, S. E., Breslau, J., Breslau, N., \& Koenen, K. C. (2011). Race/ethnic differences in exposure to traumatic events, development of posttraumatic stress disorder, and treatment-seeking for post-traumatic stress disorder 
in the United States. Psychological Medicine, 41(1), 71-83. doi:10.1017/S0033291710000401

Robinson, H. M., Sigman, M. R., \& Wilson, J. P. (1997). Duty-related stressors and PTSD symptoms in suburban police officers. Psychological Reports, 81(3), 83545.

Roitman, P., Gilad, M., Ankri, Y. L., \& Shalev, A. Y. (2013). Head injury and loss of consciousness raise the likelihood of developing and maintaining PTSD symptoms. Journal of Traumatic Stress, 26(6), 727-34. doi:10.1002/jts.21862

Rosche, P. J. (2017). Reminiscences of Hans Selye, and the Birth of "Stress." The American Institute of Stress. Retrieved from https://www.stress.org/about/hansselye-birth-of-stress/

Rosefield, H. A., Jr. (1981). Self identified stressors among correctional officers. Unpublished PhD thesis, North Carolina State University, Raleigh.

Rosine, L. (1992) Exposure to critical incidents: What are the effects on Canadian correctional officers? CSC Forum, 4(1), 31-36.

Rothbaum, B. O., Foa, E. B., Riggs, D. S., Murdock, T., \& Walsh, W. (1992). A prospective examination of post-traumatic stress disorder in rape victims. Journal of Traumatic Stress, 5(1), 455-475.

Scarpa, A., Haden, S. C., \& Hurley, J. (2006). Community violence victimization and symptoms of posttraumatic stress disorder: The moderating effects of coping and social support. Journal of Interpersonal Violence, 21(4), 446-69. 
Schaufeli, W. B., \& Peeters, M. C. W. (2000). Job stress and burnout among correctional officers: A literature review. International Journal of Stress Management, 7(1), $19-48$.

Schnurr, P. P., Ford, J. D., Friedman, M. J., Green, B. L., Dain, B. J., \& Sengupta, A. (2000). Predictors and outcomes of posttraumatic stress disorder in World War II veterans exposed to mustard gas. Journal of Consulting and Clinical Psychology, $68(2), 258-268$.

Selye, H. (1976). The stress of life (Rev. ed.). New York, NY: McGraw-Hill.

Shalev, A., Freedman, S., Peri, T., Brandes, D., Sahar, T., Orr, S. P., \& Pitman, R. K. (1998). Prospective study of posttraumatic stress disorder and depression following trauma. The American Journal of Psychiatry, 155(5), 630.

Shamir, B., \& Drory, A. (1982). Occupational tedium among prison officers. Criminal Justice and Behavior, 9(1), 79-99.

Shannon, M. P., Lonigan, C. J., Finch, A. J., \& Taylor, C. M (1994). Children exposed to disaster: I. Epidemiology of post-traumatic symptoms and symptom profiles. Journal of the American Academy of Child and Adolescent Psychiatry, 33(1), 8093.

Sherbourne, C. D., \& Stewart, A. L. (1991). The MOS social support survey. Social Science and Medicine, 32(6):705-714.

Sibai, A. M., Armenian, H. K., \& Alam, S. (1989). Wartime determinants of arteriographically confirmed coronary artery disease in Beirut. American Journal of Epidemiology, 130(4), 623-31. 
Skogstad, M., Skorstad, M., Lie, A., Conradi, H. S., Heir, T., \& Weisaeth, L. (2013). Work-related post-traumatic stress disorder. Occupational Medicine (Oxford, England), 63(3), 175-82. doi:10.1093/occmed/kqt003

Slottje, P., Witteveen, A. B., Twisk, J. W., Smidt, N., Huizink, A. C., van Mechelen, W., \& Smid, T. (2008). Post-disaster physical symptoms of firefighters and police officers: Role of types of exposure and post-traumatic stress symptoms. British Journal of Health Psychology, 13(2), 327-42.

Spinaris, C. G., Denhof, M. D., \& Kellaway, J. A. (2012). Post Traumatic Stress Disorder in US Corrections Professionals: Prevalence and Impact on Health and Functioning. Retrieved from http://desertwaters.com/wpcontent/uploads/2013/09/PTSD_Prev_in_Corrections_09-03-131.pdf

Stadnyk, B.L. (2003). PTSD in corrections employees in Saskatchewan. Retrieved from http://rpnascom.jumpstartdev.com/sites/default/files/PTSDInCorrections.pdf

Stein, M. B., Walker, J., Hazen, A., \& Forde, D. (1997). Full and partial posttraumatic stress disorder: findings from a community survey. American Journal of Psychiatry, 154(8), 1114-1119.

Stephens, C., \& Miller, I. (1998). Traumatic experiences and post-traumatic stress disorder in the New Zealand police. Policing: An International Journal of Police Strategies \& Management, 21(1), 178-191.

Tartaglini, A. J., \& Safran, D. A. (1997). A topography of psychiatric disorders among correction officers. Journal of Occupational and Environmental Medicine, 39(6), $569-73$. 
Teegen, F. \& Grotwinkel, M. (2001). Traumatic exposure and post-traumatic stress disorder of journalists: An internet-based study. Psychotherapeut, 46(3), 169-175.

The American Institute of Stress. (2017). What is stress? Fort Worth, TX: Author. Retrieved from https://www.stress.org/what-is-stress/

The Regents of the University of California. (2008). Support \& Social Conflict: Section One-Social Support. The John D. and Katherine T. MacArthur Foundation. University of California. Retrieved from http://www.macses.ucsf.edu/research/psychosocial/socsupp.php

The Treatment Advocacy Center. (2014). The Treatment of Persons with Mental Illness in Prisons and Jails: A State Survey. Arlington, VA: Author. Retrieved from http://www.treatmentadvocacycenter.org/storage/documents/treatment-behindbars/treatment-behind-bars.pdf

Tolin, D. F., \& Foa, E. B. (2006). Sex differences in trauma and posttraumatic stress disorder: A quantitative review of 25 years of research. Psychological Bulletin, 132(6), 959-92.

Tompson, T. (1994). Holistic health comes to prison. Federal Prison Journal, 3(3), 5559.

Turnbull, G. J. (1998). A review of post-traumatic stress disorder. Part I: Historical development and classification. Injury, 29(2), 87-91.

U.S. Department of Veterans Affairs. (n.d.-a). Mental Health Effects of Serving in Afghanistan and Iraq. Washington, DC: Author. Retrieved from http://www.ptsd.va.gov/public/PTSD-overview/reintegration/overview-mentalhealth-effects.asp 
U.S. Department of Veterans Affairs. (n.d.-b). PTSD history and overview. Washington, DC: Author. Retrieved from http://www.ptsd.va.gov/professional/PTSDoverview/ptsd-overview.asp

U.S. Department of Veterans Affairs. (n.d.-c). Research Findings on the Traumatic Stress Effects of Terrorism. Washington, DC: Author. Retrieved from http://www.ptsd.va.gov/professional/trauma/disaster-terrorism/research-findingstraumatic-stress-terrorism.asp

U.S. Department of Veterans Affairs. (n.d.-c). Traumatic effects of specific types of disasters. Washington, DC: Author. Retrieved from http://www.ptsd.va.gov/professional/trauma/disaster-terrorism/traumatic-effectsdisasters.asp

U.S. Geological Survey (USGS). (2006). Wildfire hazards--A national threat. Washington, DC: Author. Retrieved from http://pubs.usgs.gov/fs/2006/3015/

Ullman, S. E., \& Siegel. J. M. (1994). Predictors of exposure to traumatic events and posttraumatic stress sequelae. Journal of Community Psychology, 22(4), 328-338.

van der Ploeg, E., \& Kleber, R. J. (2003). Acute and chronic job stressors among ambulance personnel: Predictors of health symptoms. Occupational and Environmental Medicine, 60(1), 40-46.

van Zelst, W. H., de Beurs, E., Beekman, A. T. F., Deeg, D. J. H., \& van Dyck, R. (2003). Prevalence and risk factors of posttraumatic stress disorder in older adults. Psychotherapy and Psychosomatics, 72(6), 333-342. doi:10.1159/000073030

Vasterling, J. J., Brailey, K., Proctor, S. P., Kane, R., Heeren, T., \& Franz, M. (2012). Neuropsychological outcomes of mild traumatic brain injury, post-traumatic 
stress disorder and depression in Iraq-deployed US army soldiers. The British Journal of Psychiatry, 201(3), 186-192. doi:10.1192/bjp.bp.111.096461

Verhagen, J. (1986). Correctional officers' personality characteristics. Balances, 9(1), 3-

5.

Wagner, D., Heinrichs, M., \& Ehlert, U. (1998). Prevalence of symptoms of posttraumatic stress disorder in German professional firefighters. American Journal of Psychiatry, 155(12), 1727-1732.

Weaver, T. L., Kilpatrick. D. G., Resnick. H. S., Best. C. L., \& Saunden. B. E. (1997). An examination of physical assault and childhood victimization histories within a national probability sample of women. Thousand Oaks, CA: Sage.

West, C. Bernard, B., Mueller, C., Kitt, M., Driscoll, R., \& Tak, S. (2008). Mental health outcomes in police personnel after hurricane Katrina. Journal of Occupational and Environmental Medicine, 50(6), 689-95.

doi:10.1097/JOM.0b013e3181638685

Whitehead, L. (1989). Burnout in probation and corrections. New York, NY: Praeger.

Williams, D., Mohammed, S., Leavell, J., \& Collins, C. (2010). Race, socioeconomic status, and health: Complexities, ongoing challenges, and research opportunities. Annals of the New York Academy of Sciences, 1186(1), 69-101. doi:10.1111/j.1749-6632.2009.05339.x

Williams, M. T. (2011). Why African Americans avoid psychotherapy. Psychology Today. Retrieved from https://www.psychologytoday.com/blog/culturallyspeaking/201111/why-african-americans-avoid-psychotherapy 
World Health Organization. (2010) International Statistical Classification of Diseases and Related Health Problems 10th Revision (ICD-10) Version for 2010. Retrieved from http://apps.who.int/classifications/icd10/browse/2010/en\#/F43.1

Wykes, T., \& Whittington, R. (1998). Prevalence and predictors of early traumatic stress reactions in assaulted psychiatric nurses. The Journal of Forensic Psychiatry, 9(3), 643-658. doi:10.1080/09585189808405379 


\section{CURRICULUM VITA}

Ashley T. French

University of Louisville

Department of Criminal Justice

2872 Majestic View Walk

2301 South Third Street

100i Brigman Hall

Lexington, KY 40511

502-641-0449 (cell)

Louisville, KY 40292

aptfrench@gmail.com

Ashley.Terrell@louisville.edu

\section{EDUCATION}

2017 Ph.D., Criminal Justice, University of Louisville, Louisville, Kentucky

Dissertation: A Risky Business: Examining the Prevalence and Correlates of Post Traumatic Stress Disorder and Social Support in Kentucky's Adult Correctional Staff. Prospectus Defended: 07/2017

Committee: Dr. Kristin Swartz (chair), Dr. Deborah Keeling, Dr. Bradley Campbell, Dr. Gaylene Armstrong

2010 Master of Science, Administration of Justice, University of Louisville, Louisville, Kentucky.

Professional Paper: Animals in Corrections: The Past, Present, and Future of Animals in Correctional Facilities and as Treatment for Successful Prisoner Reintegration into Society. Internship: Louisville Metro Police Department; Eighth Division, Louisville, KY

2000 Bachelor of Arts, Liberal Arts and Sciences, Utah State University, Logan, Utah

\section{ACADEMIC POSITIONS}

2016 - 2016, Adjunct Faculty, Department of Criminal Justice, University of Louisville

- Utilize Blackboard 9.0 to teach undergraduate criminal justice courses.

- Serve on university committees, as requested.

2012 - Present, Lead Faculty for Undergraduate Criminal Justice Programs, Department of Criminal Justice, College of Safety \& Emergency Services, Columbia Southern University

- Utilize Blackboard 9.0 to teach undergraduate criminal justice courses.

- Monitor and mentor undergraduate criminal justice faculty to ensure compliance with policies and procedures relating to grading, assessments, communication, and feedback.

- Participate in the new hire process, including recruiting candidates and interviewing.

- Serve as course content expert to include authoring and/or reviewing courses in criminal justice. 
- Serve on university committees, as requested.

- Complete monthly, quarterly, and annual reports regarding faculty professional development (internal and external), faculty teaching loads, course quality issues, course revision schedules, and faculty/student issues.

- Benchmark concentrations and degree programs and present recommendations to program director.

- Evaluate courses for transfer credit.

2010 - 2011, Adjunct Faculty, Department of Criminal Justice, College of Safety \& Emergency Services, Columbia Southern University

- Utilize Blackboard 9.0 to teach undergraduate criminal justice courses.

- Serve on university committees, as requested.

\section{ACADEMIC PUBLICATIONS}

Works under review.

French, A., Swartz, K., \& Block, M. (2017). Part of the problem or part of the solution: Executions, deterrence, and homicide.

Swartz, K., Osborne, D., \& French, A. (2017). Gangs, drugs, and street culture: Are there distinct effects on violence and victimization?

\section{GRANTS AND RESEARCH}

2015- 2017, Senior Research Associate. Examining the Prevalence and Correlates of Post-Traumatic Stress Disorder and Life Quality Issues among Kentucky Correctional Staff. Funded by the Kentucky Department of Corrections. Principal Investigator: Dr. Kristin Swartz

\section{PROFESSIONAL PRESENTATIONS}

Swartz, K., \& French, A. (2017). Suicidality among Correctional Staff: Understanding the Comorbidity Effects of PTSD and Depression. Presented at the annual meetings of the American Society of Criminology, Philadelphia, PA. Upcoming.

Swartz, K., Pavlov, R., \& French, A. (2017). Disentangling the Effects of Trauma Experienced at Work and at Home and the Mental Health of Correctional Staff. Presented at the annual meetings of the American Society of Criminology, Philadelphia, PA. Upcoming.

Swartz, K., \& French, A. (2016). The Forgotten Ones: Exploring the Pervasiveness and Correlates of PTSD among Correctional Staff. Presented at the annual meetings of the American Society of Criminology, New Orleans, LA. 
Tolle, H., Swartz, K., \& French, A. (2016). Exploring Moderating Effects on Job Burnout Among Correctional Staff. Presented at the annual meetings of the American Society of Criminology, New Orleans, LA.

Swartz, K., French, A., \& Tolle, H. (2016). PTSD Among Correctional Staff: A Preliminary Analysis. Presented at the annual meetings of the American Criminal Justice Association, Denver, CO.

Andreescu, V., Block, M., \& French, A. (2015). The News Coverage of Lethal Violence in Louisville's Courier Journal. Poster presented at the annual meetings of the American Society of Criminology, Washington, DC.

Keeling, D., Block, M., Greenwell, L., Schwendau, A., \& French, A. (2014). Evaluation of a Day Reporting Center: Cost and Program Effectiveness. Presented at the annual meetings of the Southern Criminal Justice Association, Clearwater Beach, FL.

Walsh, K. \& Terrell, A. (2013). A Bridge Over Troubled Waters: The Role of Post Release Employment Opportunities in Offender Reintegration. Presented at the annual meetings of the American Society of Criminology, Atlanta, GA.

Guenter-Schlesinger, S., \& Terrell, A. (1999). Enhanced Sexual Harassment Prevention Training. Presented at the annual meeting of The National Association of Women in Education, New Orleans, LA.

\section{ONLINE TEACHING EXPERIENCE}

University of Louisville:

2016, CJ 415, Substance Abuse, Crime, and Criminal Justice (1 section)

Columbia Southern University:

2017, BCJ 2000, Introduction to Criminal Justice (1 section)

BCJ 2001, Theory and Practices of Law Enforcement (2 sections)

BCJ 2002, Theory and Practices of Corrections (1 section)

BCJ 2501, Criminology (1 section)

BCJ 4001, Procedures in the Justice System (3 sections)

BCJ 4101, Police and Community Relations (1 section)

BCJ 4301, Management and Supervision in Criminal Justice (2 sections)

2016, BCJ 2000, Introduction to Criminal Justice (1 section)

BCJ 2002, Theory and Practices of Corrections (2 sections)

BCJ 2201, Juvenile Delinquency (1 section)

BCJ 2501, Criminology (1 section)

BCJ 4101, Police and Community Relations (2 sections)

2015, BCJ 2000, Introduction to Criminal Justice (1 section)

BCJ 2002, Theory and Practices of Corrections (1 section)

BCJ 2201, Juvenile Delinquency (1 section) 
BCJ 4101, Police and Community Relations (1 section)

BCJ 4201, Race and Ethnic Relations (1 section)

BCJ 4701, Criminal Justice Organization and Administration (1 section)

2014, BCJ 2000, Introduction to Criminal Justice (1 section)

BCJ 2001, Theory and Practices of Law Enforcement (1 section)

BCJ 2002, Theory and Practices of Corrections (6 sections)

BCJ 2201, Juvenile Delinquency (1 section)

BCJ 4101, Police and Community Relations (2 sections)

2013, BCJ 2000, Introduction to Criminal Justice (4 sections)

BCJ 2002, Theory and Practices of Corrections (2 sections)

BCJ 2201, Juvenile Delinquency (3 sections)

BCJ 2501, Criminology (2 sections)

BCJ 4101, Police and Community Relations (2 sections)

2012, BCJ 2000, Introduction to Criminal Justice (1 section)

BCJ 2002, Theory and Practices of Corrections (3 sections)

BCJ 2201, Juvenile Delinquency (2 sections)

BCJ 2501, Criminology (1 section)

BCJ 4301, Supervision of Criminal Justice Personnel (1 section)

BCJ 4701, Criminal Justice Organization and Administration (1 section)

2011, BCJ 2201, Juvenile Delinquency (1 section)

BCJ 4701, Criminal Justice Organization and Administration (1 section)

2010, BCJ 2201, Juvenile Delinquency (2 sections)

\section{ADMINISTRATIVE EXPERIENCE}

2011 - 2012 Faculty Services Manager, College of Safety \& Emergency Services, Columbia Southern University

- Monitor and evaluate approximately 100 College of Safety and Emergency Services faculty.

- Ensure compliance with CSU policies and procedures relating to grading, assessments, emails, and feedback.

- Participate in the new hire process, including recruiting candidates, validating transcripts, and interviewing.

- Schedule faculty for courses and monitor faculty course loads. Supervise three faculty services employees.

2010 - 2011, Program Coordinator, Criminal Justice Department, Columbia Southern University

- Assist in selection of course material and assign course writers as appropriate. Assist with annual faculty review, recruitment, and orientation of new faculty. 
- Mentor and coach faculty on performance issues.

- Collaborate with instructional design team in maintaining the continuity and accuracy of program courses.

- Monitor progress regarding course development.

- Assist faculty in the evaluation and handling of cases of student plagiarism and cheating.

- Assist chair and dean with the development and implementation of program assessment documents.

- Benchmark course programs such as probation and parole, corrections, jail operations, homeland security, criminal justice, forensics, and law enforcement and present recommendations to department chair.

- Participate in graduation activities.

\section{PROFESSIONAL AFFILIATIONS}

Academy of Criminal Justice Sciences (ACJS)

American Correctional Association (ACA)

American Society of Criminology (ASC)

Golden Key International Honour Society

Southern Criminal Justice Association (SCJA)

Southern States Correctional Association (SSCA)

\section{SERVICE}

2010 - 2011, Success Center Integration Task Force, Columbia Southern University

\section{PROFESSIONAL DEVELOPMENT}

2016, Independent Applying the QM Rubric (APPQMR), Quality Matters.

2016, The Role of the School Resource Officers in School. International Association of Chiefs of Police, National Council of Juvenile and Family Court Judges, and the Office of Juvenile Justice Delinquency Prevention School Justice Collaboration Program (webinar).

2016, Fostering Processes of Reconciliation. Office of Juvenile Justice Delinquency Prevention (in collaboration with the National Initiative for Building Community Trust and Justice) (webinar).

2016, Animals in Disaster: Awareness and Preparedness. Emergency Management Institute, Federal Emergency Management Agency, Department of Homeland Security (IS 00010.a).

2015, The Neurobiology of Sexual Assault. U.S. Department of Justice (webinar). 
2015, Emerging Markets, Emerging Strategies. Inside Higher Ed (webinar).

2015, Sexual Abuse in Juvenile Correctional Environments. U.S. Department of Justice (webinar).

2015, Prosecuting Race: Mass Incarceration and the Unfinished Project of African Abolition. University of Louisville (in collaboration with California State Fullerton).

2014, Active Shooter: What You Can Do. Emergency Management Institute, Federal Emergency Management Agency, Department of Homeland Security (IS 00907).

2014, National Incident Management System (NIMS). Emergency Management Institute, Federal Emergency Management Agency, Department of Homeland Security (IS 00700.a).

2014, Introduction to Hazardous Materials. Emergency Management Institute, Federal Emergency Management Agency, Department of Homeland Security (IS 00005.a).

2014, Southern States Correctional Association Annual Summer Conference, Savannah, GA.

2011, How to Handle Conflict and Confrontation. Rockhurst University Continuing Education Center, Pensacola, FL.

2011, Emotional Intelligence. Rockhurst University Continuing Education Center, Pensacola, FL.

2011, Coaching and Mentoring Skills for Leadership Success. Rockhurst University Continuing Education Center, Pensacola, FL.

2010, Investigation of Major Crimes. Federal Bureau of Investigation, U.S. Department of Justice, Foley, AL.

\section{HONORS AND AWARDS}

2017, Multimedia Award $2^{\text {nd }}$ Quarter ( $2^{\text {nd }}$ Place for Discussion Board Video), Columbia Southern University 